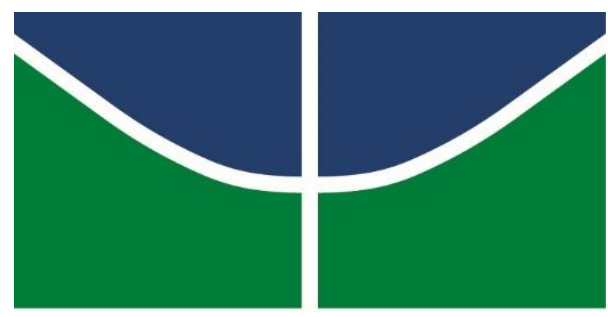

Universidade de Brasília - UnB Instituto de Ciências Humanas

Departamento de Geografia

Programa de Pós-Graduação em Geografia

\title{
CLASSIFICAÇÃO E FRAGMENTAÇÃO DAS FORMAS DE TERRENO NA ANÁLISE DO RELEVO TROPICAL
}

Vinicius Vasconcelos

\section{BRASÍLIA-DF}


Universidade de Brasília - UnB

Instituto de Ciências Humanas

Departamento de Geografia

Programa de Pós-Graduação em Geografia

\section{CLASSIFICAÇÃO E FRAGMENTAÇÃO DAS FORMAS DE TERRENO NA ANÁLISE DO RELEVO TROPICAL}

Vinicius Vasconcelos

Orientador:

Prof. Dr Eder de Souza Martins.

Co-Orientador:

Prof. Dr. Osmar Abílio de Carvalho Júnior

\section{BRASÍLIA-DF}


Universidade de Brasília - UnB

Instituto de Ciências Humanas

Departamento de Geografia

Programa de Pós-Graduação em Geografia

\title{
CLASSIFICAÇÃO E FRAGMENTAÇÃO DAS FORMAS DE TERRENO NA ANÁLISE DO RELEVO TROPICAL
}

\author{
Vinicius Vasconcelos
}

Tese de doutorado submetida ao Departamento de Geografia da Universidade de Brasília, como parte dos requisitos necessários à obtenção do Grau de Doutor em Geografia

Aprovado por:

Prof. Dr. Eder de Souza Martins (GEA/UnB e Embrapa) (Orientador)

Prof. Dr. Osmar Abílio de Carvalho Júnior (GEA/UnB) (Co-Orientador)

Prof. Dr. Antônio José Teixeira Guerra (UFRJ)

(Examinador Externo)

Prof. Dr. José Marques Júnior (Unesp)

(Examinador Externo)

Prof. Dr. Leonardo José Cordeiro dos Santos (UFPR)

(Examinador Externo)

Prof. Dr. Renato Fontes Guimarães (GEA/UnB)

(Examinador Interno) 


\section{REFERÊNCIA BIBLIOGRÁFICA}

Vasconcelos, V. Classificação e Fragmentação das Formas de Terreno na análise do Relevo Tropical 2016. 127p. Tese (Doutorado em Geografia), Universidade de Brasília, Brasília, 2016.

\section{CESSÃO DE DIREITOS}

É concedida à Universidade de Brasília permissão para reproduzir cópias desta tese e emprestar ou vender tais cópias somente para propósitos acadêmicos e científicos. $\mathrm{O}$ autor reserva outros direitos de publicação e nenhuma parte desta tese de doutorado pode ser reproduzida sem a autorização por escrito do autor.

Vinicius Vasconcelos

\section{FICHA CATALOGRÁFICA}

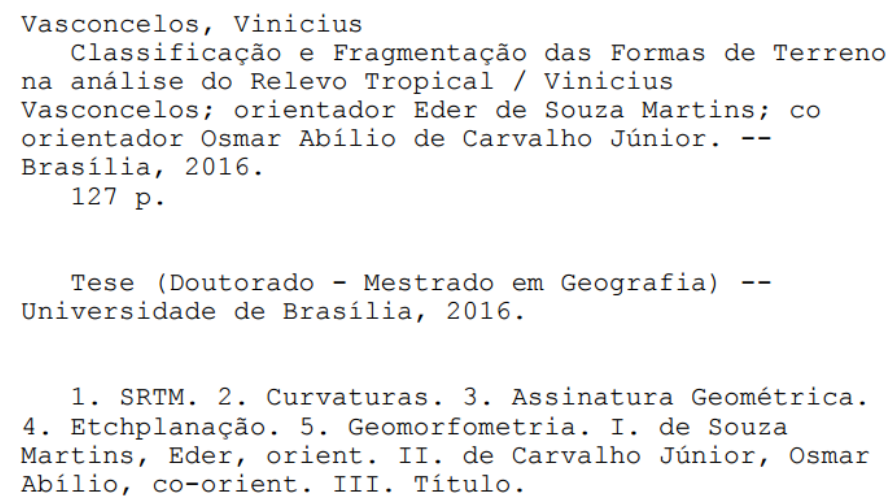




\section{DEDICATÓRIA}

Dedico essa contribuição aos meus pais (in memoriam)

e a ofereço à Luciana e Baleia 


\section{AGRADECIMENTOS}

Gostaria de agradecer a todos que contribuíram para essa tese em especial aos/às:

$\checkmark$ meus orientadores Eder Martins e Osmar Abílio de Carvalho Junior pela paciência, dedicação, amizade e oportunidade de trabalho conjunto;

$\checkmark$ meu amigo e mentor, Eder Martins, por me ensinar a ter um olhar sistêmico sobre a geomorfologia, a refletir sobre as questões filosóficas de um trabalho científico e pelo seu acolhimento acadêmico e paterno incondicional;

$\checkmark$ meu amigo e mentor, Osmar Abílio de Carvalho Junior, por me ensinar a querer sempre melhorar e inovar e correr atrás de responder as perguntas científicas da maneira mais objetiva e clara possível;

$\checkmark$ Professor Renato Fontes Guimarães, por ter aceitado ser membro da banca examinadora. Também agradeço por ter a oportunidade de ser seu aluno de graduação. Foi por meio de suas aulas e pesquisas que meu interesse pela área de modelagem e geomorfologia surgiu;

$\checkmark$ Professor Antônio José Teixeira Guerra, por ter aceitado ser membro da banca examinadora e por servir de inspiração por meio de seus tantos trabalhos, o que me faz perceber o quanto ainda tenho que aprender e estudar;

$\checkmark$ Professor José Marques Junior, por ter aceitado ser membro da banca examinadora, por antever a aplicabilidade dessa contribuição na Ciência dos Solos e por suas contribuições reflexivas;

$\checkmark$ Professor Leonardo José Cordeiro dos Santos, por ter aceitado ser membro da banca examinadora. Agradeço pelas críticas e apontamentos a fim de melhorar essa contribuição;

$\checkmark$ amigos e revisores Diego Siqueira e Antônio Felipe Couto Junior pelos conselhos, pela leitura, por estarem presente em todas etapas desse trabalho;

$\checkmark$ Professora Gabriela Bielefeld Nardoto pela sua contribuição precisa a fim de melhorar o fechamento dessa tese e por antever a aplicabilidade dessa proposta em áreas ainda não exploradas, servindo de incentivo para o fechamento desse ciclo;

$\checkmark$ Professor Richard Heck por ter me recebido no Canadá, durante o meu estágio de doutorado no exterior, onde tive oportunidade de divulgar e discutir o meu trabalho com outros cientistas e alunos do mundo;

$\checkmark$ amigos e colegas de trabalho Glauber e Josiel pela ajuda no campo;

$\checkmark$ João Paulo por dar continuidade a esse trabalho, pela amizade e disposição de sempre querer ajudar;

$\checkmark$ membros da secretária de pós-graduação que sempre me ajudaram;

$\checkmark$ Capes pela bolsa de doutorado e pela bolsa de estágio de doutorado no exterior;

$\checkmark$ Embrapa Cerrados por oferecer a infraestura necessária para realizar esse trabalho;

$\checkmark$ minha esposa, Luciana, por estar sempre ao meu lado. 
REFLEXÃO

As figuras imaginárias

têm mais relevo e verdade que as reais.

FERNADO PESSOA 


\section{SUMÁRIO}

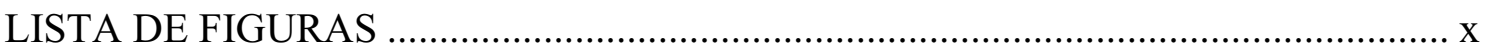

ÍNDICE DE TABELAS …............................................................................... xiv

LISTA DE ABREVIAÇÕES ...........................................................................

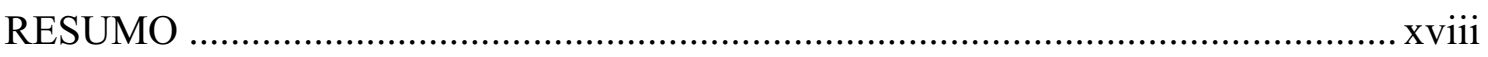

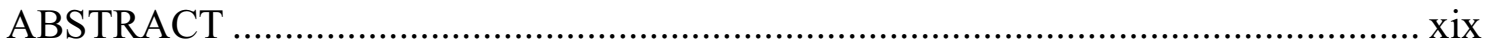

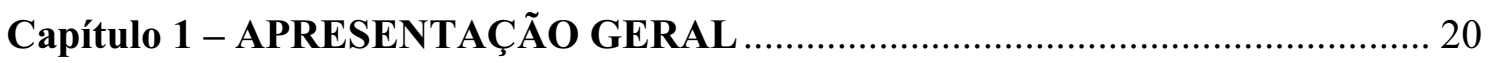

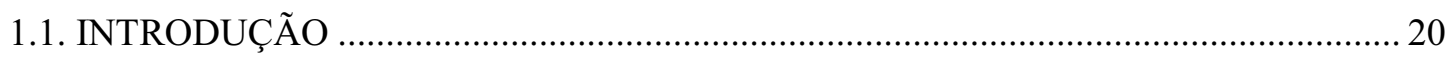

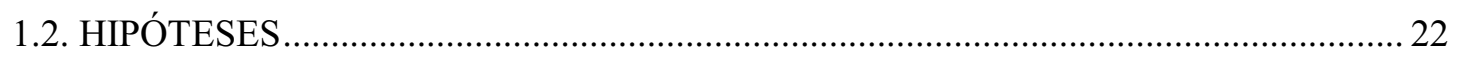

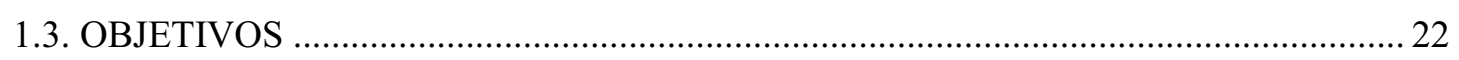

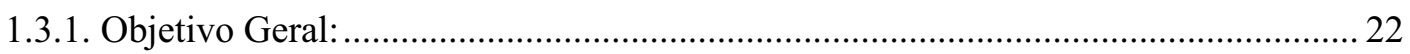

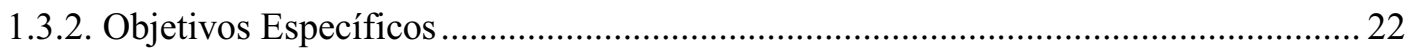

1.4. MODELO DA ETCHPLANAÇÃO EM RELEVOS TROPICAIS .................................. 22

1.5. FRAGMENTAÇÃO DE PAISAGEM DESENVOLVIDA A LONGO PRAZO ............ 27

1.6. CLASSIFICAÇÃO DAS FORMAS DE TERRENO ….................................................. 29

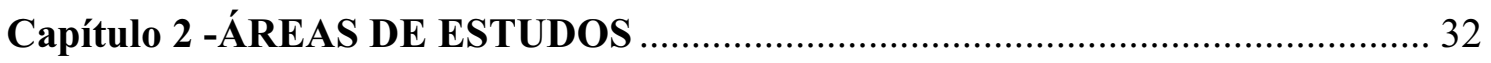

2.1. CONTEXTO GEOLÓGICO-GEOMORFOLÓGICO .................................................... 32

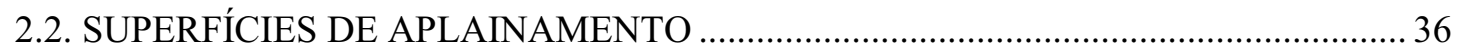

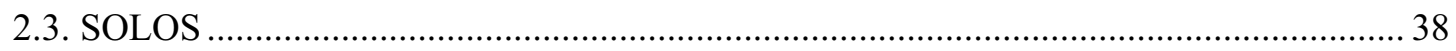

2.4. ÁREA DE REFERÊNCIA BACIA DO RIO JARDIM .................................................. 40

Capítulo 3 - MATERIAIS E MÉTODOS …............................................................. 43

3.1. SHUTTLE RADAR TOPOGRAPHY MISSION - SRTM .......................................... 44

3.2. CONFIGURAÇÃO DA ASSINATURA GEOMÉTRICA ............................................. 44

3.3. SELEÇÃO DA ASSINATURA GEOMÉTRICA......................................................... 48

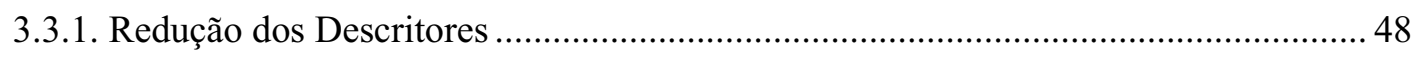

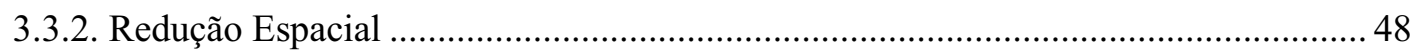

3.4. CLASSIFICAÇÃO POR CORRELAÇÃO E MÍNIMA DISTÂNCIA …......................... 49

3.5 COMPARAÇÃO COM O MÉTODO DO WOOD (1996)................................................ 50

3.6. ADAPTAÇÃO DO MÉTODO DE CLASSIFICAÇÃO DE FORMAS DE TERRENO

PARA ESTUDO DE FRAGMENTAÇÃO DO RELEVO ………......................................... 52

3.6.1. Frequência, Fragmentação e Análise Multivariada .................................................... 53

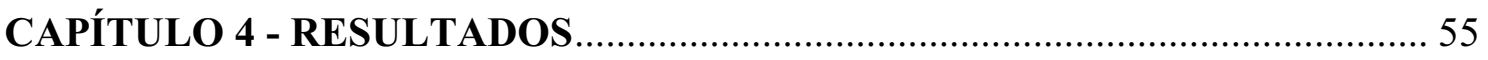

4.1. DESENVOLVIMENTO DO MÉTODO DE CLASSIFICAÇÃO DE FORMAS DE

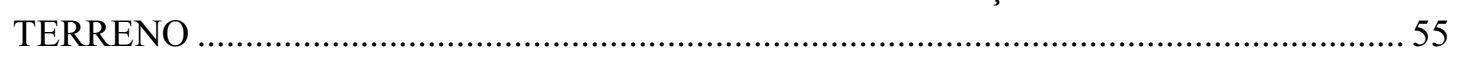

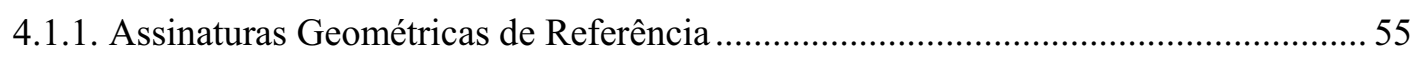

4.1.2. Classificação das Assinaturas Geométricas.............................................................. 58

4.1.3. Comparação entre as classificações por assinatura geométrica e a de Wood ............ 62

4.2. CLASSIFICAÇÃO DAS FORMAS DE TERRENO DO CONTEXTO REGIONAL .... 66 
4.2.1. Análise de Frequência das Formas de Terreno dos Compartimentos

Geomorfológicos

4.2.2. Análise da Proporção de Patches das Formas de Terreno dos Compartimentos

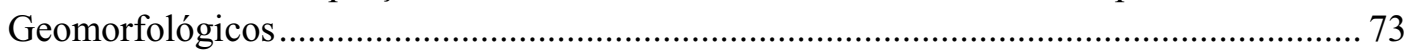

4.2.3. Índice Geomorfométrico de Denudação..................................................................... 80

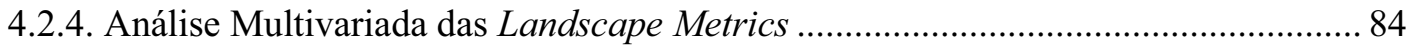

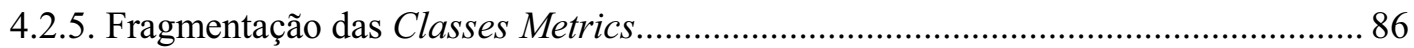

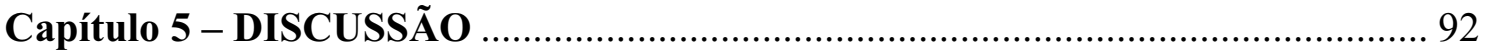

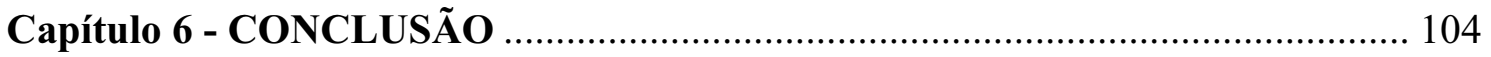

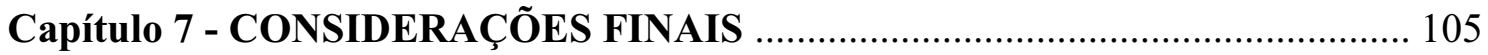

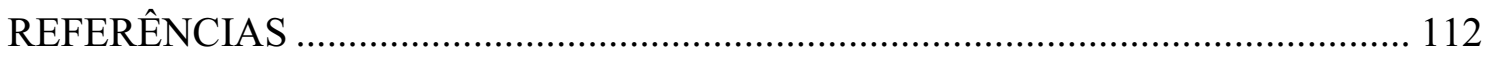

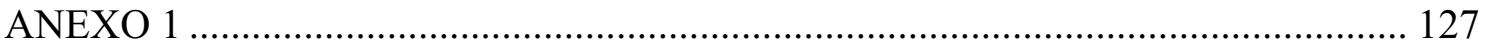




\section{LISTA DE FIGURAS}

Figura 1 - Etchplano Mantado (A); Etchplano Parcialmente Denudado (ou Etchplano Dissecado, mais de 50\% do manto preservado) (B); Etchplano Denudado (de 10\% a 50\% do manto preservado) (C); Etchplano Complexo (D); Etchsuperfície (E) (menos de 10\% do manto preservado) (adaptado de Thomas, 1994).

Figura 2 - Localização regional da área de estudo dentro da Faixa Brasília de Dobramentos composta por planaltos residuais e depressões no contexto das Bacias Hidrográficas do Tocantins, São Francisco e Paraná (A). Compartimentação geomorfológica composto por Planalto Retocado do Paranoá (PRP), Planalto Retocado Bambuí-Canastra (PRBC), Planalto Dissecado Araxá-Canastra (PDAC), Planalto Dissecado Paranoá-Canastra (PDPC), Depressão Cárstica Vazante-Bambuí (DCVB), Depressão Cárstica Paranoá-Canastra (DCPC) e Depressão Cárstica Paranoá-Bambuí (DCPB) (B) (Adaptado de Dantas 2002; Latrubesse e Carvalho, 2006; Baptista et al., 2010).

Figura 3 - Mapa de Geologia simplificado (adaptado de Freitas-Silva e Campos, 1999; Scislewski et al., 2002; CPRM, 2008; Baptista et al., 2010) e respectivos compartimentos geomorfológicos: Planalto Retocado do Paranoá (PRP), Planalto Retocado BambuíCanastra (PRBC), Planalto Dissecado Araxá-Canastra (PDAC), Planalto Dissecado Paranoá-Canastra (PDPC), Depressão Cárstica Vazante-Bambuí (DCVB), Depressão Cárstica Paranoá-Canastra (DCPC) e Depressão Cárstica Paranoá-Bambuí (DCPB).

Figura 4: Mapa de Classes de Solos nível de ordem (adaptado de SIEG, 2005 e Batista et al., 2010) por compartimento geomorfológico: Planalto Retocado do Paranoá (PRP), Planalto Retocado Bambuí-Canastra (PRBC), Planalto Dissecado Araxá-Canastra (PDAC), Planalto Dissecado Paranoá-Canastra (PDPC), Depressão Cárstica VazanteBambuí (DCVB), Depressão Cárstica Paranoá-Canastra (DCPC) e Depressão Cárstica Paranoá-Bambuí (DCPB).

Figura. 5. Localização da Bacia do Rio Jardim dentro do Distrito Federal com Modelo Digital de Elevação (A). Bacia do Rio Jardim com os principais tributários, Estanislau, Cariru, Lamarão que desaguam no rio Preto (B).

Figura 6 - Seis Formas de Terreno baseado em Wood (1996) (A). Nove Formas de Terreno baseado em Dikau (1989) (B) (adaptado de Schmidt e Hewitt, 2004). 
Figura 7 - Esquema ilustrativo de uma janela 3x3 sobre o Modelo Digital de Elevação, apresentando os posicionamentos e as elevações dos pontos $(Z)$ referentes às equações das curvaturas (Zevenbergen e Thorne, 1987).

Figura 8 - Imagens multibandas de curvaturas Longitudinal, Transversal, Mínima e Máxima para formar assinatura geométrica.

Figura 9 - Efeito de gain e de offset: (A) assinatura de referencia, (B) variação do offset, e (C) variação de ganho. Curvaturas: Longitudinal = Long, Transversal = Trans, Mínima $=$ Min, e Max $=$ Max.

Figura 10 - Mapa da $1^{\mathrm{a}}(\mathrm{A}), 2^{\mathrm{a}}(\mathrm{B}), 3^{\mathrm{a}}(\mathrm{C})$ e $4^{\mathrm{a}}$ componente (D) do Minimum Noise Fraction (MNF). Esquema do n-dimensional com as $1^{\text {a }}, 2^{\text {a }}$ e $3^{\text {a }}$ componente do Minimum Noise Fraction (E) a partir do resultado do Pixel Purity Index (PPI).

Figura. 11 - Esquema de classificação em dois estágios. Primeiro a classificação por SCM, determinando os dois tipos de assinaturas. Em seguida a classificação por Mínima Distância, determinando a intensidade dos tipos de assinaturas. Cada etapa gera seis diferentes tipos de assinaturas: formas convexas (HiNCx, LoNCx, HiUCx e LoUCx), formas transicionais (HiNTr, LoNTr, HiUTr e LoUTr), e formas côncavas (HiNCc, LoNCc, HiUCc e LoUCc).

Figura 12 - Mapas de classificação de Formas de Terreno da bacia do Rio Jardim dividido em três níveis progressivos. As três classes básicas, convexa, transicional e côncava (A). As classes convexa, transicional e côncava dos dois tipos de assinaturas N-Type e UType, totalizando seis classes (B). As subclasses baseadas na subdivisão anterior e nas diferenças de intensidade dos tipos de assinaturas. Nessa classificação as classes básicas (côncavo, convexo e transicional) são subdivididas em 12 subclasses (C). Zoom de detalhe (à direita) com curvas de nível (20m) dos mapas A, B e C.

Figura 13 - Mapa de Formas de Terreno (A) composto por 12 assinaturas geométricas (B, C, D) da bacia do Rio Jardim apresentando as mudanças graduais do terreno: HiNCx (1), LoNCx (2), HiNTr (3), LoNTr (4), LoNCc (5), HiNCc (6), HiUCx (7), LoUCx (8), HiUTr (9), LoUTr (10), LoUCc (11), HiUCc (12).

Figura 14 - Classificação das Formas de Terreno da Bacia do Rio Jardim a partir do método do Wood (1996), considerando diferentes valores de Tolerância de Declividade $\left({ }^{\circ}\right)$ e Tolerância de Curvatura $(\% / m)$. 
Figura 15 - A comparação dos mapas de Formas de Terreno entre a classificação por assinatura geométrica (Convexo, Transicional e Côncavo do N-Type e do U-Type) (A) e (B), e classificação de Wood (Peak, Ridge, Plane, Pass, Pit e Channel) (D) e (E). Um perfil topográfico para descrever as variações das Formas de Terreno, considerando o método de assinatura geométrica (C) e o método de Wood (F).

Figura 16 - Assinaturas geométricas selecionadas para a classificação das Formas de Terreno do contexto regional.

Figura 17 - Gráficos de Frequência (Fr \%) por compartimento geomorfológico apresentando a variação da Formas de Terreno do contexto regional.

Figura 18 - Classificação das Formas de Terreno representada pelas setes assinaturas geométricas do contexto regional.

Figura 19 - Gráficos de Frequência (Fr \%) e Proporção de Patches (PP \%) das Formas de Terreno por Compartimento Geomorfológicos (A). Diferença entre a Proporção de Patches e Frequência (PP-Fr) das Formas de Terreno por Compartimento Geomorfológico (B).

Figura 20 - Tabela de Frequência (Fr \%) e de Proporção de Patches (PP \%) de relevos convexos $(\mathrm{Cx})$, planos $(\mathrm{Pl})$ e côncavos $(\mathrm{Cc})$ e Índice Geomorfométrico de Denudação (IGD) calculada pela razão entre o Cx e Cc da frequência (f) e da proporção de patches (n) e pela razão entre o $\mathrm{Pl}$ e Cc da frequência (f) e da proporção de patches (n) por compartimento (A). Gráfico de frequência (Fr \%) de relevos Cx, Pl e Cc; IGDf Cx/Cc; e IGDf $\mathrm{Pl} / \mathrm{Cc}$ por compartimento (B). Gráfico de proporção de patches (PP\%) de relevos $\mathrm{Cx}$, Pl e Cc; IGDn Cx/Cc; e IGDn P1/Cc por compartimento (C).

Figura 21 - Resultado da Análise de Componentes Principais das Landscape Metrics de fragmentação por compartimento geomorfológico.

Figura 22 - Esquema apresentando a variação geomorfométrica dos etchplanos a partir do compartimento mais residual, Planalto Retocado do Paranoá (PRP), até a depressão mais aplainada, Depressão Cárstica do Paranoá-Bambuí (DCPB). Índice Geomorfométrico de Denudação (IGDf e IGDn) representado com setas verticais (cor preta) apontadas em direção aos maiores valores. Frequência $(\mathrm{Fr} \%)$ e Proporção de Patches (PP\%) dos relevos convexos e côncavos por compartimento representados com setas horizontais. Setas horizontais vermelhas apontadas para os relevos convexos com 
os maiores valores de Frequência (Fr\%) e Proporção de Patches (PP\%) no PRP e no PRBC. Setas verticais vermelhas indicando o aumento da Frequência ( $\mathrm{Fr} \%)$ e da Proporção de Patches (PP\%) do PRP ao PRBC. Setas horizontais azuis apontadas para os relevos côncavos com os maiores valores de Frequência (Fr\%) e Proporção de Patches (PP\%) no PDAC e no PDPC. Setas verticais azuis indicando o aumento da Frequência (Fr\%) e Proporção de Patches (PP\%) do PDPC ao PDAC. Setas horizontais amarelas apontadas para os relevos côncavos com os maiores valores de Frequência (Fr\%) e Proporção de Patches (PP\%) nas DCVB, DCPC e DCPB. Setas verticais amarelas indicando o aumento da Frequência (Fr\%) do DCVB ao DCPB. Setas verticais amarelas indicando o aumento da Proporção de Patches (PP\%) do DCPB ao DCVB. 


\section{ÍNDICE DE TABELAS}

Tabela 1 - As seis Formas de Terreno (FTs) definidas pelos parâmetros geomorfométricos: Declividade e, Curvaturas Longitudinal, Transversal, Mínima e Máxima (Wood, 1996).

Tabela 2 - Equações e definições das variáveis que compõe as métricas de fragmentação

Tabela 3 - Variação das Landscape Metrics por Unidade Geomorfológica (Unit. Geo.) e por Compartimento Geomorfológico (Comp. Geo.).

Tabela 4 - Class Metrics dos Compartimentos Geomorfológico. Maiores e menores valores das métricas dos relevos convexos $(\mathrm{Cx})$ e de relevo côncavos $(\mathrm{Cc})$ realçados. Valor total (TOTAL) do resultado das Class Metrics por compartimento. Valor total do resultado das Class Metrics dos relevos convexos (Total (Cx)) e côncavos (Total (Cc)) por compartimento. 


\section{LISTA DE ABREVIAÇÕES}

(Por ordem de aparição)

MDE - Modelo Digital de Elevação

FT - Formas de Terreno

SIG - Sistemas de Informação Geográfica

ISODATA - Organizing Data Analysis Technique

SOM - Self-Organizing Map

ENVI - Environment for Visualizing Images

SAM - Spectral Angle Mapper

SCM - Spectral Correlation Mapper

FBM - Faixa Brasília Setentrional

FBM - Faixa Brasília Meridional

PDAC - Planalto Dissecado Araxá-Canastra

DCPC - Depressão Cárstica Paranoá-Canastra

PRP - Planalto Retocado do Paranoá

DCPB - Depressão Cárstica Paranoá-Bambuí

PRBC - Planalto Retocado Bambuí-Canastra

PDPC - Planalto Dissecado Paranoá-Canastra

DCVB - Depressão Cárstica Vazante-Bambuí

CODEPLAN - Companhia de Desenvolvimento do Planalto Central

RIDE-DF - Região Integrada de Desenvolvimento do Distrito Federal e Entorno

Embrapa - Empresa Brasileira de Pesquisa Agropecuária

MD - Mínima Distância

SRTM - Shuttle Remote Topographic Mission

ACP - Análise de Componentes Principais

MNF - Minimum Noise Fraction

PPI - Pixel Purity Index

Long - Longitudinal

Trans - Transversal

Min - Mínima

Max - Máxima

Fr - Frequência

NP - Número de Patches

PP - Proporção de Patches 
SHDI - Shanon Diversity Index

MPAR - Mean Perimeter Area Ratio

ED - Edge Density

MPE - Mean Patch Edge

MPS - Mean Patch Size

PD - Patch Density

PSSD - Patch Size Standard Deviation

Cx - Convexo

$\operatorname{Tr}$ - Transicional

Cc - Côncavo

$\mathrm{N}$ - N-Type

U - U-Type

Hi - higher

Lo - Lower

HiNCx - formas de terreno mais convexas do N - Type

LoNCx - forrmas de terreno menos convexas $\mathrm{N}$ - Type

HiUCx - formas de terreno mais convexas do U - Type

LoUCx - formas de terreno menos convexas do U - Type

HiNTr - Transição entre as formas de terreno convexas e côncavas com valores próximos das formas convexas do $\mathrm{N}$ - Type

LoNTr - Transição entre as formas de terreno convexas e côncavas com valores próximos das formas côncavas do $\mathrm{N}$ - Type

HiUTr - Transição entre as formas de terreno convexas e côncavas com valores próximos das formas convexas do U - Type

LoUTr - Transição entre as formas terreno convexas e côncavas com valores próximos das formas côncavas do U - Type

HiNCc - formas de terreno mais côncavas do N - Type

LoNCc - formas de terreno menos côncavas do $\mathrm{N}$ - Type

HiUCc - formas de terreno mais côncavas do U - Type

LoUCc - formas de terreno menos côncavas do U - Type

TC - Tolerância de Curvatura

TD - Tolerância de Declividade

Pl - Plano

Cx-Cc-Convexo-Côncavo

Cc-Cx - Côncavo-Convexo 
$\mathrm{HiCx}$ - formas de terreno mais convexas

$\mathrm{HiCc}$ - formas de terreno mais côncavas

LoCx - forrmas de terreno menos convexas

LoCc - formas de terreno menos côncavas

PP-Fr - diferença entre a Proporção de Patches e a Frequência

IGD - Índice Geomorfométrico de Denudação

IGDf $\mathrm{Cx} / \mathrm{Cc}$ - Índice Geomorfométrico de Denudação da frequência da relação entre relevos convexos e relevos côncavo

IGDf Pl/Cc - Índice Geomorfométrico de Denudação da frequência da relação entre relevos planos e côncavos

IGDn Cx/Cc - Índice Geomorfométrico de Denudação de proporção de patches da relação entre relevos planos e côncavos

IGDn Pl/Cc - Índice Geomorfométrico de Denudação da proporção de patches da relação entre o relevo plano e côncavo 
Relevos tropicais desenvolvem superfícies de aplainamento que podem remontar ao início do Terciário, cujo desenvolvimento é caracterizado pela evolução de etchplanos em paleoclima mais quente e úmido e posterior denudação e dissecação, tornando a paisagem mais heterogênea e fragmentada. O desafio recorrente para a Geomorfometria é modelar relevos suaves de baixa amplitude a partir de Modelo Digital de Elevação (MDE). Assim, o objetivo desse trabalho foi desenvolver uma abordagem de classificação de Formas de Terreno e de fragmentação para avaliar a evolução tropical por etchplanação. A área de estudo localiza-se na Faixa Brasília de Dobramentos, caracterizada por Planaltos Retocados, Planaltos Dissecados e Depressões Cársticas em diferentes estágios denudação. Inicialmente, a classificação das Formas de Terreno foi realizada na bacia de referência do Rio Jardim com as seguintes etapas: (1) obtenção das curvaturas longitudinal, transversal, mínima e máxima a partir de MDE; (2) criação uma assinatura geométrica a partir dessas curvaturas; (3) aplicação dos processamentos digitais sequenciais Mínimum Noise Fraction e Purity Pixel Index para reconhecer e selecionar as assinaturas geométricas; (4) classificação sequencial por similaridade, utilizando o Spectral Correlation Mapper $(S C M)$ e a Mínima Distância (MD). A identificação das assinaturas geométricas evidenciou a existência de curvas formato de "U" (U-Type) e de "N" (N-Type). Os resultados dessa classificação podem ser divididos em três níveis de detalhe: (1) nível simples com três classes (convexo, transicional e côncavo); (2) nível intermediário com as mesmas três classes, mas em padrões diferentes (N-Type e U-Type), totalizando 6 classes; (3) nível mais detalhado com 12 classes. A classificação dentro da bacia do Rio Jardim mostra o contexto das vertentes assimétricas, canais e cabeceiras de drenagem em diferentes níveis de dissecação e interflúvios bem delimitados. Aplicação do procedimento foi realizado no contexto regional que considera 7 compartimentos geomorfológicos: Planalto Retocado do Paranoá (PRP), Planalto Retocado Bambuí-Canastra (PRBC), Planalto Dissecado Araxá-Canastra (PDAC), Planalto Dissecado Paranoá-Canastra (PDPC), Depressão Cárstica Vazante-Bambuí (DCVB), Depressão Cárstica Paranoá-Canastra (DCPC), Depressão Cárstica Paranoá-Bambuí (DCPB). Na abordagem regional a classificação utilizou apenas a MD, visando individualizar uma assinatura única das formas planas, considerada a matriz para o estudo da fragmentação do relevo e sua correlação com o processo de etchplanação. Assim, foram classificadas 7 Formas de Terreno ( $\mathrm{HiCx}, \mathrm{LoCx}, \mathrm{Pl}, \mathrm{Cx}-\mathrm{Cc}, \mathrm{Cc}-\mathrm{Cx}, \mathrm{LoCc}, \mathrm{HiCc}$ ) correlacionadas, respectivamente, aos relevos: residuais, residuais/denudados, denudados, denudados/dissecados/depositados, dissecados/depositados e dissecados. A organização dessas Formas de Terreno é medida, primeiramente, por compartimento, considerando a Frequência (Fr), Número de Patches (NP) e Proporção de Patches (PP). Os valores desses parâmetros variam de acordo com o estágio de denudação do compartimento que está intimamente relacionado com o balanço entre as formas convexas, côncavas e planas. A partir da Fr e da PP foi gerado o Índice Geomorfométrico de Denudação (IGD), considerando a relação entre relevos convexos e côncavos e entre relevos planos e côncavos, tanto para Frequência (IGDf), quanto para a Proporção de Patches (IGDn). Também foi analisada a diferença dos valores entre PP e Fr, que mostra a fragmentação de uma mesma classe de Formas de Terreno em diferentes compartimentos. As Formas de Terreno também foram medidas por métricas de tamanho do patch (MPS e PSSD), tamanho do contorno do patch (MPE), de complexidade (MPAR), de diversidade (SHDI) e de densidade (PD e ED). Análise de Principais Componentes (ACP) apresenta que as métricas de densidade determinaram Planaltos Dissecados, as métricas de tamanho determinaram Planaltos Retocados e a métrica de diversidade determinaram Depressões Cársticas. A dinâmica do relevo avaliada pela as métricas e auxiliada pelas as informações pedológicas, litológicas e geomorfológicas dos compartimentos possibilitou a classificação dos estágios de etchplanação: Etchplano Mantado levemente dissecado (PRP), Etchplano Mantado dissecado (PRBC) Etchplano Parcialmente Denudado (PDAC), Etchplano Denudado (PDPC e DCVB), Etchplano Coberto (DCPC) e Etchplano Coberto/Exumado (DCPB).

Palavras-Chaves: SRTM, Curvaturas, Assinatura Geométrica, Etchplanação, Mapeamento, Geomorfometria. 


\begin{abstract}
Tropical reliefs develop planning surfaces that can be traced back to the beginning of Tertiary. Etchplanation proccess is characterized by the evolution of etchplains in paleoclimate wetter and warmer, influencing denudation and desiccation, consequently, fragmenting the landscape. Considering the planning surfaces, the applicant challenge for Geomorphometry is to model plain landforms from Digital Elevation Model (DEM). The objective of this work was to develop a landform classification and fragmentation approach to assess the evolution of tropical relief by etchplanation. The study area is located in Brasilia Fold Belt, characterized by Retouched Plateaus, Dissected Plateaus, and Karst Depressions at different stages of differential denudation. Initially, the classification of landforms was held in Jardim River Basin with the following steps: (1) obtaining the longitudinal, cross-section, minimum and maximum curvatures from DEM; (2) creating a geometric signature from these curvatures; (3) application of the sequential digital processing Minimum Noise Fraction and Pixel Purity Index to recognize and select the geometric signatures; (4) sequential classification using similarity by Spectral Correlation Mapper (SCM) and distance by Minimum Distance (MD). The identification of the geometrical signatures showed the existence of curves in the form of "U" (U-type) and "N" (N-type). The results of this classification can be divided into three levels of detail: (1) simple level with three classes (convex, concave and transitional); (2) intermediate level with the same three classes, but with different patterns (N-Type and U-Type), totalling 6 classes; (3) more detailed level with 12 classes. The classification within Jardim River Basin shows the asymmetrical hillsides, channels and drainage headslope in different dissection levels, and well-defined interfluves. Application of the procedure was carried out in the regional context that considers 7 geomorphological compartments: Retouched Plateau of Paranoá (RPP), Retouched Plateau Bambuí-Canastra (RPBC), Dissected Plateau Araxá-Canastra (DPAC), Dissected Plateau Paranoá-Canastra (DPPC) Karst Depression Vazante-Bambuí (KDVB), Karst Depression Paranoá-Canastra (KDPC), Karst Depression Paranoá-Bambuí (KDPB). In the Regional approach, the landform classification only used the MD, aiming to individualize a unique geometric signature of plains shapes, considered the matrix for the study of the relief fragmentation and its correlation with the etchplanation process. So, they were classified 7 landforms ( $\mathrm{HiCx}, \mathrm{LoCx}, \mathrm{Pl}, \mathrm{Cx}-\mathrm{Cc}, \mathrm{Cc}-\mathrm{Cx}$, LoCc, HiCc) correlated, respectively, with residual reliefs, residual/denudated reliefs, residual/deposited reliefs, denudated reliefs, denudated/dissected/deposited relief, dissected/deposited relief and dissected relief. The organization of these landforms is measured primarily for geomorphologic compartment, considering the Frequency (Fr) Number of Patches (NP) and Patches Proportion (PP). The values of these parameters vary with the compartment denudation stage that is closely related to the balance between convex, concave and plain landforms. From the Fr and PP was generated Geomorphometric Denudation Index (GDI), considering the relationship between convex and concave reliefs and between plains and concave relief, for Frequency (GDIf), and for Patches Proportion (GDIn). It also analyzed the difference between PP and Fr through the subtraction between the two metrics that presents the fragmentation of a landform class in different compartments. These landforms were also measured by patch size (MPS and PSSD), patch edge (MPE), complexity (MPAR), diversity (SHDI) and density (PD and ED). Principal Components Analysis (PCA) has shown that the density metrics determined Dissected Plateaus, the size metrics determined Retouched Plateaus and diversity metrics determined Karst Depressions. The relief dynamics assessed by theses metrics and aided by the soil, lithological and geomorphological compartments information allowed the classification of etchplanation stages: Slightly Dissected Mantles Etchplain (RPP), Dissected Mantles Etchplain (RPBC), Partly Stripped Etchplain (DPAC), Stripped Etchplain (DPPC and KDVB) Covered Etchplain (KDPC) and Covered/Exhumed Etchplain (KDPB).
\end{abstract}

Keywords: SRTM, Curvatures, Geometric Signature, Etchplanation, Mapping, Geomorphometry 


\section{Capítulo 1 - APRESENTAÇÃO GERAL}

\subsection{INTRODUÇÃO}

A Geomorfologia é uma ciência que tem se beneficiado dos avanços tecnológicos nas áreas de modelagem numérica do terreno e no desenvolvimento de métodos de classificação automática ou semiautomática que buscam analisar, compreender e mapear o relevo em diferentes escalas. Comumente, são utilizados Modelos Digitais de Elevação (MDE), adquiridos a partir de imageamento de sensores orbitais ou terrestre, aerofotogrametria e base cartográfica vetorial. $\mathrm{O}$ enfoque de um estudo geomorfológico com uso de MDE depende basicamente de dois parâmetros iniciais: escala cartográfica que está intimamente relacionada com a resolução espacial do MDE - e das covariáveis (geologia, clima, solos, dinâmica da água) que fazem parte da análise do relevo (Pike et al., 2009).

Em escalas regionais, destacam-se nos estudos geomorfológicos o controle da geologia estrutural diferenciando os compartimentos, a diversidade do material de origem e o clima como os principais estratificadores da paisagem. A combinação dessas três variáveis determina a velocidade do intemperismo e consequentemente a evolução do relevo. Dentro desse contexto, destaca-se a Geomorfologia Climática consolidada por meio dos trabalhos de Büdel $(1957 ; 1963 ; 1982)$. Com base na Teoria da Etchplanação (Wayland, 1933), Büdel explica que a evolução do relevo ocorre pela interação entre a erosão da camada mais superficial do relevo e uma camada subsuperficial existente no contato entre a rocha e a zona de alteração (front). Büdel (1957) conceitua essa dinâmica de "dupla superfície de planação", onde o front de intemperismo com formação de saprólitos espessos é tão importante quanto a desagregação mecânica na superfície do relevo.

Büdel (1957, 1963) ressalta que a formação dos etchplanos está associada, especialmente, aos trópicos com mais de seis meses de precipitação e às áreas tectonicamente estáveis (margens cratônicas). Nesse caso o estudo foi realizado na planície de Tamiland, no sudoeste da Índia. Contudo, Büdel (1982) passa a aceitar a existência de etchplanos nos trópicos úmidos, considerando a diversidade da alteração do material de origem e as variações climáticas.

Thomas (1989a, 1989b) retrata Büdel como o autor que consolida a importância conjugada do intemperismo químico e físico na Geomorfologia e diante disso, corrobora 
com a criação de um modelo de evolução que pode variar, a depender do estágio de denudação, entre um etchplano, em que os regolitos apresentam as superfícies superior e inferior, bem preservadas, e a etchsuperfície, quando o regolito está totalmente denudado e aflora a superfície basal de intemperismo (Thomas 1974, 1994). Para Migon (2013) o modelo desenvolvido por Thomas $(1974,1994)$ é o único que vincula explicitamente o intemperismo e evolução do relevo em ampla escala espacial e temporal. Entretanto, o autor ressalta que os conceitos de etchplanação ainda precisam ser explorados por modelos numéricos que explicam a evolução do relevo.

Modelos clássicos de evolução do relevo (e.g. Hammond, 1954; Throe, 1965; Ruhe e Walker, 1968; Darlymple et al., 1968; Conacher e Dalrymple, 1977; Speight, 1990; Skidmore et al., 1991) formaram as bases para o desenvolvimento dos métodos de classificação de Formas de Terreno (FT) (McMillian e Shary, 2009). Com o avanço da tecnologia esses procedimentos tornaram-se cada vez mais automáticos e robustos passíveis de aplicação em diversas escalas. Esses avanços culminaram no surgimento da Geomorfometria que tem como um dos seus escopos a classificação de FTs (landforms) (Pike et al., 2009). McMillian e Shary (2009) apresentam uma extensa revisão acerca de métodos de classificação de FTs, tendo como dado de entrada os atributos geomorfométricos de MDE. É recorrente o atributo de curvaturas nos métodos (e.g. Pennock et al., 1987; Wood, 1996; McMillian et al., 2000; Bolongaro-Crevenna et al., 2005; Ehsani e Quiel, 2008), que buscam classificar a morfologia do relevo quanto a sua convexidade, concavidade, aplanação, convergência e divergência da FT.

É importante salientar que apesar da forma plana estar contemplada na rotina de classificação com o uso das curvaturas, Evans (2012) destaca a dificuldade de classificar relevos suaves e contínuos típicos de contextos savânicos e tropicais. Dessa forma, é necessário desenvolver abordagens para classificar FTs sem rupturas bruscas no relevo, como é o caso da assinatura geométrica (Pike, 1986). A classificação das FTs com assinatura geométrica não apresenta especificações rígidas, exigindo apenas a distinção de uma superfície topográfica das outras semelhantes amostradas. Nesse sentido, a partir da assinatura seria possível representar a morfologia de um relevo etchplanado, classificando as FTs que irão destacar um arranjo de formas organizadas, contínuas ou fragmentadas, de acordo com o estágio de evolução do etchplano. Assim, essa contribuição se depara com o desafio de modelar relevos suaves de baixa amplitude topográfica e ao mesmo tempo criar uma forma de representar geomorfometricamente o relevo residual do processo de etchplanação. 


\subsection{HIPÓTESES}

- As formas de terreno de relevos suaves de pouca amplitude topográfica podem ser classificadas por assinaturas geométricas constituídas de dados de curvatura.

- A fragmentação de formas de terreno medida por métricas de densidade, diversidade, tamanho e complexidade em diferentes compartimentos revela estágios de evolução gemorfológica de etchplanos.

\subsection{OBJETIVOS}

\subsubsection{Objetivo Geral:}

Desenvolver uma abordagem de classificação de Formas de Terreno e de fragmentação, aplicada em escala regional para avaliar a evolução do relevo tropical por etchplanação.

\subsubsection{Objetivos Específicos}

- Desenvolver um método de classificação de Formas de Terreno por assinatura geométrica para descrever relevos tropicais sem rupturas bruscas;

- Avaliar o relevo em escala regional a partir da fragmentação das Formas de Terreno e relacionar com os estágios de evolução dos etchplanos.

\subsection{MODELO DA ETCHPLANAÇÃO EM RELEVOS TROPICAIS}

O estudo sobre superfície de aplainamento do relevo brasileiro apresenta contribuições importantes nesse último século (e.g. Martonne, 1943, 1944; Freitas 1951; Almeida 1955; King, 1956; Ab' Saber e Bigarella, 1961; Bigarella e Ab'Saber, 1964; Almeida 1964; Braun, 1970; Valadão, 1998). Dentre esses autores King (1956) pode ser considerado um "divisor de águas" no tema, decorrente da elaboração da teoria da pediplanação (King, 1953) muito utilizada no mapeamento geomorfológico nacional (IBGE, 2009) impulsionado pelo projeto "RadamBrasil" entre 1970 e 1985. Braun, (1970) foi o primeiro a reinterpretar as ideias de King (1956) para o Brasil Central. O autor ressalta que foi durante o Terciário entre o Eoceno e o Plioceno que houve o mais extenso e perfeito aplainamento com elevado processo de laterização pertencente ao ciclo Sul-Americano (King, 1956).

Do ponto de vista da etchplanação, Büdel (1982) considera a existência da laterização terciária como uma variável essencial uma vez que as glaciações do 
Quaternário não alcançam as em regiões tropicais e consequentemente, o regolito desenvolvido em período anterior não é retirado. Durante o Terciário, entre o Paleoceno e o Mioceno, nessas regiões e principalmente em cotas menores que $2000 \mathrm{~m}$, dominaram clima úmido e quente com pequenos intervalos secos (Frakes, 1979). Essas condições indicam que na maior parte do tempo, o intemperismo químico se sobressai em relação ao intemperismo físico no processo de aplainamento e consequentemente são formadores de etchplanos (Martins, 2000). Essa ideia ainda é corroborada por Summerfield (1991), Thomas (1994), Twidale e Vidal-Romani (1994), Philips (2002) que destacam o papel da história climática e do intemperismo como um dos fatores determinantes para compreender o processo de etchplanação. Os processos de denudação dos etchplanos ocorreram após a diminuição da intensidade climática no final do Terciário e Quaternário (Tardy, 1997; Maignen, 1966).

Dentro desse contexto, Thomas (1974) elabora um modelo de evolução do relevo que pode variar em sequências: (a) Etchplano Laterizado que compreende uma superfície com relevo suave sustentada por um espesso manto de intemperismo, horizontes ferruginosos endurecidos e limitada incisão de drenagem; (b) Etchplano Dissecado que apresenta fluxo de drenagem mais elevado promovido pela mudança climática ou soerguimento. A dissecação do relevo é controlada por couraças lateríticas com desenvolvimento de vales bem definidos; (c) Etchplano Parcialmente Denudado caracterizado pela intensa remoção do manto de intemperismo, inclusive do horizonte ferruginoso e dissecação pela atuação generalizada da drenagem. Perfis de intemperismo são truncados nesse estágio; (d) Etchplano Predominantemente Denudados e Etchsuperfícies representam um estágio muito avançado de denudação com pouca ou ausência do manto de intemperismo. Onde o a frente de intemperismo é praticamente inexistente é mais apropriado denominar como Etchsuperfície. Essas superfícies denudadas são geralmente resultantes de importante soerguimento crustal e/ou mudança climáticas, especialmente em regiões savânicas; (e) Etchsuperfície Encaixadas ocorrem quando a frente de intemperismo foi intensamente modificada pela erosão fluvial e não simplesmente exposta, muito provavelmente por causa da mudança de nível base; (f) Etchsuperfície Pedimentada evoluem a partir de Etchplanos Denudados e Etchsuperficie Encaixada quando a incisão cessa e o recuo das vertentes atuam.

Thomas (1994) revisita o seu próprio modelo elaborando uma sequência similar de evolução (Figura 1), porém com uma nova nomenclatura: (a) Etchplano Mantado (Mantled Etchplain), (b) Etchplano Parcialmente Denudado, (c) Etchplano Denudado, (d) 
Etchplano Complexo (Etchplano Encaixado, Pedimentado e Coberto) (e) Etchsuperfícies. O Etchplano Dissecado presente na sequência de 1974 é considerado parte da denudação parcial ou completa da superfície de aplainamento. O Etchplano Coberto corresponde a superfície coberta por depósitos ou por fluxo de lava. Quando a superfície coberta é exposta, recebe o nome de Etchplano Exumado.

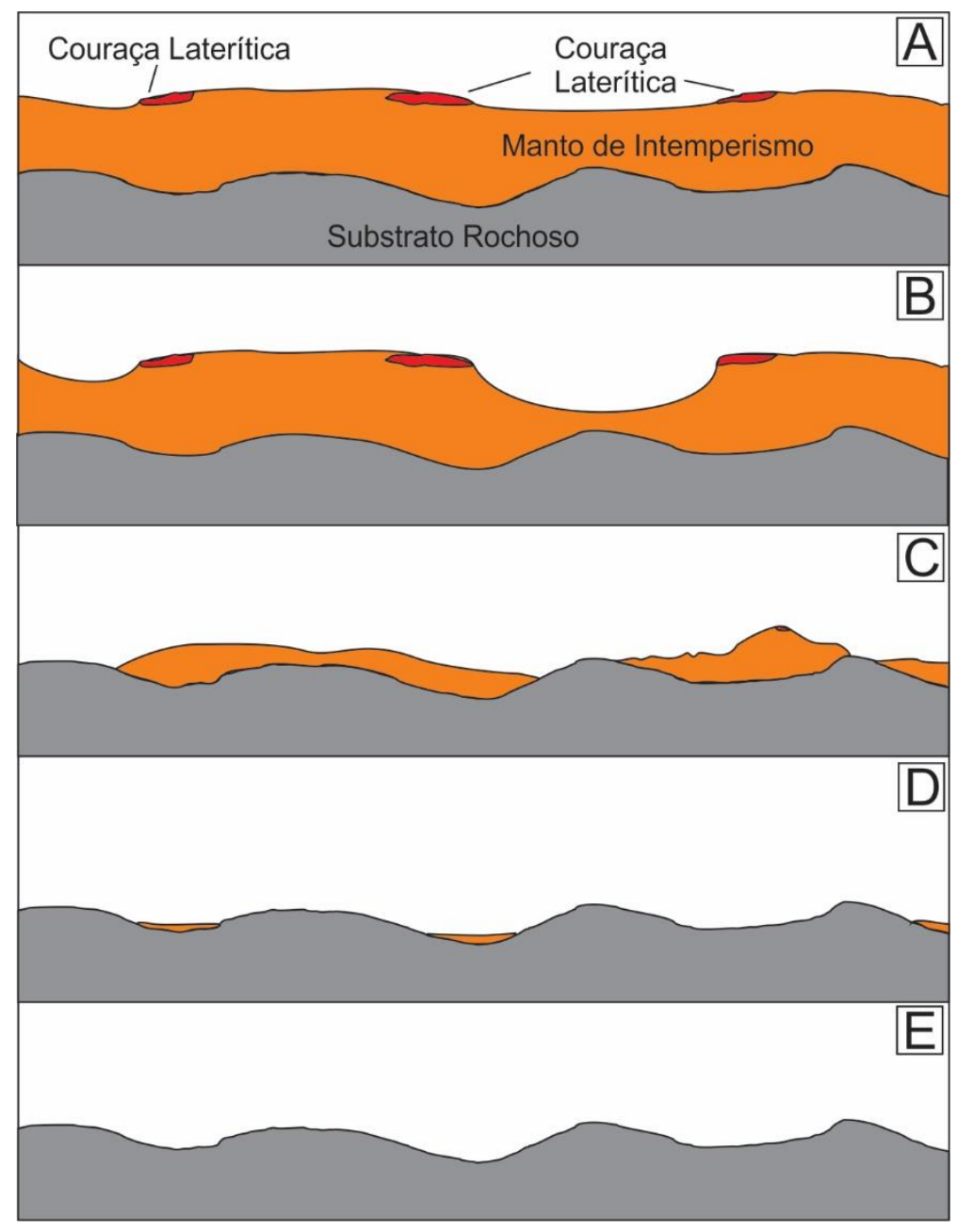

Figura 1 - Etchplano Mantado (A); Etchplano Parcialmente Denudado (ou Etchplano Dissecado, mais de 50\% do manto preservado) (B); Etchplano Denudado (de 10\% a 50\% do manto preservado) (C); Etchplano Complexo (D); Etchsuperfície (E) (menos de 10\% do manto preservado) (adaptado de Thomas, 1994).

O ponto central para a compreensão das mudanças na paisagem que evoluem em longo prazo como os etchplanos é a denudação do relevo. Denudação é o resultado da remoção das partículas sólidas (denudação mecânica) e do material dissolvido (denudação química) (Meybeck, 1987). Summerfield e Hulton (1994) e Gaillardet et al., (1999) analisando a denudação das rochas a partir das maiores bacias hidrográficas do mundo mostraram que a denudação física é superior a denudação química. Contudo, é 
importante ter atenção ao comparar a denudação física sob clima atual e a denudação química do Terciário sob paleoclima muito mais quente e úmido (Frakes, 1979).

Summerfield e Hulton (1994) explica que as taxas de denudação química estão fortemente associadas com relevo e fatores climáticos e que isso apoia a ideia de que a remoção eficiente de rocha na zona de intemperismo é o fator determinante da taxa de intemperismo químico. O relevo influencia na taxa de escoamento superficial, taxa de drenagem subterrânea e, portanto, na taxa de lixiviação de componentes solúveis, e na taxa de erosão de produtos intemperizados e, assim, na taxa de exposição dos minerais frescos (Goudie et al., 1998). Isto se reflete no solo onde três grupos de minerais permanecem como resíduo do intemperismo químico: (a) filossilicatos (argilominerais); (b) sesquióxidos de ferro e alumínio; (c) e minerais primários como quartzo, rutilo e zircão, muito resistentes ao intemperismo. Nesse sentido, considerando a ação conjunta da denudação mecânica e química atual e em paleo ambientes, a taxa de denudação é uma combinação do efeito erosivo e processos químicos, mas que em condições de equilíbrio é balanceado pela formação de solos (von Blanckenburg, 2006)

Em uma das poucas revisões bibliográficas sobre etchplanação em português Vitte (2001, 2005) explica que uma das prioridades da teoria da etchplanação é de especificar e qualificar o papel do intemperismo na morfogênese de uma maneira sistêmica nas regiões tropicais, e para isso seria importante aproximar o estudo da etchplanação com a análise da cobertura pedológica (Boulet et al., 1984, Boulet et al., 1993). Muitos destes estudos foram realizados no Brasil, como por exemplo: na região de Marília (Fernandes Barros, 1985; Castro, 1989); Bauru (Santos, 2000); Taubaté (Filizola, 1993), Sorocaba do Sul (Beltrame, 1997), Londrina (Fernandes Barros, 1996), e Manaus (Lucas et al., 1984; Chavel et al., 1987).

No contexto da relação solo-paisagem ainda é possível citar os trabalhos realizados no Planalto Ocidental Paulista com o modelo de superfície geomórfica (Ruhe, 1956; Daniels et al., 1971) onde o grau de intemperismo e o desenvolvimento dos horizontes pedogenéticos aumentam da superfície mais jovem para a mais antiga (Lepsch 1977; Marques Jr. et al., 1997; Cooper et al., 2002; Campos et al., 2012). No Planalto Central Brasileiro as superfícies geomórficas mais antigas foram tratadas com correspondência com os ciclos de aplainamento Sul-Americano e as superfícies mais jovens com o ciclo das Velhas (Motta et al., 2002), demonstrando sua relação com o relevo aplainado. Reatto et al., (2008; 2009) observam no Planalto Central Brasileiro que os Latossolos localizados na Superfície Sul-Americana são mais intemperizados com 
elevados teores de gibbsita e nas Superfícies Velhas os Latossolos tendem a ser mais cauliníticos. Rodrigues e Klamt (1978) estudaram as relações solo-paisagem no Planalto Central Brasileiro na região do Distrito Federal e o compartimentaram de acordo com a diminuição do conteúdo de gibbsita dos solos. Outros atributos do solo, como elementos traços e elementos maiores foram relacionadas com as superfícies de aplainamento e o seu grau de intemperismo no Planaltos Central e regiões adjacentes (Marques et al., 2004; 2004).

Afim de registrar as variáveis mais importante para o processo de etchplanação, Migon (2013) propõe uma equação (Equação 1) muito similar a famosa equação de Jenny (1941) para o processo de formação de solos, mas que represente a evolução do manto de intemperismo:

$$
\mathrm{WM}=f(\mathrm{R}, \mathrm{C}, \mathrm{G}, \mathrm{t})
$$

onde WM - característica do manto de intemperismo, $\mathrm{R}$ - propriedades da rocha, $\mathrm{C}-$ fatores climáticos, $\mathrm{G}$ - geomorfologia (relevo local e regional), e $\mathrm{t}$ - tempo. Propriedades da rocha e a morfologia do local condicionam a susceptibilidade ao intemperismo do material em um determinado local, enquanto o clima e o tempo são fatores externos que controlam as taxas de resistência e da natureza do produto final, respectivamente.

O relevo residual como produto final irá variar de acordo com o avanço da etchplanação. Para Thomas (1974) existe um balanço entre superfícies aplainadas e porções dissecadas. Martins (2000) explica que as superfícies de aplainamento ocorrem na forma de residuais em extensões variadas, adjacentes ou não às escarpas, podendo apresentar relevo positivo nas porções deprimidas. Migon (2013) considera depressões, relevo multi-convexo (convexo e côncavos intercalados), inselbergs e superfícies planas como marcas morfológicas das etchsuperfícies. Em etchplanos mais preservados destacam as mesas e chapadas com perfil laterítico espesso (Millot, 1964; Maignien, 1966; McFarlane, 1976, 1983).

Eschenbrenner (1988) reforça o papel do relevo residual no processo de evolução com diferentes tipos de topos (aguçados ou tabulares) e formas de domos. Quanto a morfologia da FT em escala quilométrica, as superfícies podem ser de 4 tipos: (a) convexo; (b) convexo e convexa-côncava, sub-aplainada; (c) sub-aplainada com topos planos e morros testemunhos; (d) sub-aplainadas com relevo residual na forma de glacis 
e em morros testemunhos. Em escala de centenas de metro podem ser divididas em 6 tipos: (a) convexo (meia laranja); (b) convexo com base côncava; (c) convexa-côncava; (d) sub-aplainado, convexo, plano-convexo, retilíneo ou côncavo; (e) relevo residual e glacis. Nesse sentido, cada etapa do processo de etchplanação apresenta um retrato de características morfológicas do relevo organizadas em fragmentos de FTs mais contínuos (sem ruptura do relevo) ou mais intervalados (com ruptura do relevo).

\subsection{FRAGMENTAÇÃO DE PAISAGEM DESENVOLVIDA A LONGO PRAZO}

O processo de etchplanação está inserido num conjunto de "paisagens desenvolvidas a longo prazo" (long-term landscape development) assim como os modelos de peneplanação (Davis, 1889), pediplanação (King,1953) em que a evolução do relevo registra, exuma e cobre a paisagem a depender da intensidade e velocidade do intemperismo, gerando superfícies aplainadas (Summerfield, 1991).

Paisagem é uma terminologia com diferentes raízes etimológicas e consequentemente deve ser empregada em consonância com estudo elaborado. $\mathrm{O}$ termo com origem francesa paysage pode significar territórios agrupados em coleções ou classes de terra, ou territórios transformados por meio da ação de processos dinâmicos (Martins et al., 2004a). Segundo Rocha et al., (1997) as línguas germânicas compreendem o termo paisagem como land (Lantshaft ou Landshaft) mantendo o significado para o inglês, (landscape) e holandês (landschap).

Na Ciência dos Solos, o estudo da paisagem tem no solo seu protagonista principal os fatores de formação dos solos (Jeny, 1941) ou por meio do conceito de catena (Milne, 1935). Vidal-Torrado et al. (2005) afirma que o estudo da relação solo-paisagem se iniciou em escalas genéricas, considerando as grandes zonas bioclimáticas do planeta para as primeiras interpretações do conhecimento sobre o solo como produto dessa zonalidade.

A Geografia Física estuda paisagem como parte da combinação de elementos, biofísicos e antrópicos (Bertran, 1971; Bólos 1981). Guerra e Marçal (2006) aproximam o estudo da paisagem com a geomorfologia, destacando a "unidade de paisagem" como parte de um processo de análise sistêmica que visa atender o mapeamento e o estudo das questões ambientais. Thomas (2001) define Paisagem como um complexo de rochas, depósitos superficiais, solos, plantas e animais, em conjunto com o próprio relevo. Paisagens apresentam mosaicos espaciais que formam uma 'colcha de retalhos' de 
diferentes caráter e escala e em toda a superfície da Terra. Os padrões complexos da paisagem podem ser entendidos em escalas variadas, a partir da classificação de cada elemento da paisagem com base na litologia ou em grandes bacias de hidrográficas.

Dentre os pesquisadores que trabalham com Paisagem se destacam os grupos que atuam sob a luz da "Ecologia da Paisagem" (Forman e Godron, 1986) com um grande salto em direção aos métodos de análise. Para os autores a paisagem é definida como um conjunto de ecossistemas interativos mensuráveis que se repetem no espaço. As técnicas desenvolvidas incluem modelos estatístico e matemáticos, métricas e índices (Forman e Godron, 1986; Turner, 1989; McGarigal e Marks, 1994; Lindenmayer e Fischer, 2006), extraídos geralmente de mapeamentos de uso e cobertura da terra ( $\mathrm{Su}$ et al., 2012; Sun et al., 2014) realizados por sensores remotos (Turner et al., 2001).

A estratégia de avaliação parte da análise de manchas (patch) por meio do estudo de métricas (metrics) que medem a fragmentação de um ecossistema. A fragmentação é entendida como a transformação de uma paisagem uniforme para uma paisagem mais irregular, tornando os padrões de cobertura vegetais mais fragmentados e consequentemente isolando habitats (Baldi et al., 2006). Nesse sentido, estudos da fragmentação da paisagem surgem para avaliar o uso da terra e as consequentes alterações nos sistemas ecológicos (e.g. Harris, 1984; Turner, 1989; Saunders et al., 1991; Hargis et al., 1998; Jaeger, 2000; Southworth et al., 2004; Fischer e Lindenmayer, 2007; Kang e Choi, 2014).

Apesar do foco dos trabalhos de fragmentação da paisagem estarem direcionados a cobertura da terra, observa-se uma grande contribuição de padrões e aspectos geomorfológico na análise da paisagem (Turner, 1989; Swanson et al., 1992; Swanson et al., 1998). Dorne et al., (2002), considerando o plano vertical e horizontal, utilizam a declividade e verificam que a topografia ajuda na compreensão do mosaico de vegetação e na quantificação da sua influência nos padrões da paisagem em Bristish Columiba, Canada. Guimarães et al., (2010) em estudo desenvolvido na bacia hidrográfica da Ariranha no estado de Santa Catariana relacionam dados de curvatura, declividade e fragmentos florestais com propósito de criar corredores ecológicos.

As métricas de fragmentação aos poucos têm sido exploradas em outras áreas do conhecimento. Raines (2002) demonstrou como as patch metrics do pacote FRAGSTATS (McGarigal, 1994) podem ser úteis na análise de mapas geológicos. Dinesh (2009) utiliza 9 patch metrics em análise multiescalar de ambientes montanhoso a partir de MDE em 
Nevada, USA. McGarigal et al., (2009) quantifica e analisa a estrutura da paisagem do extremo oeste da Turquia, relacionando métricas de MDE (Declividade, Topographic Wetness, Índice de Posição Topográfica e Heat Load Index), métricas de cobertura (Normalized difference vegetation, Tasseled cap brightness, Tasseled cap greenness and Tasseled cap wetness) e 27 patch metrics computados pelo FRAGSTATS. Dessa forma, os estudos de fragmentação podem ser aplicados na análise do arranjo das FTs classificadas na paisagem como mosaicos espaciais.

\subsection{CLASSIFICAÇÃO DAS FORMAS DE TERRENO}

A superfície da Terra pode ser caracterizada por atributos espaciais com diferentes formas, orientações, posição e tamanho, indicando os processos de evolução da paisagem (genética, morfológica e estrutural) (MacMillan e Shary, 2009; Bishop et al., 2012). Recentes avanços em sistemas de informação geográfica (SIG) e sensoriamento remoto têm contribuído na análise dessas superfícies por meio da modelagem numérica. MDEs são as fontes de dados mais comuns, a partir dos quais uma vasta gama de medidas geométricas são extraídas (Pike, 1988; Moore et al., 1991; Florinsky, 1998; Schmidt e Dikau, 1999; Wilson e Gallant de 2000). De primeira ordem (declividades e aspecto) e derivadas de segunda ordem do MDE (curvatura longitudinal, curvatura mínima, curvatura máxima e curvatura transversal) são os atributos geomorfométricos mais comumente utilizados (Evans, 1972; Wood, 1996). Estes descritores quantitativos permitem a comparação e classificação das diferentes FTs (Giles e Franklin, 1998; Miliaresis, 2001).

A classificação das FTs, com base em dados numéricos, mostra as seguintes vantagens: precisão, repetitividade, velocidade e facilidade de combinação com outros dados temáticos. Geralmente, as principais diferenças na classificação digital das FTs são os descritores e o método de classificação. Consequentemente, métodos com um conjunto de descritores têm sido propostos para a criação de uma representação digital consistente de terreno, que permita uma melhor compreensão dos processos superficiais da terra (Pennock et al., 1987; Wood, 1996; Irvin et al., 1997; Schmidt e Dikau, 1999; Burrough et al., 2000; MacMillan et al., 2000; Smith et al., 2006; Minar e Evans 2008; Pike et al., 2009; Jasiewicz e Stępiński, 2013).

Métodos de classificação podem ser divididos em não-supervisionados ou supervisionados. Classificação não-supervisionada cria agrupamentos de pixels semelhantes (melhores categorias de formas de terreno), sem ter uma noção pré-definida 
de cada grupo; esta abordagem é normalmente usada como análise exploratória de dados. Diferentes processos de classificação não supervisionada foram utilizados na análise geomorfológica, tais como Organizing Data Analysis Technique (ISODATA) (ex. Irvin et al., 1997; Adediran et al., 2004); Self-Organizing Map (SOM) (ex. Ehsani e Quiel, 2008, 2009; Ehsani et al., 2010); Fuzzy c-means (ex. Arrell et al., 2007; Burrough et al., 2000; De Bruin e Stein, 1998; Irvin et al., 1997; Lagacherie et al., 1997; MacMillan et al., 2000), e Nested-Means Algorithm (Iwahashi e Pike, 2007).

A classificação supervisionada usa amostras pré-definidas e conhecidas de elementos geomorfológicos homogêneos para o mapeamento; um conjunto inteligente de configurações para estabelecer os comportamentos de classe (Brown et al., 1998; Hengl e Rossiter, 2003; Prima et al., 2006; Ghosh et al., 2009). Esta abordagem tem como objetivo identificar o grau de conformidade entre os dados com modelos conhecidos ou hipotéticos, considerando-se as medidas de distância ou semelhança. Métodos de reconhecimento de padrões multivariados comparam as assinaturas conhecidas com curvas desconhecidas por uma medida de similaridade ou distância.

Um passo importante na classificação é definir o conjunto de descritores e assinaturas que melhor representa o terreno ou um determinado processo em análise, tais como deslizamento de terra, inundações, e instabilidade de encostas. Embora o termo "assinatura geométrica" tenha sido empregado em Pike e Rozema (1975), Pike (1986) a define como um conjunto de medidas que descreve formas topográficas que são capazes de distinguir paisagens geomorfológicas. Pike (1988) aplica a assinatura geométrica para caracterizar uma topografia contínua da superfície terrestre, de acordo com o conceito de “general geomorphometry” (Evans, 1972).

$\mathrm{Na}$ classificação supervisionada, a extração da assinatura geométrica pode ser feita por diferentes abordagens. O algoritmo de Boardman, incorporada ao Environment for Visualizing Images (ENVI), um pacote de software para processamento de imagens digitais, é o método mais amplamente utilizado na detecção de membros finais de dados de sensoriamento remoto. Este algoritmo é composto de três etapas: (1) redução de descritores, (2) redução espacial, e (3) um identificador n-dimensional (Boardman e Kruse, 1994). O principal objetivo da seleção de assinaturas geométricas representativas é estabelecer uma biblioteca extensa que levam em consideração a diversidade da superfície da terra para a classificação. 
A discriminação entre duas assinaturas geralmente emprega medidas de similaridade ou distância, que desempenham um papel crítico na classificação e reconhecimento de padrões. Vasconcelos et al., (2012) elaboraram um procedimento de classificação utilizando apenas medidas de similaridade por meio do Spectral Angle Mapper (SAM) (Kruse et al., 1993). O SAM utiliza o ângulo entre a assinatura de referência (assinatura selecionada) e a imagem (assinatura do pixel da imagem) para classificar aquilo que é semelhante. Sena-Souza et al., (2016) ao comparar o SAM com a Distância Euclidiana (menor distância entre dois pontos), observaram a eficiência da mínima distância ao classificar FTs com ausência de rupturas bruscas de relevo no Planalto Central Brasileiro.

A medida de similaridade mais comum é o coeficiente de correlação de Pearson, que mede de acordo com o padrão de diferentes tipos de assinaturas. Nesse sentido, de Carvalho Júnior e Meneses, (2000) desenvolveram um classificador chamado Spectral Correlation Mapper (SCM) empregado em trabalhos de sensoriamento remoto (Giroud et al., 2004; Pengra et al., 2007; de Carvalho Júnior et al., 2011), mas nunca explorado concomitantemente com a Distância Euclidiana (Mínima Distância) para classificar FTs. 


\section{Capítulo 2 -ÁREAS DE ESTUDOS}

\subsection{CONTEXTO GEOLÓGICO-GEOMORFOLÓGICO}

A região estudada está localizada entre as coordenadas $-15,10^{\circ}$ e $-16,30^{\circ}$ de latitude e $-47,00^{\circ}$ e $-48,60^{\circ}$ de longitude, considerando o Distrito Federal, o seu entorno dentro dos limites do estado de Goiás e parte do estado de Minas Gerais. A região foi escolhida por representarem planaltos residuais e depressões em diferentes estágios de denudação e dissecação, imprimindo a evolução geomorfológica dentro das bacias hidrográficas do Paraná, Tocantins e São Francisco no limite centro-oriental da Faixa Brasília de Dobramentos (Almeida, 1967) (Figura 2).

A Faixa Brasília de Dobramentos apresenta um conjunto de terrenos e escamas de empurrão de escala crustal com direção para leste contra o Craton do São Francisco (Marini et al., 1981; Fuck, 1994; Dardenne, 2000) desenvolvida dentro um sistema orogenético situado entre os crátons Amazônico e São Francisco, no contexto dos eventos colisionais que culminaram da amalgamação do supercontinente Gondwana ao final do Neoproterozoico (Tohver et al., 2010).

A Faixa Brasília é marcada por dois seguimentos distintos: a Faixa Brasília Setentrional (FBS), de orientação NE, e a Faixa Brasília Meridional (FBM), de orientação NW. A litologia apresenta elevado controle estrutural decorrente, principalmente, da tectônica gerada durante o Ciclo Brasiliano há cerca de 600 milhões de anos (Almeida, 1969). FBS e FBM se encontram na altura do paralelo de Brasília formando a Megaflexão dos Pireneus (Dardenne, 2000; Valeriano et al., 2004). Nessa porção, a Faixa Brasília apresenta a maior largura, possibilitando um acamamento menos verticalizado decorrente da dissipação da energia de colisão entre os cratons Amazônico e São Francisco. 

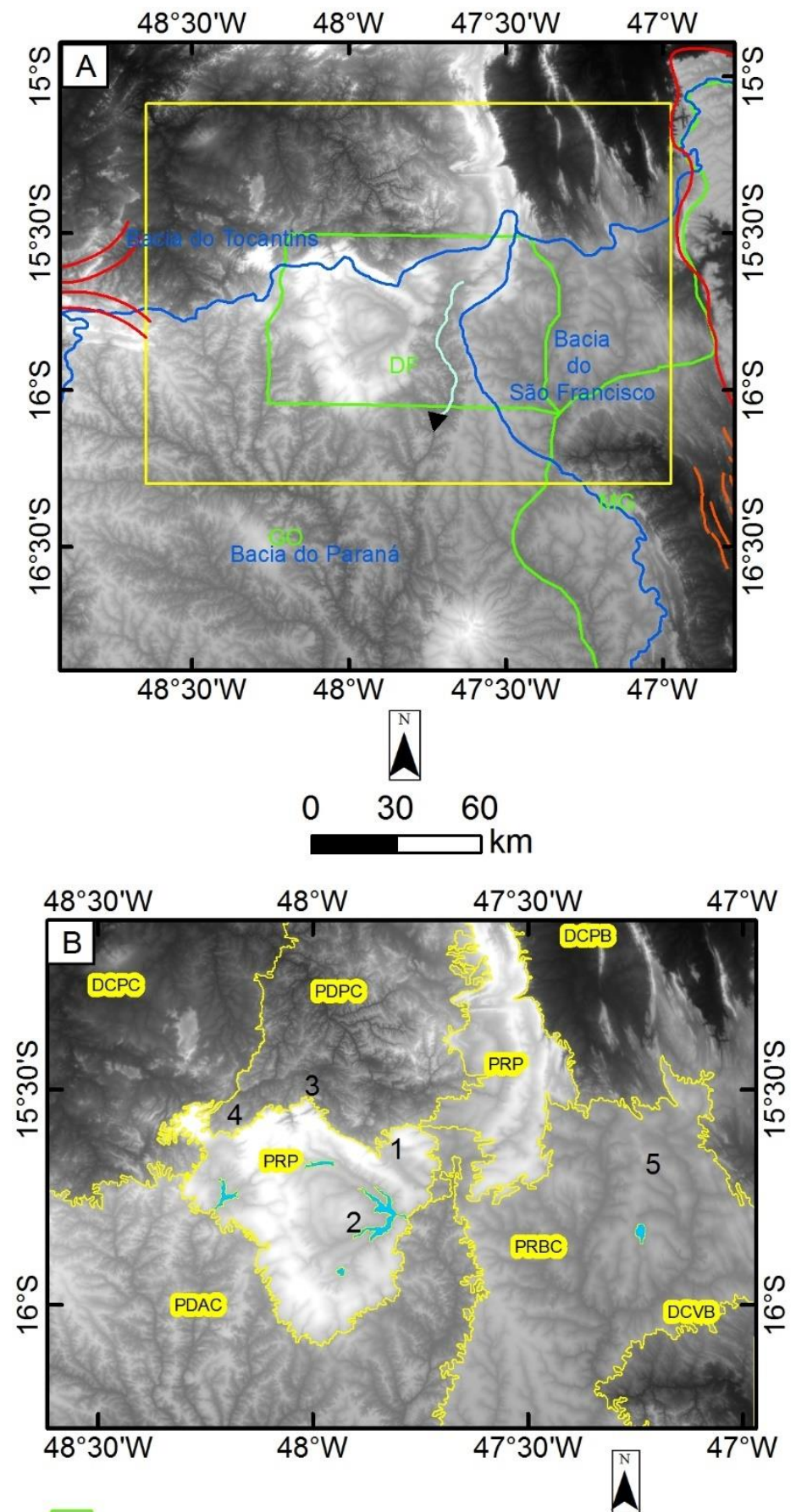

$\square$ Limite Estadual (A)
$\square$ Limite Hidrográfico $(A)$

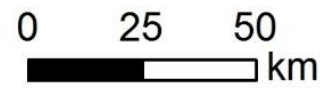

Área de Estudo (A)

Compartimentação Geomorfológica (B)

Limite Faixa Brasília-Cráton do São Francisco $(A)$

Cristas de Unaí (A)

$\underset{\sim}{\rightleftharpoons}$ Megainflexão dos Pireneus (A)

Fluxo do Rio São bartolomeu (A)

\section{Corpos d'agua (B)}

1 - Lago Paranoá

2 - Represa

3 - Barragem de Santa Maria

4 - Barragem do Descoberto

5 - Lagoa Cárstica
Figura 2 - Localização regional da área de estudo dentro da Faixa Brasília de Dobramentos composta por planaltos residuais e depressões no contexto das Bacias Hidrográficas do Tocantins, São Francisco e Paraná (A). Compartimentação geomorfológica composto por Planaltos Retocados do Paranoá (PRP), Planalto Retocado Bambuí-Canastra (PRBC), Planaltos Dissecados Araxá-Canastra (PDAC), Planalto Dissecado Paranoá-Canastra (PDPC), Depressão Cárstica Vazante-Bambuí (DCVB), Depressão Cárstica Paranoá-Canastra (DCPC) e Depressão Cárstica Paranoá-Bambuí (DCPB) (Adaptado de Dantas 2002; Latrubesse e Carvalho, 2006; Baptista et al., 2010). 
Durante a orogênese do final do Neoproterozoico, foram geradas diversas zonas de cisalhamento e diferentes tipos de falhas (empurrão, normais ou transcorrentes), dobramentos e domos. Dentro da Faixa Brasília se encontra o Planalto Central Brasileiro ou Planaltos e Serras Residuais Góias-Minas (Ross, 2009) com diferentes estágios de denudação, contribuindo para uma paisagem formada por planaltos com níveis de dissecação associados ao intemperismo diferencial das rochas e falhas com diferentes orientações, dobras e domos (Dantas et al., 2003). Esse controle litoestrutural gerou depressões intraplanálticas (dentro do Planalto Central) e interplanálticas (adjacente ao Planalto Central).

Os grupos geológicos Araxá, Canastra, Paranoá, Bambuí e Vazante representam as unidades presentes na região (Figura 3). Ocorrem de forma associada dentro dos planaltos e depressões. O Grupo Araxá está localizado predominantemente dentro dos planaltos dissecados a sul do Distrito Federal associados a rochas do Grupo Canastra (Scislewski et al., 2002), denominado nesse trabalho de Planalto Dissecado AraxáCanastra (PDAC). Diversos litotipos são encontrados associados aos grupos. De acordo com Scislewski et al., (2002) foram mapeados diferentes tipos de xistos, lentes de metacalcários e quartzitos micáceos pertencentes ao Araxá. No Canastra, predominam quartzo-sericita-clorita xistos, quartzo-sericita-clorita xistos carbonosos e localmente lentes de mármore, minolitos e calcixistos. Dentro desse contexto litológico, a amplitude do relevo residual com nível de base é marcada por chapadas ligeiramente convexas e vales escavados entre morros, ou na presença de rampas aplainadas suaves com vales mais abertos (Dantas et al., 2003).

O Grupo Canastra ainda está localizado dentro das depressões intraplanáltica representadas principalmente por metarenitos, metasiltitos e xistos, dentro de uma Superfície Regional de Aplainamento com presença de afloramentos de calcários e inselbergs (Latrubesse e Carvalho, 2006). No limite do Distrito Federal, a depressão apresenta um aspecto mais dissecado decorrente da Unidade Rítmica Quartzítica Intermediária e da Unidade Pelito Carbonatada do Grupo Paranoá formando serras e morros de diversas amplitudes. Sendo assim, esse compartimento foi denominado de Depressão Cárstica Paranoá-Canastra (DCPC).

O Grupo Paranoá é a unidade geológica mais recorrente na área de estudo, margeando todos os outros compartimentos geomorfológicos. Em ambiente planáltico, está situado dentro do Núcleo Semidômico do Paranoá (Novaes Pinto 1986a) e em cotas mais baixas ao norte da área de estudo. A Unidade Rítmica Quartzítica Intermediária 
aflora principalmente nas escarpas do planalto (Scislewski et al., 2002). Os flancos são mais elevados com relevo tabular do que a parte central levemente dissecada com padrão de drenagem anelar (Dantas et al., 2003). Apesar do controle estrutural e da dissecação interna do semidomo, o planalto está praticamente todo coberto por cobertura detritolaterítica ferruginosa (Scislewski et al., 2002; CPRM, 2008). Esse planalto foi denominado por Dantas, (2002) de Planalto Retocado, mas por estar todo embasado nas rochas do Paranoá é chamado nesse trabalho de Planalto Retocado do Paranoá (PRP). Abaixo dos rebordos na parte norte do PRP se desenvolve um planalto dissecado com alta densidade de drenagem (Dantas, 2002) associado as rochas do Grupo Canastra, denominado Planalto Dissecado Paranoá-Canastra (PDPC),

A Unidade Pelito Carbonatada do Paranoá ainda está presente nas depressões intraplanáticas em um conjunto de serras residuais no formato de cristas e isoladamente formando Hogbacks (Latrubesse e Carvalho, 2006). Abaixo desse relevo se desenvolve uma superfície aplainada sob rochas clásticas do Grupo Bambuí representadas por siltitos, argilitos, calcários e arcóseos. A superfície aplainada é denominada regionalmente de Vão do Paranã. A superfície é capeada por cobertura detrito-lateríticas (Latrubesse e Carvalho, 2006; Baptista et al., 2010) e fases pedimentadas por sedimentos friáveis associado a um sistema lacustre e cárstico (Latrubesse e Carvalho, 2006). A superfície plana quando interrompida, forma colinas alongadas desenvolvidas por rochas dobradas, podendo pertencer tanto ao Grupo Paranoá quanto ao Grupo Bambuí (Latrubesse e Carvalho, 2006). Nesse sentido, a depressão foi nomeada como Depressão Cárstica Paranoá-Bambuí (DCPB).

O Grupo Bambuí ainda cobre o Craton do São Francisco associado ao Grupo Vazante na depressão. O Bambuí é constituído na região basicamente por calcários, ritmitos, siltitos, argilitos e dolomitos (Baptista et al., 2010). Dificilmente, o Bambuí forma serras residuais, sendo assim responsáveis, pelos terrenos arrasados e planos (Campos et al., 2006). A porção mais dissecada da região está associado ao Grupo Vazante constituído por quartzitos e ardósias (Baptista et al., 2010). Foram também registrados ritmitos e arenitos líticos em cortes de estrada (Campos et al., 2006). Os autores ainda observaram afloramento desses arenitos em vales encaixados. Assim, esse compartimento recebe o nome de Depressão Cárstica Vazante-Bambuí (DCVB).

Em planaltos, o Grupo Bambuí está associado ao Grupo Canastra. Localizado na parte oriental do Distrito Federal e estado do Goiás, o planalto é controlado por escarpas de quartzitos do Grupo Canastra que cavalgam em direção do Grupo Bambuí por meio 
de falhas de empurrão (Freitas-Silva e Campos, 1999). A parte central está sobre rochas metassedimentares do Bambuí representadas por siltitos e argilitos, localmente por lentes de calcário, veios de quartzo e filitos do Grupo Canastra (CPRM, 2008). O planalto apresenta uma área mais dissecada promovida pelo recuo das cabeceiras de drenagem pertencente a bacia do São Francisco, com cotas mais baixas do que o Planalto Retocado do Paranoá, dentro do Distrito Federal. Na porção do planalto dentro do estado de Goiás, a superfície é mais plana coberta por crostas detrito-lateríticas e coberturas arenosas pleistocênicas (Scislewski et al., 2002). As vertentes formam vales abertos de onde afloram sericita xistos do Grupo Canastra (Dantas et al., 2003). É importante destacar que essa porção do planalto está situado no contexto da bacia do Rio Paraná (Figura 2B). Dantas (2002) caracteriza a região como um planalto retocado decorrente da manutenção do relevo residual e baixa densidade de drenagem. Nesse sentido, o planalto é denominado como Planalto Retocado Bambuí-Canastra (PRBC).

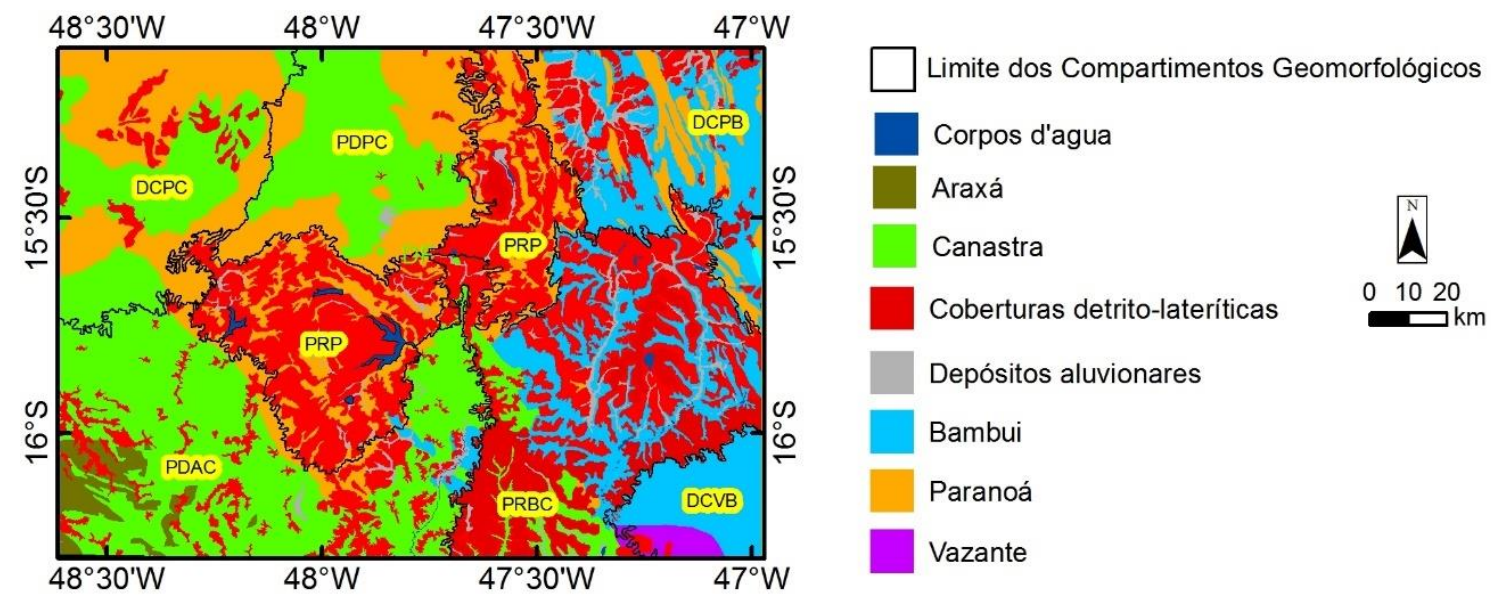

Figura 3 - Mapa de Geologia simplificado (adaptado de Freitas-Silva e Campos, 1999; Scislewski et al., 2002; CPRM, 2008; Baptista et al., 2010) e respectivos compartimentos geomorfológicos: Planalto Retocado do Paranoá (PRP), Planalto Retocado BambuíCanastra (PRBC), Planalto Dissecado Araxá-Canastra (PDAC), Planalto Dissecado Paranoá-Canastra (PDPC), Depressão Cárstica Vazante-Bambuí (DCVB), Depressão Cárstica Paranoá-Canastra (DCPC) e Depressão Cárstica Paranoá-Bambuí (DCPB).

\subsection{SUPERFÍCIES DE APLAINAMENTO}

O contexto regional da área de estudo foi descrito como parte do Domínio de Chapadões Tropicais Interiores com cerrados e matas de galeria marcados por duas estações, uma chuvosa e outra seca (Ab'Saber, 1970). O autor relaciona esse domínio com aplainamentos extensivos promovidos por uma ou duas fases de pediplanação, formando 
relevo residual (Braun, 1970; Ab’Saber, 1963). Ab’Saber, (1965) classifica três níveis diferentes de pediplanos na região de Brasília. Localizados em cotas superiores a $1200 \mathrm{~m}$ dentro do Planalto Retocado do Paranoá atualmente se desenvolve um pediplano de idade Paleógena, denominado pediplano de Brasília. Em cotas entre 1.000 - $1.100 \mathrm{~m}$, um pediplano de idade Eoceno-Oligoceno e uma outro pediplano abaixo de $1.000 \mathrm{~m}$ de idade pliopleistocênico.

A Companhia de Desenvolvimento do Planalto Central (CODEPLAN) descreve a área do Distrito Federal como uma superfície aplainada intercalada de uma superfície aplainada arrasada. A primeira está localizada em cota por volta de $1.300 \mathrm{~m}$ dentro do PLANALTO RETOCADO DO PARANOÁ. A segunda superfície, laterizada desde o Terciário Inferior, se encontra em cotas entre 1.250 e $1.270 \mathrm{~m}$ e apresenta chapadas arrasadas pela denudação. Essa chapada é uma grande divisora de águas da bacia do rio Paraná e São Francisco dentro do Planalto Retocado Bambuí-Canastra. A terceira superfície com cotas inferiores até $1.000 \mathrm{~m}$ constituem relevos mais acidentados com presença de superfícies mais aplainadas nos vales abertos do Planalto Retocado BambuíCanastra e do Planalto Dissecado Araxá-Canastra (CODEPLAN, 1984).

A partir de estudos desenvolvidos na região (Novaes Pinto, 1986a; Novaes Pinto, 1986b; Novaes Pinto, 1987; Novaes Pinto, 1988; Novaes Pinto, 1994) o processo de aplainamento da região começa a ser compreendido por diferentes estágios de pediplanação e etchplanação. A denudação teria deixado registro do aplainamento por etchplanação (mais antigo), pediplanação (intermediário) e pedimentação (mais recente) (Novaes Pinto 1987; Novaes Pinto 1994) divididos em Etchplano do Paleógeno, Etchplano do Neógeno, Pediplano do Pliopleisoceno e por Pedimentos do Pleistoceno na parte dissecada. A explicação para haver dois processos atuando conjuntamente está associado a oscilação paleoclimática entre Terciário Inferior e Quaternário e pela estabilidade tectônica desses períodos com aumento progressivo da temperatura e umidade até o Terciário Médio, seguido por queda constante até as oscilações climáticas do Quaternário (Frakes, 1979)

As diferentes cotas entre os etchplanos, o estágio de dissecação e os modelados encontrados na região estão associados ao intemperismo diferencial das rochas e à presença de couraça laterítica com resistência ao intemperismo elevada. Penteado (1976) correlacionou as concreções ferruginosas com idade entre o Paleógeno e o Mioceno como parte que sustenta o relevo residual do Distrito Federal. O projeto RADAM, Folha SD23 Brasília, classificou as couraças como pedogenética, em alteritos e na forma de detritos 
recimentados, formando pediplanos retocados e arrasados (Brasil, 1984). Martins (2000) mostra que existem diferentes tipos concreções ferruginosas que se relacionam com a maturidade do relevo, podendo sofrer degradação mecânica lateral nas bordas de planaltos e degradação vertical pedogenética.

Dantas et al., (2003) no mapeamento da Região Integrada de Desenvolvimento do Distrito Federal e Entorno (RIDE-DF) considera uma alternância entre o processo de etchplanação e pediplanação para explicar o aplainamento. Em um primeiro momento, seriam elaborados pediplanos e pedimentos decorrente do clima árido do Cretáceo Superior que e em seguida seriam remodelados pelo intemperismo químico diferencial com a formação de espessos mantos de intemperismo durante o Terciário, produzindo um lento rebaixamento da superfície. Com a volta do clima mais árido novamente, a pediplanação voltaria a atuar. Diferentemente dos autores citados, Martins et al., (2004b) propõe um modelo de evolução para o Distrito Federal como parte de um etchplano, associado a gênese da Superfícies Sul-Americana (King, 1956) que sofreu denudação diferencial promovida pela susceptibilidade distinta das rochas ao intemperismo, controle estrutural e soerguimentos, gerando um Etchplano Dissecado (Thomas, 1974).

Latrubesse e Carvalho, (2006) em estudo elaborado para o Estado de Goiás delimita as unidades aplainadas compostas por planaltos e depressões, denominando-as de Superfície Regional de Aplainamento para não favorecer um processo de aplainamento em detrimento de outro. Entretanto, observam que nas regiões da área de estudo a etchplanação parece ser a mais adequada. Baptista et al., (2010) no mapeamento da geodiversidade de Minas Gerais não considera a gênese do relevo decorrente da escala de trabalho (1:500.000 a 1:1.000.000). Assim termos como: depressão, crista, patamar, platô, cuesta, hogback, pediplano, peneplanos, etchplano, escarpa, serra e maciço, dentre tantos outros, foram englobados em um reduzido número de conjuntos morfológicos. Nesse estudo, as superfícies aplainadas recebem nomenclatura superfícies aplainadas degradadas e conservadas de acordo com IBGE (2009).

\subsection{SOLOS}

O mapa de solo regional (Figura 4) apresenta a organização das classes nos compartimentos. Os Planaltos Retocados são basicamente cobertos por Latossolos no relevo residual e Cambissolos e Gleissolos ambos associados a parte mais dissecada. Onde os vales são mais encaixados com erosão superior a deposição, prevalecem os 
Cambissolos. No Planalto Retocado Bambuí-Canastra ainda é observado Plintossolos nos vales que cortam a chapada. Foram mapeados como Plintossolos Pétricos (Reatto, et al., 2004; SIEG, 2005), provavelmente, associados a degradação da couraça laterítica que nesses planaltos estão mais expostos. Em estudos mais detalhados Naime et al., (2002) mostram Latossolos Vermelhos de textura muito argilosa localizados nos flancos das Chapadas do Planalto Retocado do Paranoá. Na parte central do domo dissecado prevalecem Latossolos Vermelho-Amarelos claramente organizados em uma hidrossequência (Macedo e Bryant, 1987). No Planalto Retocado Bambuí-Canastra a organização pedológica é inversa, sendo no topo Latossolos Vermelho-Amarelos e nas rampas retilíneas os Latossolos Vermelhos.

Nos planaltos dissecados prevalecem os Cambissolos. No Planalto Dissecado Araxá-Canastra os Latossolos se encontram nas mesas e chapadas residuais, mas também podem se desenvolver abaixo dos rebordos erosivos em superfícies mais planas. Nos vales abertos do São Bartolomeu apresentam depósitos mais recentes, formando Neossolos (SIEG, 2005). Naime et al., (2002) explicam que nas vertentes lançadas e suaves abaixo dos rebordos erosivos existem uma associação entre Latossolos Vermelhos e Cambissolos rasos. A organização dos Latossolos do Planalto Dissecado AraxáCanastra é muito similar a organização encontrada no Planalto Retocado BambuíCanastra com Latossolos Vermelho-Amarelos no topo de Chapadas e Latossolos Vermelho nas vertentes retilíneas dos rebordos erosivos. O Planalto Dissecado ParanoáCanastra praticamente desenvolve apenas Cambissolos, Argissolos e Neossolos localmente decorrente da dissecação dessa unidade que não apresenta relevo residual de chapada e sim um conjunto de serras e morros intercalados.

Os Latossolos predominam na Depressão Cárstica Paranoá-Canastra principalmente sobre os carbonatos do Grupo Canastra. Os Cambissolos da Depressão Cárstica Paranoá-Canastra estão associados basicamente ao relevo residual com serras e morros que bordejam o Planalto Retocado do Paranoá e na parte oriental do compartimento onde a influência dos carbonatos diminui. Nos vales abertos ainda é possível encontrar Neossolos associados a pedimentos. A Depressão Cárstica ParanoáBambuí apresenta relevo residual em formato de serras e cristas coberto por Neossolos. No sopé das serras se desenvolvem Latossolos a partir de um depósito de talus (Casseti, 1990). Os Cambissolos se desenvolvem entre serras e abaixo desses Latossolos associado a uma drenagem pouco eficiente. Na Depressão Cárstica Vazante-Bambuí, os Latossolos Vermelhos ocorrem apenas sobre depósitos localizados e planos (Batista et al., 2010). A 
depressão é mais dissecada com um conjunto de serras que formam Cambissolos. Os Neossolos estão associados aos arenitos líticos do Grupo Vazante (Campos et al., 2006).

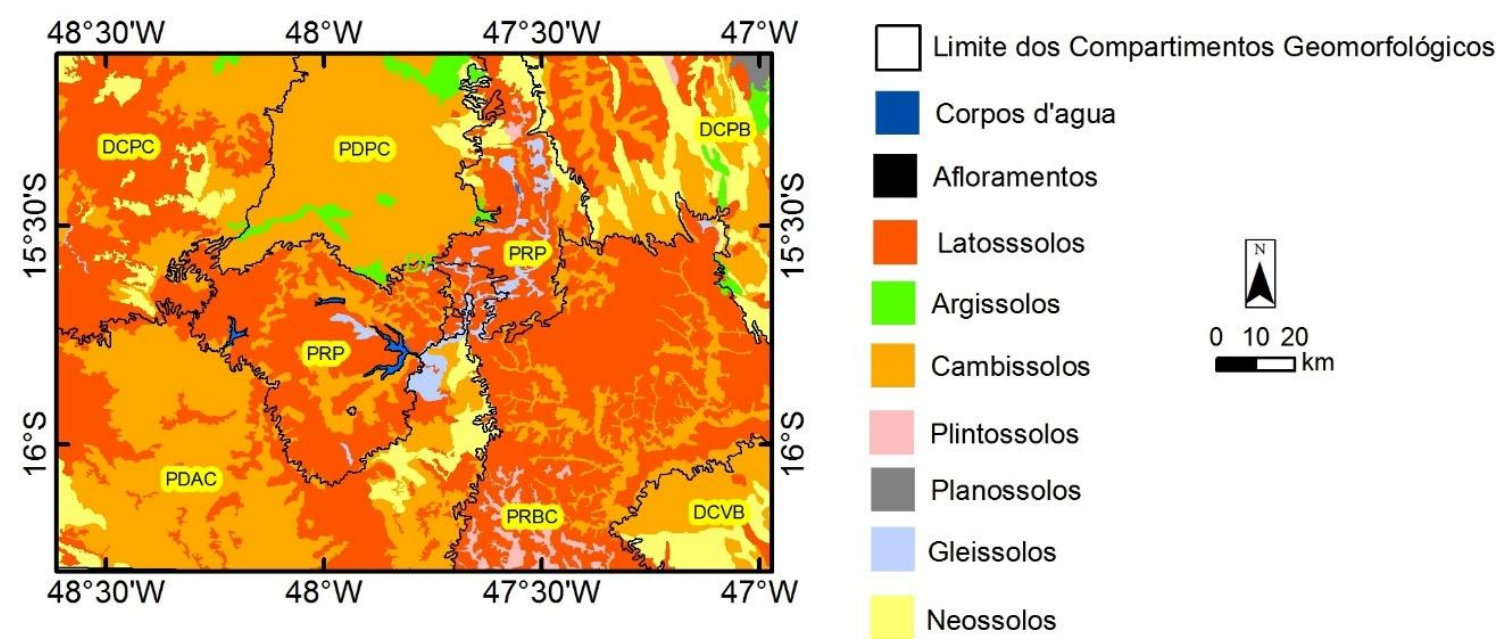

Figura 4: Mapa de Classes de Solos nível de ordem (adaptado de SIEG, 2005 e Batista et al., 2010) por compartimento geomorfológico: Planalto Retocado do Paranoá (PRP), Planalto Retocado Bambuí-Canastra (PRBC), Planalto Dissecado Araxá-Canastra (PDAC), Planalto Dissecado Paranoá-Canastra (PDPC), Depressão Cárstica VazanteBambuí (DCVB), Depressão Cárstica Paranoá-Canastra (DCPC) e Depressão Cárstica Paranoá-Bambuí (DCPB).

\section{4. ÁREA DE REFERÊNCIA BACIA DO RIO JARDIM}

O estudo foi realizado na Bacia do Rio Jardim, afluente da Bacia do Rio São Francisco localizada na porção oriental do Distrito Federal no Planalto Retocado BambuíCanastra (Figura 5). Esta bacia possui uma área de aproximadamente $535 \mathrm{~km}^{2}$. Tem sido intensamente estudada por diversas instituições de pesquisa brasileiras, como a Universidade de Brasília e a Empresa Brasileira de Pesquisa Agropecuária (Embrapa), por causa das atividades agrícolas locais intensivas (e.g Braucher et al., 2004; Muniz et al., 2011; Strauch et al, 2013). O clima é tropical caracterizada por um regime de precipitação bem definido: chuvoso (outubro a abril) e seca (maio a setembro).

O embasamento da Bacia do Rio Jardim contém rochas predominantemente metapeliticas do Grupo Bambuí (Pimentel et al., 2001). Localmente, quartzito do Grupo Paranoá ocorre na região norte e filito, do Grupo Canastra, na região leste. O intemperismo diferencial do material de origem promove uma denudação e dissecação heterogênea. O manto de intemperismo é composto por um saprólito espesso, recoberto 
por um solo laterítico poligenético, com espessuras e distribuições que dependerão das formas de relevo sobre rochas metamórficas e ígneas. Nesta região, o rególito laterítico pode chegar a centenas de metros, como resultado da denudação química tropical desde a transição do Mesozoico-Cenozoico (Büdel, 1957; Millot, 1980; Thomas, 1994).

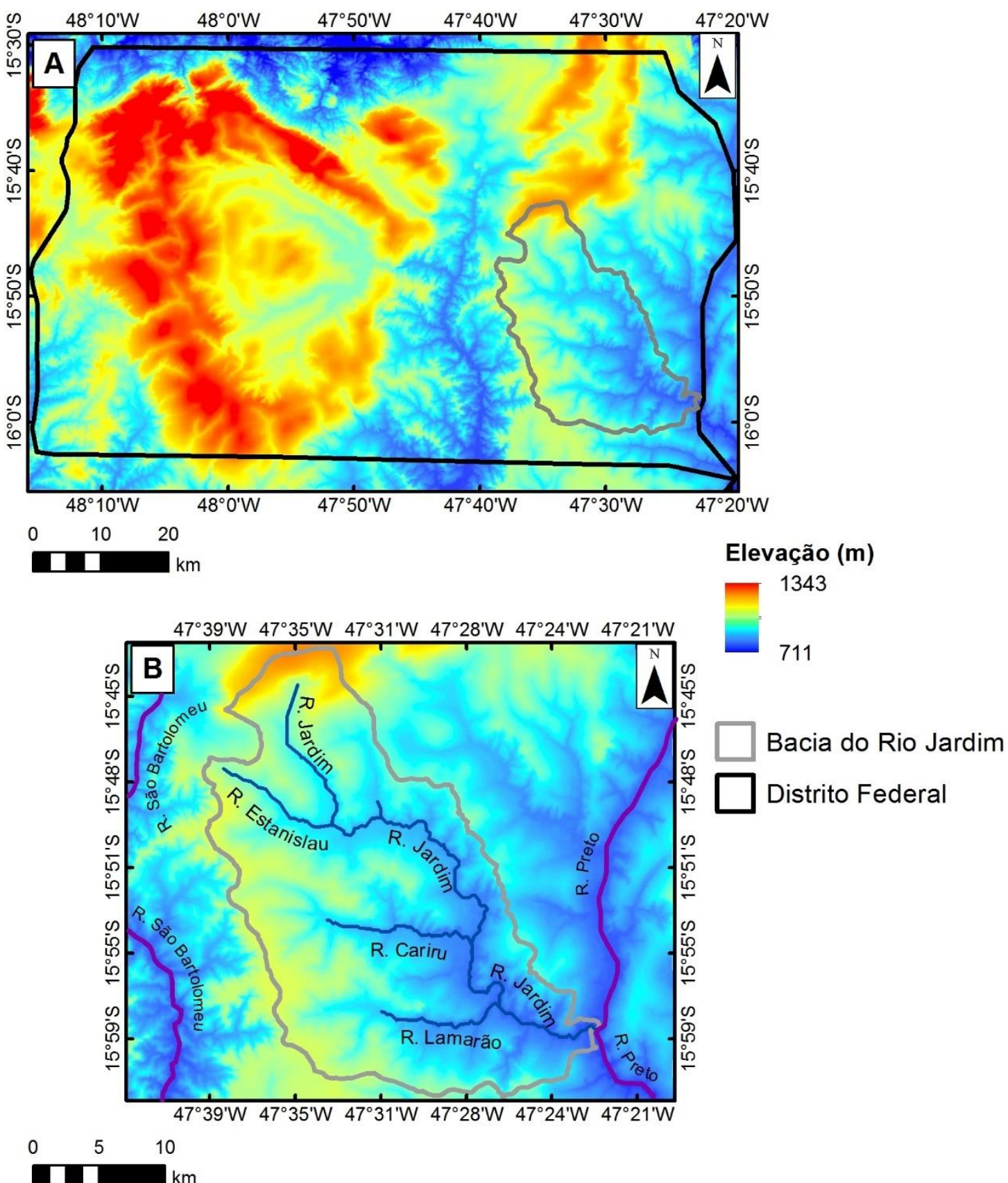

Figura. 5. Localização da Bacia do Rio Jardim dentro do Distrito Federal com Modelo Digital de Elevação (A). Bacia do Rio Jardim com os principais tributários, Estanislau, Cariru, Lamarão que desaguam no rio Preto (B).

Essas paisagens formam Latossolos Vermelho-Amarelos ácricos com mineralogia gibbsítica nos interflúvios e Latossolos Vermelhos ácricos mais cauliníticos nas vertentes abaixo dos interflúvios (Reatto et al., 1999) e entre os Latossolos, se encontram os 
Cambissolos Háplicos (Reatto et al., 1999; Reatto et al., 2000). Em estudos de descrição de topossequências foi observado que os solos estão organizados em hidrossequência, alterando a dinâmica do ferro nas rampas suaves (Macedo e Bryant, 1987; Reatto et al., 2008).

A bacia exibe uma rede de drenagem marcada pela assimetria de vertente, onde as rampas são longas e suaves na margem direita, mas curtas e íngremes na margem esquerda. A base subjacente apresenta controle estrutural sob a assimetria de bacias hidrográficas, onde escamas de escala regional, com vergência para sudeste, marcam as camadas do Canastra e Bambuí. A drenagem regional caracteriza a dissecação do relevo com uma rede de baixa densidade e padrões dendrítico a sub-dendrítico que desenvolvem vales amplos e abertos com direção NW-SE, gradientes entre $3^{\circ}$ e $5^{\circ}$, e amplitudes de relevo entre 20 e 50 m (Dantas, 2002; Dantas et al., 2003). A interpretação de características morfológicas é fator chave para compreender os processos de denudação, deposição e dissecação da bacia. 


\section{Capítulo 3 - MATERIAIS E MÉTODOS}

Uma primeira proposta de utilizar assinaturas foi publicada em 2012 sob o título de "Sistema de Classificação Geomorfométrica baseado em uma arquitetura sequencial em duas etapas: Árvore de Decisão e Classificador Espectral, no Parque Nacional Serra da Canastra". Essa técnica de classificação teve como parâmetro um conjunto de curvaturas ( $2^{\text {a }}$ derivada da altitude) organizadas em uma assinatura (Vasconcelos et al., 2012).

O método de Vasconcelos et al. (2012) tinha como roteiro de análise uma compartimentação do relevo prévia por meio de árvore de decisão, utilizando os atributos geomorfométricos, altitude e declividade. Em seguida, cada compartimento individualizado foi classificado pelo método Spectral Angle Mapper (SAM) (Kruse et al., 1993) por um conjunto de assinaturas formadas pelas seguintes curvaturas: vertical, longitudinal, mínima, máxima e horizontal. Esse estudo foi realizado no Chapadão do Zagaia.

Nessa tese é proposta a evolução dessa ideia de classificar as FTs por meio de uma assinatura formada pelas curvaturas longitudinal, transversais, mínima, máxima utilizando um classificador por similaridade, Spectral Correlation Mapper (SCM) (de Carvalho Júnior e Meneses, 2000) e outro por Distância Euclidiana, ou seja, Mínima Distância (MD) (Sena-Souza et al., 2016), tendo como dado de entrada uma imagem Shuttle Remote Topographic Mission (SRTM). O método foi desenvolvido na Bacia do Rio Jardim no Distrito Federal. O método foi aplicado regionalmente na porção centroleste da Faixa Brasília de Dobramentos, utilizando apenas a MD.

A compartimentação geomorfológica adotada para área de estudo nessa porção da Faixa Brasília de Dobramentos foi adapatada de mapeamentos geomorfológicos prévios da região. (Dantas 2002; Latrubesse e Carvalho, 2006; Baptista et al., 2010). Os compartimentos foram nomeados de acordo com os Grupos geológicos mais representativo: Planalto Retocado do Paranoá (PRP), Planalto Retocado BambuíCanastra (PRBC), Planalto Dissecado Araxá-Canastra (PDAC), Planalto Dissecado Paranoá-Canastra (PDPC), Depressão Cárstica Vazante-Bambuí (DCVB), Depressão Cárstica Paranoá-Canastra (DCPC) e Depressão Cárstica Paranoá-Bambuí (DCPB). 
As campanhas de campo exploratórias foram realizadas em todos os compartimentos para verificar a classificação das Formas de Terreno, tanto contexto da Bacia do Rio Jardim, quanto no contexto regional. Foram utilizados mapas de solos (Naime et al., 2002; Reatto et al. 2000; 2004) para reconhecer os padrões pedológicos regionais e assim relaciona-los com o estágio de denudação do compartimento. Atividade de campo se limitou em explorar relevos residuais com perfil lateríticos espessos e áreas dissecadas com presença de Cambissolos e Neossolos.

\subsection{SHUTTLE RADAR TOPOGRAPHY MISSION - SRTM}

Nesse trabalho foi utilizado o MDE do SRTM adquirido gratuitamente no site do United States Geological Survey (http://hydrosheds.cr.usgs.gov/index.php), com uma resolução espacial de $3 \operatorname{arcsec}$ ( 90 metros), datum WGS84 na horizontal e vertical, e precisão vertical da ordem de 16 e 20 m (Smith e Sandwell, 2003). Esta missão usou o ônibus espacial Endeavour em fevereiro de 2000 com dois radares de abertura sintética na banda C (5,6 cm; RADAR-C) e banda X (3,1 cm, X-radar) (Farr et al, 2007).

Os dados topográficos foram adquiridos a partir de um único sobrevoo cobrindo $80 \%$ da superfície da Terra em apenas 11 dias, entre $60^{\circ} \mathrm{N}$ e $57^{\circ} \mathrm{S}$. O sistema de aquisição de dados contínuo garantiu a homogeneidade de dados para todo mundo (Rabus et al., 2003; Van Zyl, 2001). Erros como speckle, depressões espúrias, vazios, baixa qualidade da rede canais influenciados pela vegetação que a cobre são conhecidos na imagem SRTM. O produto HydroSHEDS desenvolvido para modelagem hidrológica, procurou tratar os ruídos existentes por meio de filtragem, utilizando mapas digitais hidrográficos e processamento interativos (Lehner et al., 2008). Este produto oferece informação hidrográfica consistente em formatos vetoriais e raster, incluindo limites das bacias hidrográficas, direções de drenagem, acumulações de fluxo e informações sobre a topologia do rio, entre outros.

\subsection{CONFIGURAÇÃO DA ASSINATURA GEOMÉTRICA}

O conceito de assinatura geométrica (Pike, 1986) é análogo ao termo "assinatura espectral" usada em processamento de imagens de sensoriamento remoto (Brown et al.,1998). Consequentemente, a assinatura geométrica é uma combinação específica de descritores geométricos que representam uma variação continua da superfície da Terra. 
Evans (1972) considera os atributos de declividade e a curvatura como estimativas confiáveis para a rugosidade da superfície ou variabilidade do relevo.

A curvatura de perfil segue a declividade, indicando a concavidade e convexidade da vertente, enquanto que a curvatura de plano é perpendicular à declividade, indicando convergência e divergência de fluxo superficial (Blaszczynski, 1997). Vários autores têm se dedicado a estudar as curvaturas para obter uma representação melhor da superfície da Terra (Evans, 1972; Krcho, 1991; Mitasova e Hoffierka, 1993; Shary et al., 2002; Shary, 1995; Schmidt et al., 2003; Wood, 1996; Zevenbergen e Thorne, 1987, Wilson e Galante, 2000).

Pennock et al. (1987) classificam 7 FTs a partir de curvaturas de plano e vertical: Convergent Footslope, Divergent Footslope, Convergent Shoulder, Divergent Shoulder, Convergent Backslope, Divergent Backslope e Level. A combinação de Pennock reflete a posição da paisagem e a tendência de fluxo (convergente, divergente e planar). Dikau (1989) diferencia 9 FTs baseadas na combinação de convexo, plano e côncavo a partir da curvatura tangencial e vertical. Schmidt e Hewitt (2004) propuseram 15 diferentes tipos de FTs divididos em duas categorias. Em regiões planas, os autores classificaram a partir das curvaturas mínima e máxima 6 FTs baseado em Wood (1996): ridge, channel, plane, peak, pit, e pass (Figura 6A). Em regiões acidentadas utilizaram as curvaturas vertical e tangencial para classificar 9 FTs baseado em Dikau (1989): nose, shoulder slope, spur, planar slope, hollow shoulder, hollow, spur foot, foot slope e hollow foot (Figura 6B).
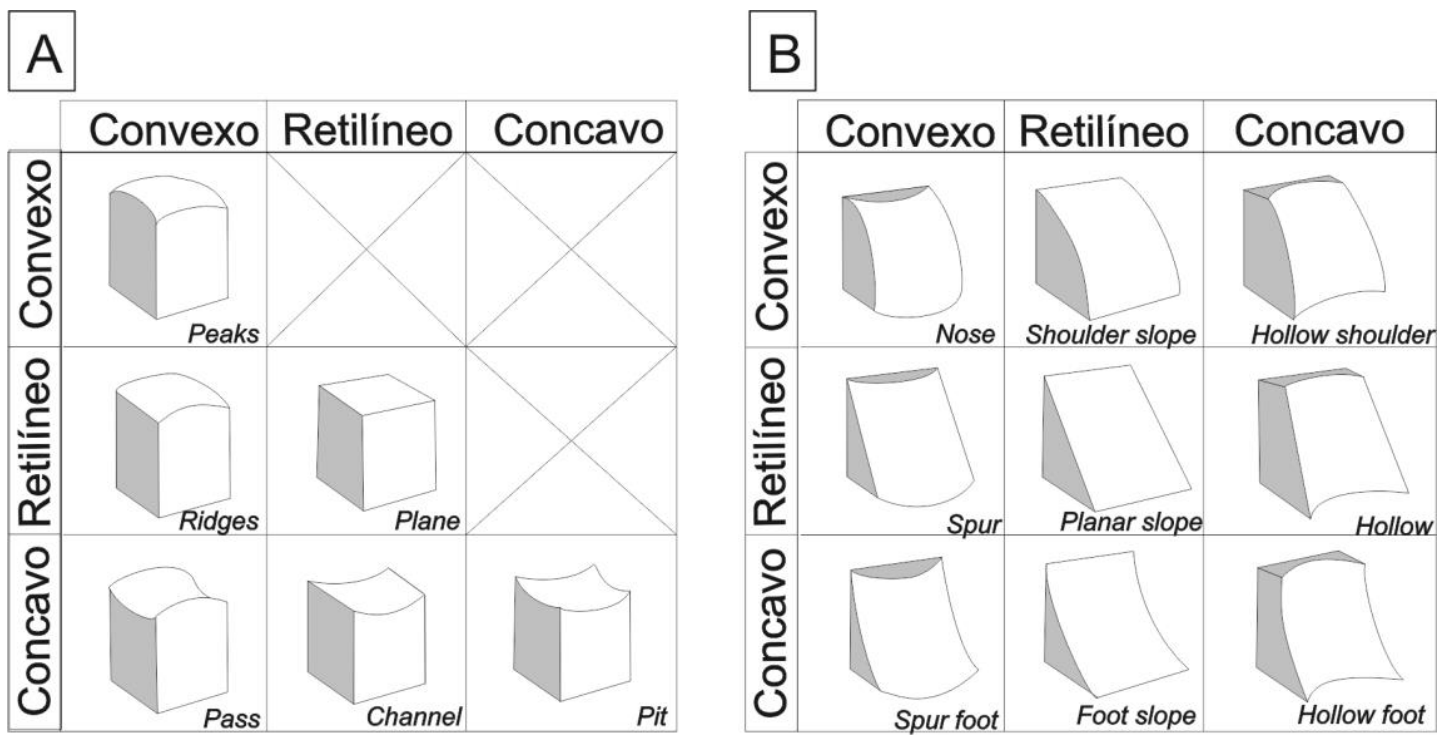

Figura 6 - Seis Formas de Terreno baseado em Wood (1996) (A). Nove Formas de Terreno baseado em Dikau (1989) (B) (adaptado de Schmidt e Hewitt, 2004). 
Nesse trabalho, foram empregadas as curvaturas de Wood (1996) para compor a assinatura geométrica. Wood (1996) propôs um conjunto de critérios com base nos valores de declividade e curvatura (longitudinal, transversal, máxima e mínima) para formas de terreno que descrevem um número reduzido de FTs: Peak, Channel, Plane, Ridge, Pit e Pass. As curvaturas Longitudinal ( $\left.c_{\text {long }}\right)$, Transversal ( $\left.c_{\text {trans }}\right)$, Mínima $\left(c_{\text {mín }}\right)$ e Máxima $\left(c_{m a ́ x}\right)$ (Wood, 1996; Young, 1978) são expressas pelas seguintes equações:

$$
\begin{aligned}
& c_{\text {long }} \\
& =-2\left(\frac{a d^{2}+b e^{2}+c d e}{d^{2}+e^{2}}\right) \\
& c_{\text {trans }} \\
& =-2\left(\frac{b d^{2}+a e^{2}-c d e}{d^{2}+e^{2}}\right) \\
& c_{\text {mín }} \\
& =-a-b-\sqrt{(a-b)^{2}+c^{2}} \\
& c_{\text {max }} \\
& =-a-b+\sqrt{(a-b)^{2}+c^{2}}
\end{aligned}
$$

onde " $a$ ", " $b$ ”, “c”, “d” e "e" são variáveis baseadas nas nove elevações $(Z)$ da janela (Figura 7), descritas palas equações:

$$
\begin{aligned}
& a=\frac{\left(\frac{\left(Z_{4}+Z_{6}\right)}{2-Z_{5}}\right)}{L^{2}} \\
& b=\frac{\left(\frac{\left(Z_{2}+Z_{8}\right)}{2-Z_{5}}\right)}{L^{2}} \\
& c=\frac{\left(-Z_{1}+Z_{3}+Z_{7}-Z_{9}\right)}{4 L^{2}} \\
& d=\frac{\left(-Z_{4}+Z_{6}\right)}{2 L} \\
& e=\frac{\left(-Z_{2}+Z_{8}\right)}{2 L}
\end{aligned}
$$


onde "L" é a distância entre os pontos da matriz nas direções de linha e coluna e deve estar na mesma unidade que o Z (Zevenbergen e Thorne, 1987).

\begin{tabular}{|c|c|c|}
\hline $\mathrm{Z}_{1}$ & $\mathrm{Z}_{2}$ & $\mathrm{Z}_{3}$ \\
\hline $\mathrm{Z}_{4}$ & $\mathrm{Z}_{5}$ & $\mathrm{Z}_{6}$ \\
\hline $\mathrm{Z}_{7}$ & $\mathrm{Z}_{8}$ & $\mathrm{Z}_{9}$ \\
\hline
\end{tabular}

Figura 7 - Esquema ilustrativo de uma janela 3x3 sobre o Modelo Digital de Elevação, apresentando os posicionamentos e as elevações dos pontos $(Z)$ referentes às equações das curvaturas (Zevenbergen e Thorne, 1987).

Diferentes tipos de tamanhos de janelas foram calculados e testados para obter as curvaturas. O tamanho $15 \times 15$ foi mais apropriado para a classificação, evitando a formação de pequenos polígonos, pixels isolados e mitigar valores anômalos na classificação. Análogo à imagem multibanda de estudos de sensoriamento remoto, as quatro imagens de curvatura foram unidas estabelecendo para cada pixel uma assinatura geométrica (z-profile) (Figura 8). Conceitualmente, os valores positivos correspondem às FTs convexas e os valores negativos para as côncavas, enquanto os valores próximos de zero indicam formas retilíneas. Nesse procedimento o padrão e a intensidade da assinatura geométrica possibilitam a classificação das mudanças graduais da superfície da Terra.

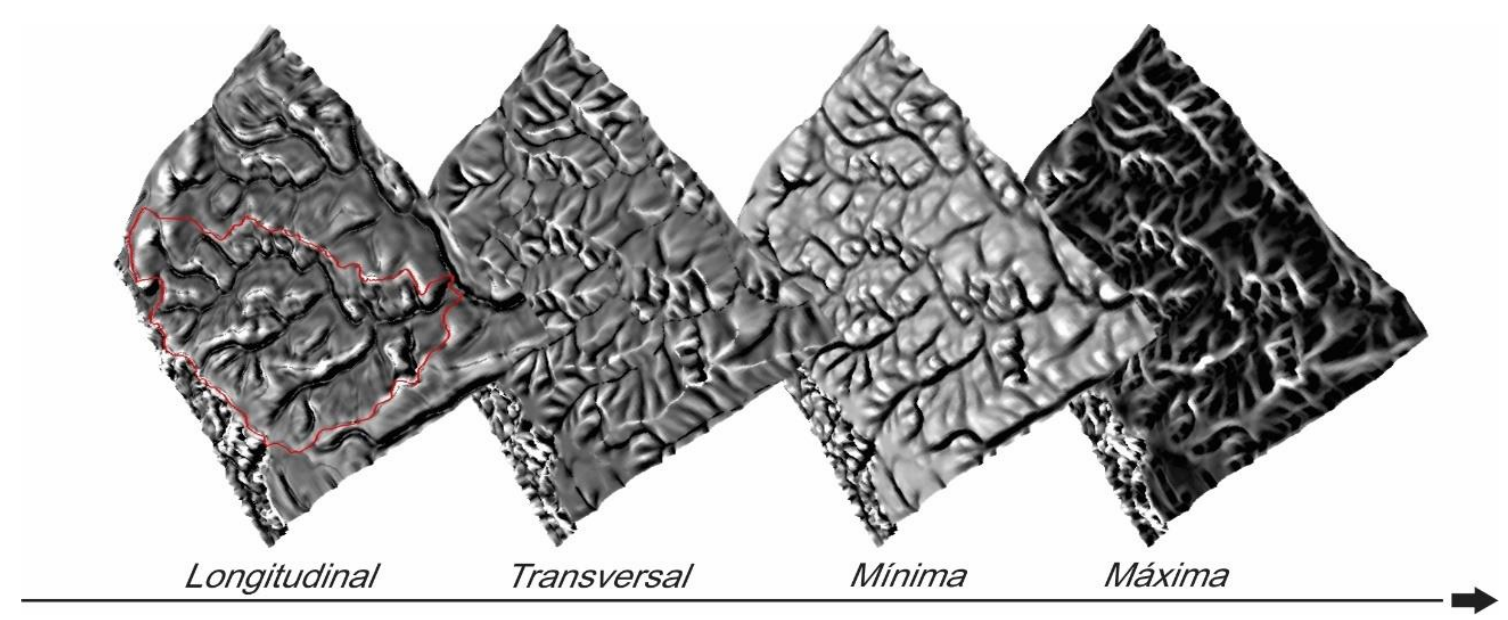


Figura 8 - Imagens multibandas de curvaturas Longitudinal, Transversal, Mínima e Máxima para formar assinatura geométrica.

\subsection{SELEÇÃO DA ASSINATURA GEOMÉTRICA}

\subsubsection{Redução dos Descritores}

A redução de dimensionalidade do espaço geomorfométrico é desejável a fim de priorizar os principais parâmetros e conseguir uma fácil visualização do simplex. A este respeito, a Análise de Componentes Principais (ACP) é um dos métodos mais recorrentes para a redução da dimensão espacial do dado. Cada componente principal é uma combinação linear dos descritores originais, e os coeficientes indicam a importância relativa destes descritores que representam a variância dos dados.

O Minimum Noise Fraction (MNF) funciona como uma ACP de modo a reduzir a interferência do ruído (Green et al., 1998, Lee et al., 1990). Este método é uma transformação linear que maximiza a razão sinal-ruído (Green et al., 1988). Algoritmo MNF calcula um índice de fracionamento do ruído, em vez da matriz de variânciacovariância usada por ACP. Nesse sentido, os componentes MNF apresentam continuamente o aumento da qualidade da imagem. O MNF tem sido usado em vários tipos de dados, como imagens hiperespectrais (e.g. Underwood et al., 2003), em pesquisa com raios gama (e.g. Dickson e Taylor, 2000), séries temporais de dados de sensoriamento remoto (e.g. de Carvalho Júnior et al., 2008, 2012), e dados de radar (e.g. de Carvalho Júnior et al., 2014) e em dados de curvatura (e.g. Vasconcelos et al., 2012; Sena-Souza et al., 2016).

\subsubsection{Redução Espacial}

O algoritmo Pixel Purity Index (PPI) identifica os potenciais membros finais que são adequados como amostras de referência na classificação supervisionada. Os dados são projetados em torno de um simplex em um espaço n-dimensional (Boardman, 1994). Os membros finais foram localizados nos pontos extremos do simplex (Boardman, 1993). O procedimento PPI calcula o número de vezes que os dados de cada pixel são projetados em ou próximo de um dos pontos extremos (Boardman et al., 1995). Os valores de PPI 
são observados em um visualizador n-dimensional, que permite a rotação da nuvem de pixels.

\subsection{CLASSIFICAÇÃO POR CORRELAÇÃO E MÍNIMA DISTÂNCIA}

Os classificadores espectrais comparam uma curva de pixel (X) a uma assinatura de referência (Y) a partir de bibliotecas ou membros finais espectrais (Adams e Gillespie, 2006). As medidas de distância ou similaridade enfatizam uma característica particular da curva descritora, sendo apropriada para situações específicas de classificação (de Carvalho Júnior et al., 2011). Nesse trabalho foi utilizado dois métodos de classificação: (a) Spectral Correlation Mapper (SCM) (de Carvalho Júnior e Meneses, 2000) baseado na correlação de Pearson (Equação 11), e (b) Mínima Distância (MD) (Equação 12):

As principais medidas de similaridade que têm sido empregadas na classificação espectral são de correlação de cosseno por meio do SAM (Kruse et al., 1993) e de coeficiente de correlação de Pearson utilizada no classificador SCM (de Carvalho Júnior e Meneses, 2000).

O SCM tem a seguinte expressão:

$$
S C M_{C D}=\frac{\sum_{i=1}^{i=N}\left(X_{i}-\bar{X}_{i}\right)\left(Y_{i}-\bar{Y}_{i}\right)}{\sqrt{\sum_{i=1}^{i=N}\left(X_{i}-\bar{X}_{i}\right)^{2} \sum_{i=1}^{i=N}\left(Y_{i}-\bar{Y}_{i}\right)^{2}}}
$$

$\mathrm{O}$ valor d SCM varia de 1 à -1 indicando que duas assinaturas podem ser idênticas quando o valor é 1 , ou completamente não correlacionadas quando o valor é 0 , ou que são opostos perfeitos quando o valor é -1. A MD entre dois pontos de dados X e Y no espaço n-dimensional é dada por:

$$
M D=\sqrt{\sum_{i=1}^{N}\left(X_{i}-Y_{i}\right)^{2}}
$$

onde " $\mathrm{X}_{\mathrm{i}}$ " $\mathrm{e}$ "Y $\mathrm{Y}_{\mathrm{i}}$ " são valores de $\mathrm{i}^{\mathrm{th}}$ atributos geomorfométricos de $\mathrm{X}$ e $\mathrm{Y}$, respectivamente.

A escolha de uma medida é um fator importante para a classificação. Cada medida reforça um aspecto diferente da assinatura geométrica. A principal distinção entre os métodos é a sua capacidade para identificar padrões ou estabelecer diferenças de magnitude. O padrão é um componente tradicional de uma assinatura e uma característica fundamental para a classificação. As assinaturas geométricas com o mesmo padrão, mas 
com magnitudes diferentes podem representar mudanças graduais na superfície da Terra. Portanto, além do padrão, os valores absolutos de assinaturas geométricas são fundamentais para distinguir os diferentes alvos de FTs. Essa característica é diferente nos dados de sensoriamento remoto, onde a absorção representa o mesmo alvo, mesmo variando os valores de gain e de offset. (Figura 9).
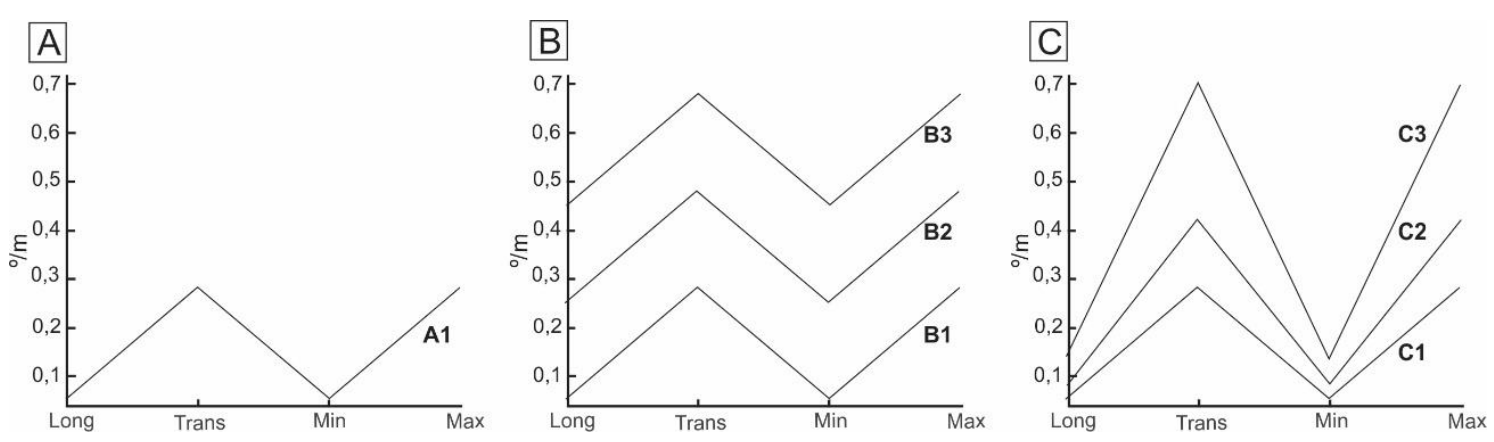

Figura 9 - Efeito de gain e de offset: (A) assinatura de referencia, (B) variação do offset, and (C) variação de ganho. Curvaturas: Longitudinal = Long, Transversal = Trans, Mínima $=$ Min, e Maxíma $=$ Max.

Dessa forma, a complexidade adicional da assinatura geométrica está na variabilidade do padrão e da magnitude. Assim, a classificação pode ser feita em duas fases sucessivas: (a) uma primeira classificação usando uma medida de similaridade para separar os padrões de FTs e (b) uma segunda classificação restrita a cada subconjunto utilizando uma medida de distância para o distinguir magnitudes destas assinaturas.

\subsection{COMPARAÇÃO COM O MÉTODO DO WOOD (1996)}

Para realizar a classificação com o método do Wood (1996) é preciso configurar a tolerância de declividade e a tolerância de curvatura. A primeira controla aquilo que é plano. A segunda o quanto do modelo será convexo, plano ou côncavo. Esses valores de tolerância são arbitrários e dependem da natureza da área de estudo. Felicísimo (1999) acrescenta outras duas classes no algoritmo de Wood: Cliff e Ramp. No entanto, Bolongaro-Crevenna et al. (2005) demonstraram que o algoritmo de Wood não podem descrever completamente FTs mais complexas.

Foram adotados os seguintes parâmetros para classificação das FTs com o método de Wood (1996): 0,1;0,01;0,001\%/m de tolerância de curvaturas, e 0,5; 1 e 1,5 de tolerância de declividade. Essa configuração representa as diferenças entre as 6 FTs de Wood (1996): Peak, Ridge, Pass, Channel, Plane e Pit (Tabela 1). 
Observa-se na Tabela 1 que quando a declividade é zero, o autor utiliza os pares de curvaturas Mínima e Máxima e quando a declividade é diferente de zero são utilizadas as curvaturas Longitudinal e Transversal. Valores de curvaturas $\geq 0$ representam os Ridge e Peak, valores $\leq 0$ representam os Pit e Channel, valores positivos e negativos representam o Pass e valores $=0$ representam o Plane. É importante destacar que, apesar do Wood (1996) atribuir o valor zero para as superfícies planas, sabe-se que os relevos suaves de baixa amplitude topográfica podem ter valores positivos e negativos desde que estejam próximo de zero. Como a assinatura geométrica não necessita de valores rígidos para representar as FTs, a classificação irá obedecer a seguinte regra para facilitar a comparação: assinaturas com valores positivos representam relevos convexos; com valores negativos representam relevos côncavos; e com valores negativos e positivos representam os relevos transicionais. 
Tabela 2 - As seis Formas de Terreno (FTs) definidas pelos parâmetros geomorfométricos: Declividade e, Curvaturas Longitudinal, Transversal, Mínima e Máxima (Wood, 1996).

\begin{tabular}{c|ccccc}
\hline FTs & \multicolumn{5}{|c}{ DeclividadeLongitudina Transversal Mínima Máxima } \\
\hline \multirow{2}{*}{ Peak } & 0 & $\mathrm{~N} / \mathrm{A}$ & $\mathrm{N} / \mathrm{A}$ & + & + \\
& + & + & + & $\mathrm{N} / \mathrm{A}$ & $\mathrm{N} / \mathrm{A}$ \\
\hline \multirow{3}{*}{ Ridge } & 0 & $\mathrm{~N} / \mathrm{A}$ & $\mathrm{N} / \mathrm{A}$ & 0 & + \\
& + & 0 & + & $\mathrm{N} / \mathrm{A}$ & $\mathrm{N} / \mathrm{A}$ \\
& + & + & 0 & $\mathrm{~N} / \mathrm{A}$ & $\mathrm{N} / \mathrm{A}$ \\
\hline \multirow{3}{*}{ Pass } & 0 & $\mathrm{~N} / \mathrm{A}$ & $\mathrm{N} / \mathrm{A}$ & - & + \\
& + & - & + & $\mathrm{N} / \mathrm{A}$ & $\mathrm{N} / \mathrm{A}$ \\
& + & + & - & $\mathrm{N} / \mathrm{A}$ & $\mathrm{N} / \mathrm{A}$ \\
\hline \multirow{2}{*}{ Plane } & 0 & $\mathrm{~N} / \mathrm{A}$ & $\mathrm{N} / \mathrm{A}$ & 0 & 0 \\
& + & 0 & 0 & $\mathrm{~N} / \mathrm{A}$ & $\mathrm{N} / \mathrm{A}$ \\
\hline \multirow{3}{*}{ Channel } & 0 & $\mathrm{~N} / \mathrm{A}$ & $\mathrm{N} / \mathrm{A}$ & - & 0 \\
& + & - & 0 & $\mathrm{~N} / \mathrm{A}$ & $\mathrm{N} / \mathrm{A}$ \\
& + & 0 & - & $\mathrm{N} / \mathrm{A}$ & $\mathrm{N} / \mathrm{A}$ \\
\hline \multirow{2}{*}{ Pit } & 0 & $\mathrm{~N} / \mathrm{A}$ & $\mathrm{N} / \mathrm{A}$ & - & - \\
& + & - & - & $\mathrm{N} / \mathrm{A}$ & $\mathrm{N} / \mathrm{A}$ \\
\hline
\end{tabular}

(0) valor zero; (+) valor positivo; (-) valor negativo; (N/A) não se aplica

\subsection{ADAPTAÇÃO DO MÉTODO DE CLASSIFICAÇÃO DE FORMAS DE TERRENO PARA ESTUDO DE FRAGMENTAÇÃO DO RELEVO}

Para adaptar o método de classificação de FTs para estudo de fragmentação do relevo é preciso considerar um número reduzido de classes para não tornar a paisagem extremamente fragmentada, dificultando interpretar o processo de evolução geomorfológica. É importante destacar que o método de classificação por assinatura permite a seleção de inúmeras amostras desde que represente a morfologia do relevo suficientemente para distinguir de uma outra amostra. Sendo assim, para evitar um número elevado de classes optou-se por classificar o contexto regional da área de estudo apenas com a MD.

Sena-Souza et al. (2016) demonstraram o quanto que a MD é eficaz para classificar superfícies aplainadas. Os autores observaram que o relevo muito plano independe do padrão da assinatura (classificação por similaridade), pois a assinatura estará cada vez mais próxima de uma reta horizontal. Dessa maneira, a classificação apenas com a MD permite individualizar uma assinatura específica para as formas planas 
onde serão identificadas pelos valores próximo de zero, além das outras regras já estabelecidas.

\subsubsection{Frequência, Fragmentação e Análise Multivariada}

Após a classificação das assinaturas geométricas, cada compartimento geomorfológico foi analisado quanto à Frequência (Fr) e à fragmentação das FTs. A Fr foi mensurada pela área classificada das FTs. A métrica Número de Patches (NP) representa o número absoluto de cada classe. Dessa forma, para comparar a fragmentação das FTs em diferentes compartimentos, foi calculada a Proporção de Patches (PP) que representa a porcentagem de uma determinada classe dentro de um total de patches para cada compartimento.

Para realizar a fragmentação das FTs ainda foram calculadas as métricas Shanon Diversity Index (SHDI), Mean Perimeter Area Ratio (MPAR), Edge Density (ED), Mean Patch Edge (MPE), Mean Patch Size (MPS) Patch Density (PD) e Patch Size Standard Deviation (PSSD) (Tabela 2). Essas métricas representam os grupos de parâmetros do pacote de fragmentação do programa ArcGIS, Patch Analysis que podem ser calculadas

para todo compartimento geomorfológico (Landscape Metric) e para cada patch (Class Metrics), salvo o SHDI que apenas é calculado no nível de paisagem. Essas métricas foram calculadas a partir dos resultados da classificação das FTs. Assim cada classe de FTs representa um patch a ser analisado. 
Tabela 2 - Equações e definições das variáveis que compõe as métricas de fragmentação

\begin{tabular}{|c|c|c|c|}
\hline Métrica & Landscape Metric & Class Metric & \begin{tabular}{|c} 
Definição \\
\end{tabular} \\
\hline NP & 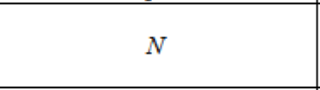 & $n_{i}$ & $\begin{array}{l}N=\text { número total de patches do compartimento: } \\
n=\text { número de patches de uma determinada classe }(i) \\
\text { (Forma de Terreno) no compartimento. }\end{array}$ \\
\hline PP & $* * * * * * * * * * * * * * *$ & $\frac{n_{i}}{N}(100)$ & Unidade: (\%) \\
\hline SHDI & $-\sum_{i=1}^{m}\left(\mathrm{P}_{\mathrm{i}} \ln \mathrm{P}_{\mathrm{i}}\right)$ & $* * * * * * * * * * * *$ & $\begin{array}{l}m=\text { número de patches presentes em cada compartimento, } \\
\text { excluindo as bordas do compartimento: } \\
\mathrm{P}_{\mathrm{i}}=\text { proporção do compartimento ocupado por um tipo de } \\
\text { patch (1) (Formas de Terreno) }\end{array}$ \\
\hline MPAR & $\frac{\sum_{i=1}^{m}\left(\frac{p_{i}}{a_{i}}\right)}{N}$ & $\frac{\sum_{i=1}^{m}\left(\frac{p_{i}}{a_{i}}\right)}{n i}$ & $\begin{array}{l}\mathrm{p}_{\mathrm{i}}=\text { perimeitro de uma determinada classe }(\mathrm{i}) ; \\
\mathrm{a}_{\mathrm{i}}=\text { área de uma determinda classe }(\mathrm{i}) ; \\
\text { Unidade: } \mathrm{m} / \mathrm{ha}\end{array}$ \\
\hline MPE & $\frac{E}{N}$ & $\frac{\sum_{i=1}^{m \prime} e_{i}}{n_{i}}$ & $\begin{array}{l}\mathrm{E}=\text { comprimento total médio do edge }(\mathrm{m}) \text { das classes } \\
\text { presentes no compartimento; } \\
\mathrm{m}^{\prime}=\text { número de patches presentes em cada compartimento, } \\
\text { incluindo as bordas do comvartimento: } \\
\mathrm{e}_{\mathrm{i}}=\text { comprimento do edge de uma determinada classe } \\
\text { Unidade }=\mathrm{m} \text { /patch }\end{array}$ \\
\hline MPS & $\frac{A}{N}$ & $\frac{\sum_{i=1}^{n} a_{i}}{n_{i}}\left(\frac{1}{10.000}\right)$ & $\begin{array}{l}\mathrm{A}=\text { área total do compartimento }\left(\mathrm{m}^{2}\right) \\
\text { Unidade }=\text { ha }\end{array}$ \\
\hline PSSD & $\sqrt{\frac{\sum_{i=1}^{n}\left[a_{i}-\left(\frac{A}{N}\right)\right]^{2}}{N}}\left(\frac{1}{10.000}\right)$ & $\sqrt{\frac{\sum_{i=1}^{n}\left[a_{i}-\left(\frac{\sum_{i=1}^{n} a_{i}}{n_{i}}\right)\right]^{2}}{n_{i}}}\left(\frac{1}{10.000}\right)$ & Unidade $=$ ha \\
\hline PD & $\frac{N}{A}(10.000)(100)$ & $\frac{n_{i}}{A}(10.000)(100)$ & Unidade $=\mathrm{patch} / 100 \mathrm{ha}$ \\
\hline ED & $\frac{E}{A}$ & $\frac{\sum_{i=1}^{m \prime} e_{i}}{A}(10.000)$ & Unidade $=\mathrm{m} / \mathrm{ha}$ \\
\hline
\end{tabular}

Além disso, para identificar o parâmetro que melhor representa os diferentes estágios de evolução geomorfológica foi aplicada uma Análise de Componentes Principais (ACP) (Wong, 1963) das métricas de fragmentação calculadas para cada compartimento. As métricas de fragmentação escolhidas (Tabela 2) foram previamente selecionadas sem relação entre si para evitar a subestimação da variância durante a análise direta (Mingoti, 2005; Ferreira, 2008; Manly, 2008).

A ACP foi realizada a partir de uma matriz de correlação das variáveis padronizadas (Khattree e Naik, 2000; Johnson e Wichern, 2002). O propósito deste préprocessamento de padronização é permitir que todos os parâmetros da fragmentação selecionados possam exercer influências equitativas nos resultados além de torná-las adimensionais. Após a padronização os parâmetros de fragmentação ficaram com média 0 e variância 1 . 


\section{CAPÍTULO 4 - RESULTADOS}

\subsection{DESENVOLVIMENTO DO MÉTODO DE CLASSIFICAÇÃO DE FORMAS DE TERRENO}

\subsubsection{Assinaturas Geométricas de Referência}

A seleção das assinaturas geométricas adotada é relativa à informação do sinal concentrado nas três primeiras componentes do MNF (Figura 10A), os quais foram subsequentemente utilizados no PPI e no visualizador n-dimensional (Figura 10B). As assinaturas geométricas, identificadas pelo procedimento PPI, mostrou uma sequência de transição no visualizador n-dimensional, o que refletiu gradientes entre duas formas e variações de intensidade.
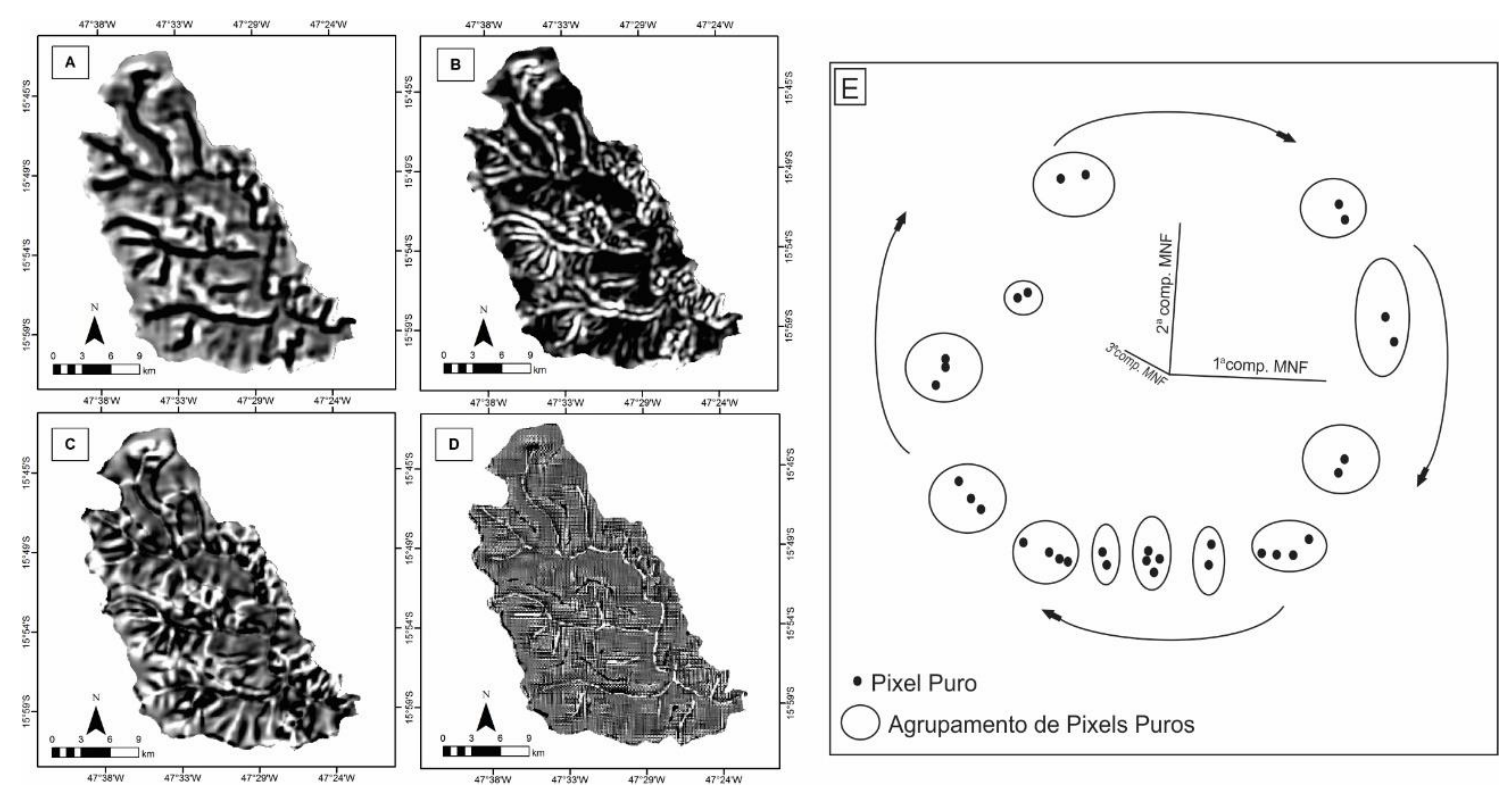

Figura 10 - Mapa da $1^{\mathrm{a}}$ (A), $2^{\mathrm{a}}$ (B), $3^{\mathrm{a}}$ (C) e $4^{\mathrm{a}}$ componente (D) do Minimum Noise Fraction (MNF). Esquema do n-dimensional com as $1^{\text {a }}, 2^{\mathrm{a}}$ e $3^{\mathrm{a}}$ componente do Minimum Noise Fraction (E) a partir do resultado do Pixel Purity Index (PPI).

Os dois tipos de forma foram: (a) N-Type onde os valores das curvaturas transversal e máxima são semelhantes e maior do que os das curvaturas longitudinal e mínima, e (b) U-Type em que os valores das curvaturas longitudinal e máxima são semelhantes e maior do que os das curvaturas transversal e mínima. Estes dois padrões constituem os dados de entrada no classificador SCM (Figura 10). 
Diferenças internas de cada grupo de FTs foram exploradas individualmente. Assim, a detecção dos membros finais pode ser refinada dentro de cada subconjunto, visando uma segunda classificação com base na medida de Mínima Distância. Neste contexto, foram selecionadas as seis assinaturas geométricas mais representativas em cada subconjunto de dados, caracterizado por ter a mesma forma e a mesma variação vertical de offset (deslocamento vertical) (Figura 11). Para cada assinatura foi adotado uma terminologia a partir de abreviações: (a) Forma $(\mathrm{Cx}=$ Convexa, $\mathrm{Tr}=$ Transicional, $\mathrm{Cc}=$ Côncava), (b) tipo da assinatura $(\mathrm{N}=\mathrm{N}$-Type, $\mathrm{U}=\mathrm{U}$-Type), e (c) posição do valor de curvatura em relação a uma outra de mesma forma e tipo $(\mathrm{Hi}-$ Higher, Lo = Lower $)$. 


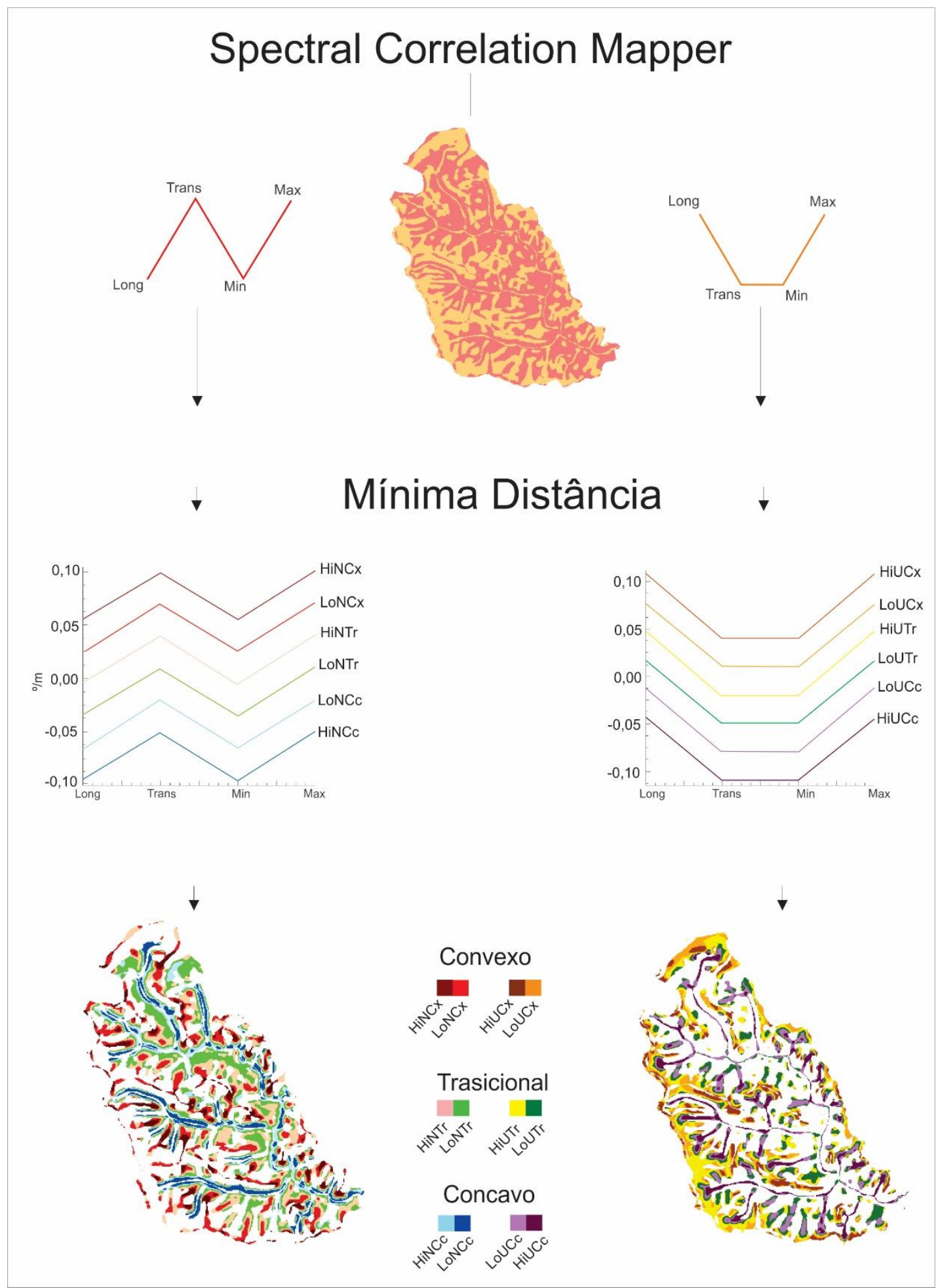

Figura. 11 - Esquema de classificação em dois estágios. Primeiro a classificação por SCM, determinando os dois tipos de assinaturas. Em seguida a classificação por Mínima Distância, determinando a intensidade dos tipos de assinaturas. Cada etapa gera seis diferentes tipos de assinaturas: formas convexas (HiNCx, LoNCx, HiUCx e LoUCx), formas transicionais (HiNTr, LoNTr, HiUTr e LoUTr), e formas côncavas (HiNCc, LoNCc, HiUCc e LoUCc). 


\subsubsection{Classificação das Assinaturas Geométricas}

Resultados da classificação das FTs pode ser dividido em três níveis progressivos de detalhamento (Figura 12). A primeira análise é o mais alto nível de agregação, adotando três classes: côncava, transicional e convexa. O segundo nível subdivide as classes anteriores de acordo com o tipo de assinaturas N-Type e U-Type (seis classes). Finalmente, o terceiro nível subdivide as seis classes anteriores em valores altos (High) e baixos (Low) de assinatura geométrica, totalizando 12 classes de FTs. Esta abordagem oferece um meio para investigar minuciosamente a natureza da assinatura e suas particularidades no resultado da classificação. Não existe um número ideal e único de classes, considerando a complexidade das paisagens naturais. Por outro lado, a propostas destes níveis progressivos permite avaliar a dependência escalar das FTs.

As FTs convexa, transicional e côncavas ocorrem em posições definidas na paisagem (Figura. 12A). As convexas ocorrem em relevo residual composto por couraças lateríticas e veios de quartzo, que são quimicamente e mecanicamente resistentes, ocupando as regiões mais altas. Essas feições representam colinas convexas derivadas da denudação do Planalto Retocado. Eventualmente, observa-se a uma ruptura brusca em direção a drenagem devido ao afloramento de horizontes lateríticos. As formas transicionais descrevem superfícies de deposição e de dissecção, contendo FTs convexas e côncavas. Essas feições nos vales assimétricos formam rampas amplas e suaves, ligeiramente convexas em direção do Rio Jardim e cobertas por Latossolos profundos (Reatto et al., 2000). Além disso, essas feições são mais estreitas nas margens dos tributários, principalmente nas bacias do Cariru e do Lamarão. As formas côncavas são encontradas nas regiões dissecadas pela erosão da água e ao longo dos canais de drenagem. Portanto, as superfícies podem ser organizadas do topo para a base como colinas convexas/interflúvios, rampas suaves na direção NNE, ou rampas íngremes na direção SSO e vales côncavos. 

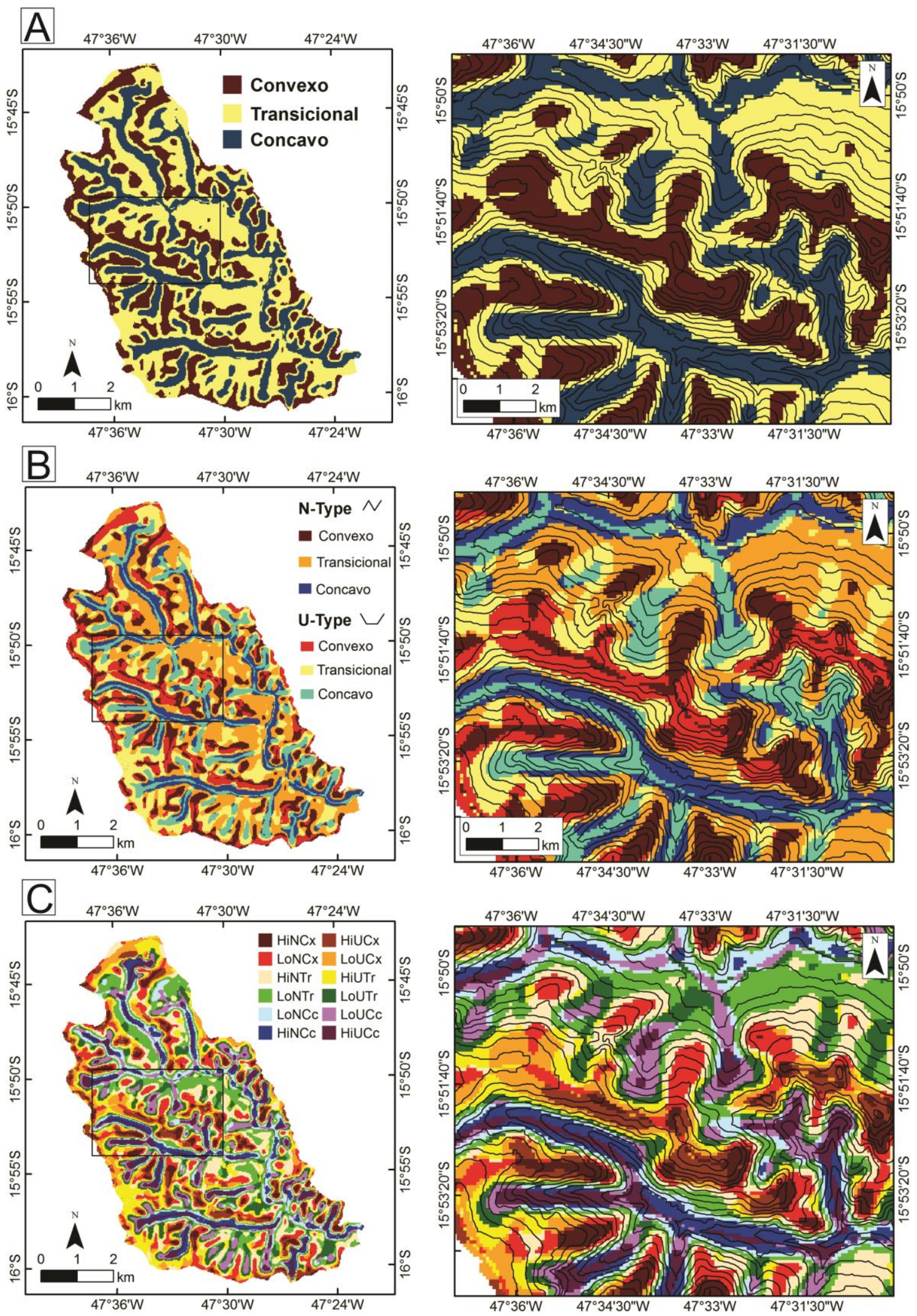

Figura 12 - Mapas de classificação de Formas de Terreno da bacia do Rio Jardim dividido em três níveis progressivos. As três classes básicas, convexa, transicional e côncava (A). As classes convexa, transicional e côncava dos dois tipos de assinaturas N-Type e UType, totalizando seis classes (B). As subclasses baseadas na subdivisão anterior e nas diferenças de intensidade dos tipos de assinaturas. Nessa classificação as classes básicas 
(côncavo, convexo e transicional) são subdivididas em 12 subclasses (C). Zoom de detalhe (à direita) com curvas de nível (20m) dos mapas A, B e C.

Subdividindo as três formas básicas anteriores, observa-se a tendência dos dois tipos de assinaturas (Figuras 12B e 13). As FTs convexas do N-Type ocorrem nos interflúvios, enquanto as FTs do U-Type são encontradas complementarmente ao redor do N-Type em porções ligeiramente mais íngremes. As FTs transicionais do N-Type contêm uma ligeira convexidade e ocorrem predominantemente nas rampas, cobertas por antigos depósitos laterizados. Essas formas laterizadas também ocorrem nos interflúvios de extensa lateralidade. As FTs transicionais do U-Type apresentam tendência a uma leve concavidade e estão presentes em torno das áreas de cabeceira e nos vales abertos, onde a convergência de fluxo começa a escavar o canal. As FTs côncavas U-Type encontramse ao longo dos canais, enquanto as FTs côncavas N-Type ocorrem adjacentes às U-Type. As FTs U-Type também destacam as características das cabeceiras em formato de hollow.

Nas FTs convexas cada subclasse enfatiza a zona de interflúvios ao longo do eixo longitudinal (HiNCx e LoNCx) ou eixo transversal (HiUCx e LoUCx) (Figura 12C). No relevo mais residual consistem principalmente de crostas lateríticas que recobrem o manto de intemperismo e exibem maior convexidade (HiNCx). A desintegração marginal das crostas lateríticas apresenta diferentes superfícies convexas (LoNCx, HiUCx e LoUCx), onde diferentes quantidades de material foi removido por denudação. O LoNCx está posicionado nos $\operatorname{colos}^{1}$ entre colinas ao longo dos interflúvios, nas bordas desses divisores e em rampas. O HiUCx ocorre nas encostas íngremes a partir dos interflúvios. O LoUCx aparece em altitudes mais baixas, em torno das outras feições convexas. Esta abordagem permite distinguir as principais áreas, onde os processos pedogenéticos e morfogenéticos estão associados com o movimento da água na paisagem.

Nas zonas côncavas, a divisão em quatro unidades permite uma descrição mais detalhada das formas de vale. Estas classes apresentam uma organização espacial, que define faixas estreitas e paralelas em relação ao leito do canal. Estes padrões espaciais variam de vales confinados a abertos, de acordo com a predominância de uma das seguintes classes: HiUCc (altamente confinado), LoUCc (confinado), HiNCc (parcialmente confinado), LoNCc (não-confinado). Por exemplo, nos rios Cariru, Lamarão e Estanislau representam canais confinados, mostrando faixas paralelas e

\footnotetext{
${ }^{1}$ A definição de colos nesse texto está associada aos "colos de flanco", que são depressões que aparecem num divisor de águas que separa dois vales de trajetos mais ou menos paralelos (Guerra e Guerra,2008, p.147).
} 
estreitas de todas as classes côncavas. Em contraste, o Rio Jardim tem um canal nãoconfinado (LoNCc), contendo fases mais confinadas com destaque para a classe HiNCc.

A classe HiUTr é a forma de transição entre o relevo residual e de deposição mais comum na bacia. Esta forma pode ocorrer nas porções mais denudadas dos interflúvios e, ainda, nas cabeceiras e em setores mais planos. As outras FTs transicionais apresentam as seguintes variações: ligeiramente convexa (HiNTr), rampas extensas (LoNTr), e ligeiramente côncava (LoUTr). Os vales assimétricos formam, de um lado, vertentes com rampas extensas e suaves, e de outro, vertentes íngremes. No interior das rampas suaves de maior extensão, LoNTr, ocorrem formas com uma ligeira concavidade classificada como LoUTr e formas com uma ligeira convexidade, HiNTr, abaixo dos interflúvios.
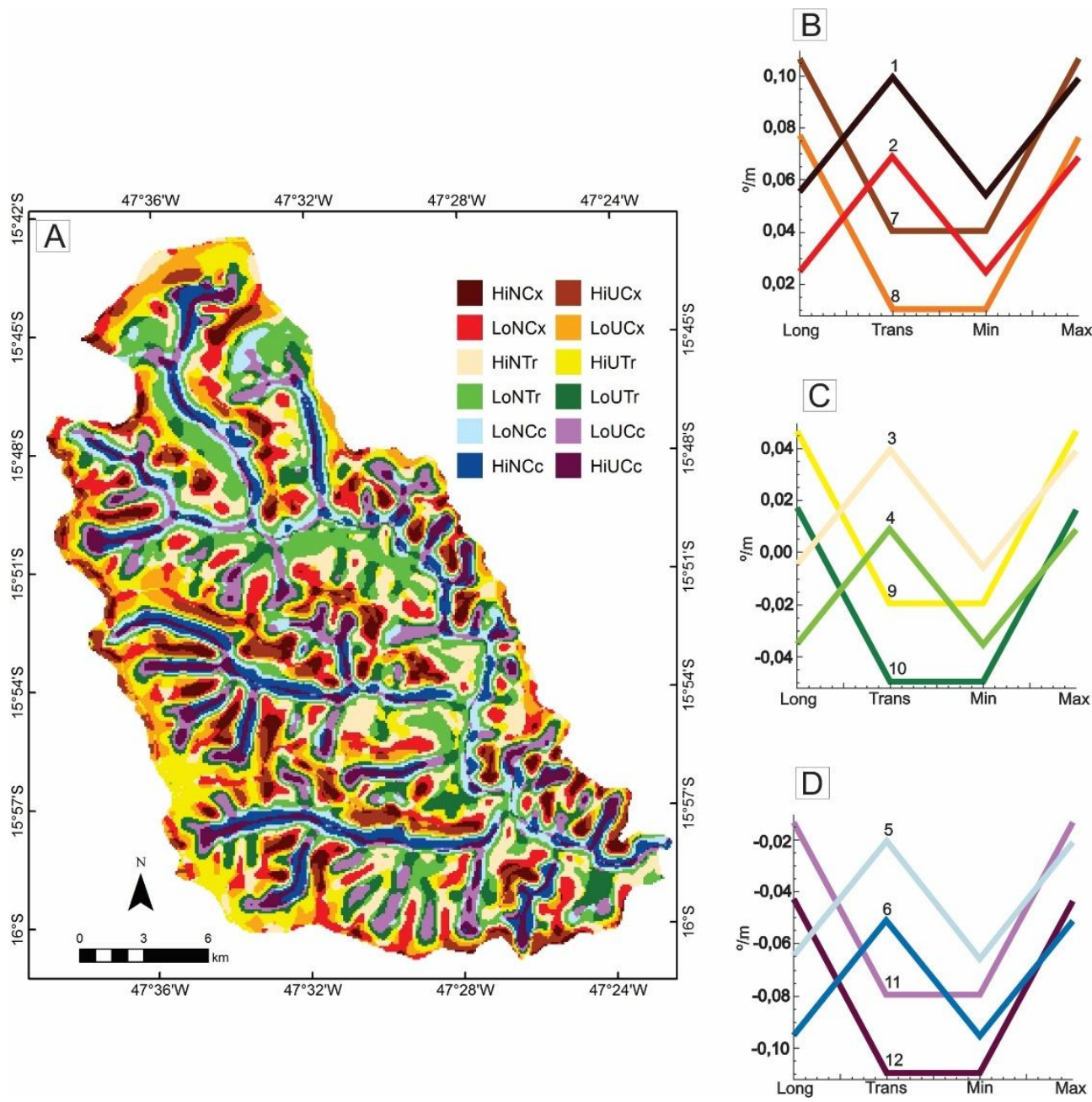

Figura 13 - Mapa de Formas de Terreno (A) composto por 12 assinaturas geométricas (B, C, D) da bacia do Rio Jardim apresentando as mudanças graduais do terreno: HiNCx (1), LoNCx (2), HiNTr (3), LoNTr (4), LoNCc (5), HiNCc (6), HiUCx (7), LoUCx (8), HiUTr (9), LoUTr (10), LoUCc (11), HiUCc (12). 
Apesar da grande variação de classes, é possível determinar sequências de transição de FTs do topo para a base. A partir do interflúvio entre os rios Jardim e Cariru destaca-se a variação do relevo convexo ( $\mathrm{HiNCx}>\mathrm{HiUCx}>\mathrm{LoNCx}>\mathrm{LoUCx})$ para FTs transicionais (HiNTr), onde a transição entre o relevo convexo e côncavo é mais suave, ou diretamente para FTs côncavas onde o contato do relevo convexo com o côncavo é abrupto. Outra sequência pode ser observada a partir dos interflúvios (HiNCx e HiUCx), passando pelas rampas suaves (LoNTr) até o vale aberto côncavo, não confinados (LoNCc) e/ou parcialmente confinados (HiNCc) do Rio Jardim. Nas sequências a partir das cabeceiras de drenagem, normalmente no contato entre HiUCx ou LoUCx com HiUTr e LoUTr, observa-se o aumento da concavidade decorrente da intensidade da incisão vertical dos rios. Sendo assim, HiUCc $>$ LoUCc $>$ HiNCc $>$ LoNCc.

\subsubsection{Comparação entre as classificações por assinatura geométrica e a de Wood}

Vários mapas de FTs foram gerados de acordo com o método de Wood (1996) considerando a configuração das Tolerância de Curvatura (TC) $(0,1 \% \mathrm{~m} ; 0,01 \% \mathrm{~m}$; $\left.0,001^{\circ} / \mathrm{m}\right)$ e Tolerância de Declividade (TD) $\left(0,5^{\circ} ; 1^{\mathrm{o}} ; 1^{\circ} 5^{\circ}\right.$ (Figura 14). O resultado das classificações apresentou diferenças consideráveis a depender da escolha das tolerâncias. Por exemplo, quando a TC de $0,1 \%$ m foi utilizado, apenas os principais interflúvios (ridge) e canais (channel) foram realçados. O cenário da classificação do Wood que melhor descreveu as características geomorfológicas da bacia foi a configuração com valores de $\mathrm{TD}$ de $1,5^{\circ}$ e de TC de $0,01^{\circ} / \mathrm{m}$. Esta configuração apresentou um melhor equilíbrio entre as classes. 


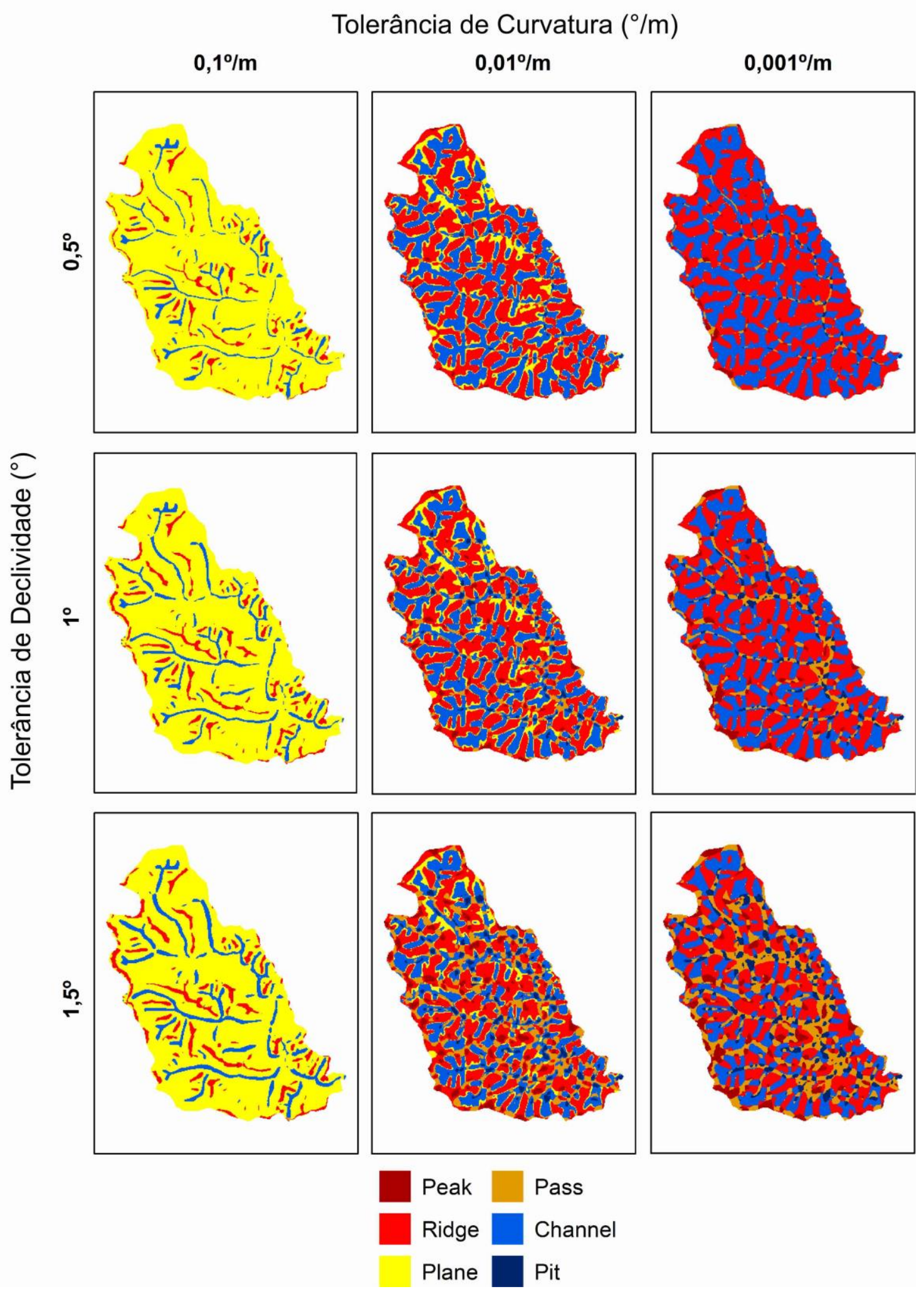

Figura 14 - Classificação das Formas de Terreno da Bacia do Rio Jardim a partir do método do Wood (1996), considerando diferentes valores de Tolerância de Declividade $\left({ }^{\circ}\right)$ e Tolerância de Curvatura $(\% / m)$.

A Figura 15 fornece uma comparação entre as classificações das assinaturas geométricas (dados agregados em seis classes) e o método de Wood. Foi adotado a 
classificação com as seis classes para facilitar a comparação com as classes de Wood. A classificação pelo método de assinatura geométrica rendeu uma melhor distinção do relevo residual e de dissecação (Figura 15A e 15B). Portanto, a classificação proposta revelou padrões morfológicos que são imperceptíveis pelo método de Wood (Figura 15D e 15E).

O Perfil a - b, ilustrado nas Figuras 15C e 15F demonstra vertentes assimétricas. A inclinação do lado do vale íngreme mostra uma sequência N-Type de FTs (convexa, transicional e côncava), que termina no canal com uma FT côncava do U-Type. De acordo com o método de Wood, este perfil demonstra uma sequência constituída pelo Peak, Ridge, e Pass, sendo que as classes de canais foram delimitadas pela forma Pass. Com método de assinatura geométrica, foi possível detectar uma elevação residual da FT convexa do N-Type no lado da vertente suavemente inclinada, sendo imperceptível pelo método de Wood. 


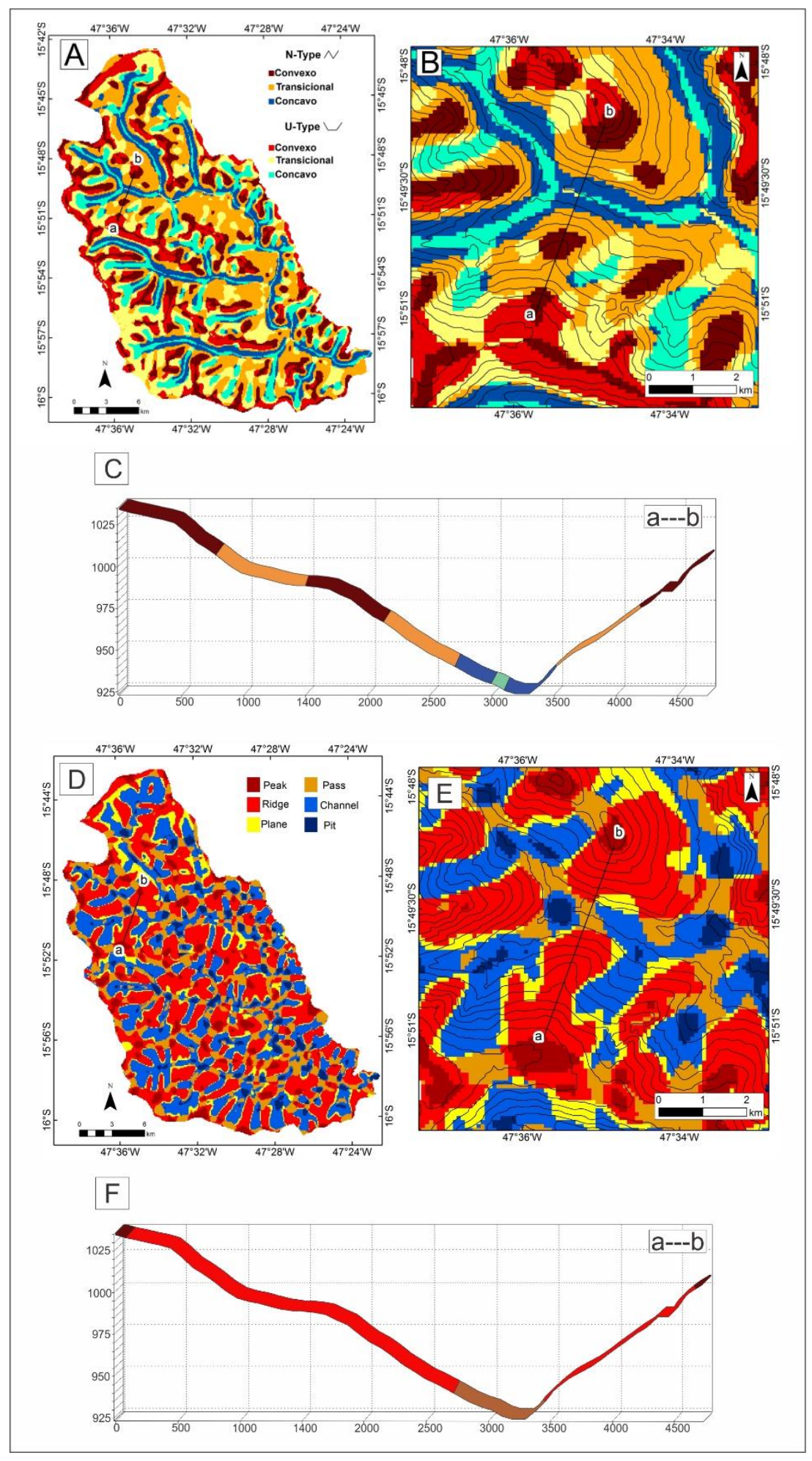

Figura 15 - A comparação dos mapas de Formas de Terreno entre a classificação por assinatura geométrica (Convexo, Transicional e Côncavo do N-Type e do U-Type) (A) e (B), e classificação de Wood (Peak, Ridge, Plane, Pass, Pit e Channel) (D) e (E). Um perfil topográfico para descrever as variações das Formas de Terreno, considerando o método de assinatura geométrica $(\mathrm{C})$ e o método de Wood $(\mathrm{F})$. 


\subsection{CLASSIFICAÇÃO DAS FORMAS DE TERRENO DO CONTEXTO REGIONAL}

Para a classificação do contexto regional é preciso realizar uma nova seleção de assinaturas utilizando a rotina de processmaneto do MNF e do PPI. A nomenclatura adotada para as classes de FTs no contexto regional são similares à da proposição do método na bacia do Rio Jardim. Os dois padrões de assinaturas N-Type e U-Type foram selecionados para compor as assinaturas (Figura 16). Nessa classificação diferenças do gain das assinaturas foram exploradas conforme Sena-Souza et al., (2016). Assim, os relevos de transição foram individualizados, formando três formas diferentes: o plano (Pl) foi classificado como um U-Type com valores de todas as curvaturas próximas a zero; o convexo-côncavo $(\mathrm{Cx}-\mathrm{Cc})$ foi classificado como um U-Type com valores positivos (longitudinal e máxima) e negativos (transversal e mínima); o côncavo-convexo foi classificado como um N-Type com valores positivos (transversal e máxima) e negativos (longitudinal e mínima).

A Cx-Cc apresenta valores próximos a $0,075 \% \mathrm{~m}$ nas curvaturas longitudinal e máxima e aproximadamente $-0,065 \%$ ma transversal e mínima. Quase opostos perfeitos, porém como uma leve tendência para as FTs convexas. A Cc-Cx apresenta valores de $0,05 \% \mathrm{~m}$ nas curvaturas longitudinal e mínima e valores positivos próximos de zero nas curvaturas transversal e máxima. Sendo assim, tendendo para as FTs côncavas.

As outras assinaturas selecionadas $\mathrm{HiCx}$ e HiCc são representados pelo U-Type, e as assinaturas LoCx e LoCc pelo N-Type. Apesar de valores próximos, o $\mathrm{HiCx}$ apresenta valores superiores ao LoCx nas curvaturas longitudinal, mínima e máxima e o LoCx tem valores próximo de zero na curvatura longitudinal e mínima. Na comparação entre a HiCc e a LoCc, observa-se que os valores do HiCc apresentam menor amplitude entre as curvaturas. Os valores do HiCc permanecem abaixo de $-0,05 \% \mathrm{~m}$ em todas as curvaturas, enquanto que a LoCc apresenta valores próximos a zero nas curvaturas longitudinal e máxima, e valores de $-0,15 \% / \mathrm{m}$ nas curvaturas transversal e mínima, indicando menor intensidade desses ambientes côncavos. 


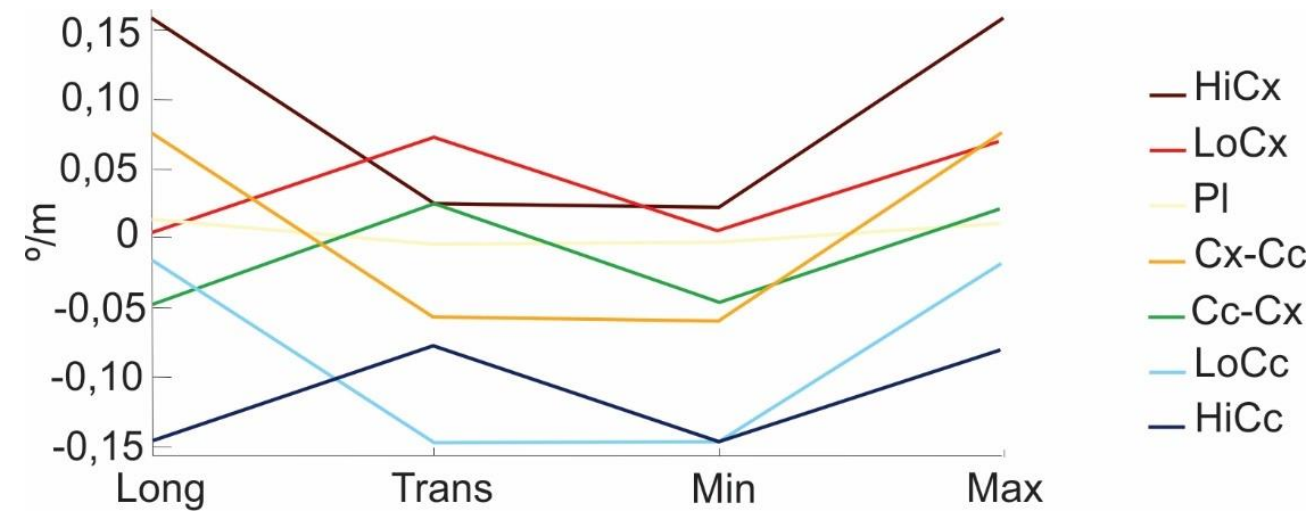

Figura 16 - Assinaturas geométricas selecionadas para a classificação das Formas de Terreno do contexto regional.

\subsubsection{Análise de Frequência das Formas de Terreno dos Compartimentos Geomorfológicos}

A análise de Frequência (Fr) avalia a classificação das FTs considerando o balanço que existe entre relevos convexos, planos e côncavos dentro de um compartimento (Figura 17). Dessa forma, é preciso observar principalmente dois pares de FTs: (a) a $\mathrm{HiCx}$ e a HiCc que representam o balanço entre o relevo mais a montante e residual ( $\mathrm{HiCx})$ e o relevo mais encaixados e dissecados ( $\mathrm{HiCc}$ ) da paisagem. Quanto maior a amplitude entre o relevo residual e os vales encaixados, maior será a frequência dessas classes; (b) a LoCx e a LoCc que representam fases intermediária da denudação onde o LoCx caracteriza o relevo residual um pouco mais denudado, sempre localizado em cotas inferiores à $\mathrm{HiCx}$ adjacente, e à LoCc representa a dissecação do relevo residual, formando FTs mais deprimidas e canais levemente encaixados associados a vales abertos. Assim, a LoCc pode ser um relevo de dissecação ou de deposição.

O conjunto dessas quatro FTs deve ser interpretado associado aos relevos de transição $\mathrm{Cx}-\mathrm{Cc}$ e $\mathrm{Cc}-\mathrm{Cx}$ que caracterizam os contatos entre os gradientes dos pares mencionados, podendo ter características mais residuais convexas $(\mathrm{Cx}-\mathrm{Cc})$ ou de superfícies côncavas $(\mathrm{Cc}-\mathrm{Cx})$ caracterizando depósitos adjacentes à $\mathrm{LoCc}$ ou canais parcialmente dissecados. A forma Pl pode ser um residual (mesas e chapadas) ou um material depositado decorrente da denudação, formando superfícies aplainadas e rampas aplainadas. 
A

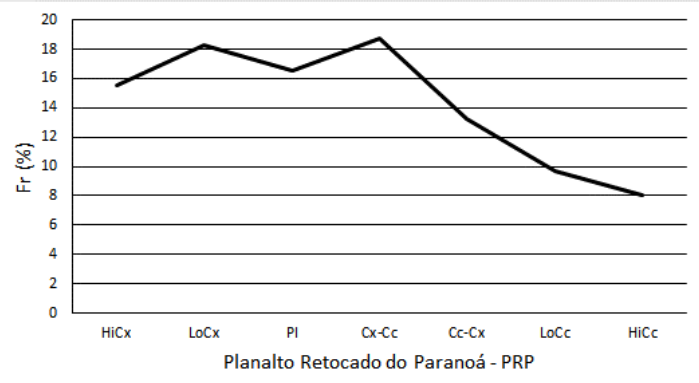

C

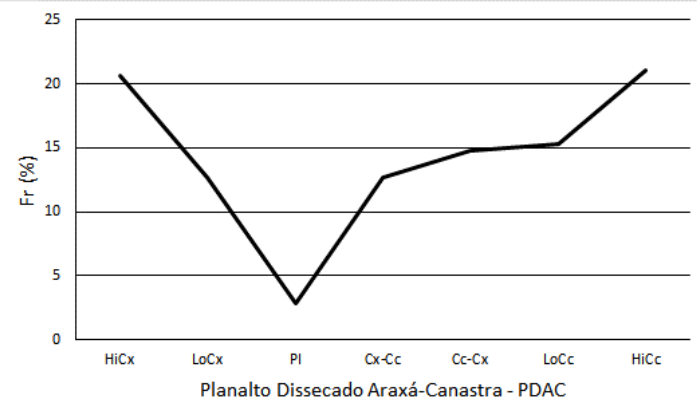

$\mathrm{E}$

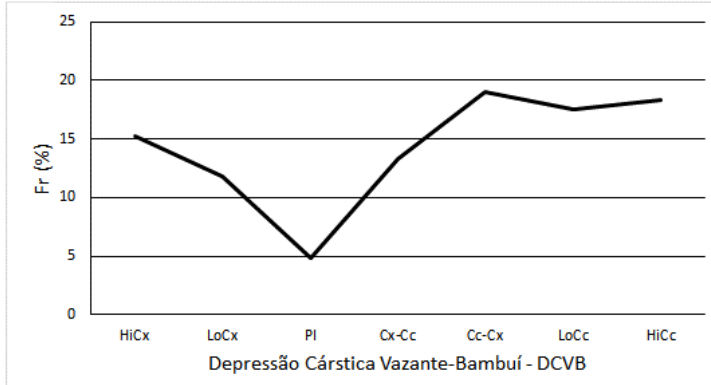

G

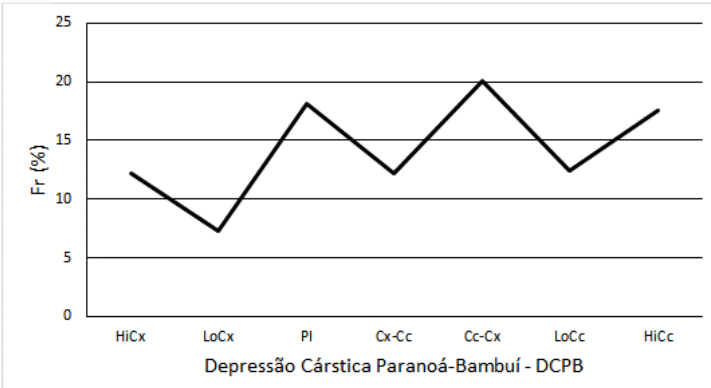

B

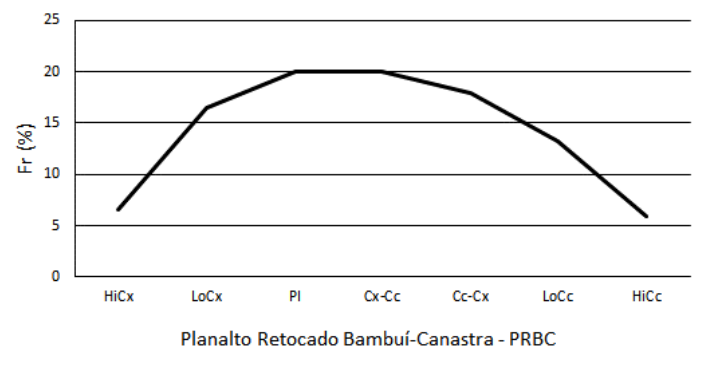

D

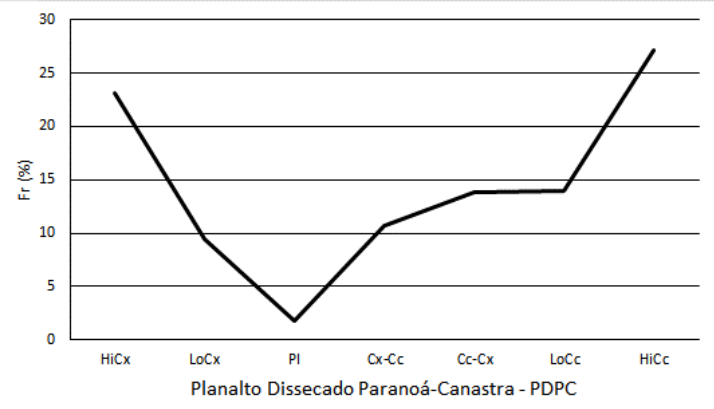

$\mathrm{F}$

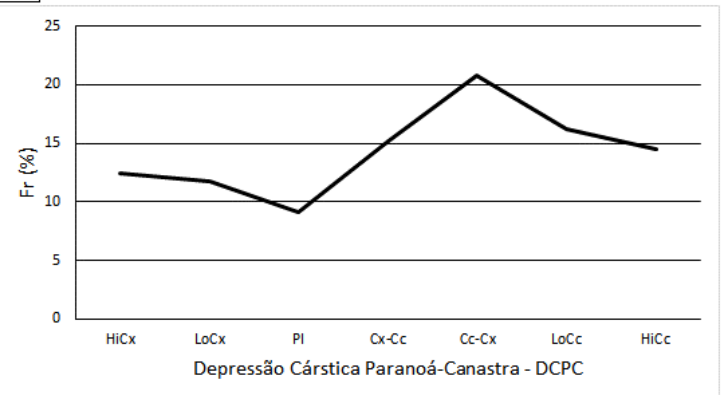

Figura 17 - Gráficos de Frequência $(\mathrm{Fr} \%)$ por compartimento geomorfológico apresentando a variação da Formas de Terreno do contexto regional.

No mapa (Figura 18) (Anexo 1) destaca-se a classe P1 nos Planaltos Retocados do Paranoá e do Bambuí-Canastra, e nas depressões Paranoá-Canastra e Paranoá-Bambuí. Os Planaltos Dissecados Araxá-Canastra e Paranoá-Canastra são unidades que destacam as formas HiCx e HiCc. A Depressão Cárstica Vazante-Bambuí apresenta características similares aos planaltos dissecados e às depressões cársticas. A $\mathrm{Cx}-\mathrm{Cc}$ e a $\mathrm{Cc}-\mathrm{Cx}$ estão presente em todas as unidades, normalmente indicando a denudação de um interflúvio, 
formando um colo (depressão ao longo de um interflúvio que divide dois vales) e na transição entre relevo convexo e côncavo nas cabeceiras de drenagem, formando um relevo denudado. Essas formas de transição $(\mathrm{Cx}-\mathrm{Cc}$ ou $\mathrm{Cc}-\mathrm{Cx})$ representam as áreas mais susceptíveis a erosão, pois se localizam em frentes erosivas, principalmente quando associadas às cabeceiras de canais. A Cc-Cx ainda pode aparecer no sopé de rampas suaves e longas sempre entre a LoCx e a LoCc, formando um relevo deposicional.

A curva de frequência do Planalto Retocado do Paranoá (Figura 17A) apresenta um padrão com valores próximas entre as FTs de características mais convexas conjuntamente com a forma plana: $\mathrm{HiCx}$ (Fr: 16\%), LoCx (Fr: 18\%), Cx-Cc (Fr: 19\%) e Pl (Fr: 17\%). A partir da Cc-Cx (Fr: 13\%) observa-se um constante decréscimo nos valores. Esse equilíbrio entre $\mathrm{HiCx}, \mathrm{LoCx}, \mathrm{Pl}$ e $\mathrm{Cx}-\mathrm{Cc}$ preserva principalmente o relevo residual plano e convexo. O relevo suave de baixa amplitude topográfica está localizado principalmente nos flancos alçados do domo e na parte central em rampas retilíneas (Figura 18). A HiCx está localizada nas escarpas da borda sul do compartimento e nas chapadas ligeiramente convexas. O Planalto Retocado do Paranoá é o divisor entre as bacias do Paraná, Tocantins e São Francisco. Nesse sentido, as escarpas apresentam entranças pelo avanço de frente de recuo erosiva dessas bacias, formando canyons classificados pela HiCc (Fr: 8\%). A dissecação interna em direção ao lago Paranoá apresenta uma drenagem anelar normalmente com formas LoCc (Fr: 10\%) associadas ao $\mathrm{Cc}-\mathrm{Cx}$ e com zonas pontuais mais encaixadas classificadas pela HiCc. A LoCx e a Cx-Cc estão associadas a denudação da $\mathrm{HiCx}$ ou estão localizados em interflúvios formando colos, principalmente na parte central do domo (Figura 18). As diferenças de frequência entre a HiCx e a HiCc, assim como entre a LoCx e a LoCc, além da elevada frequência da forma $\mathrm{Pl}$, indicam que pouco dessa paisagem foi dissecada. 


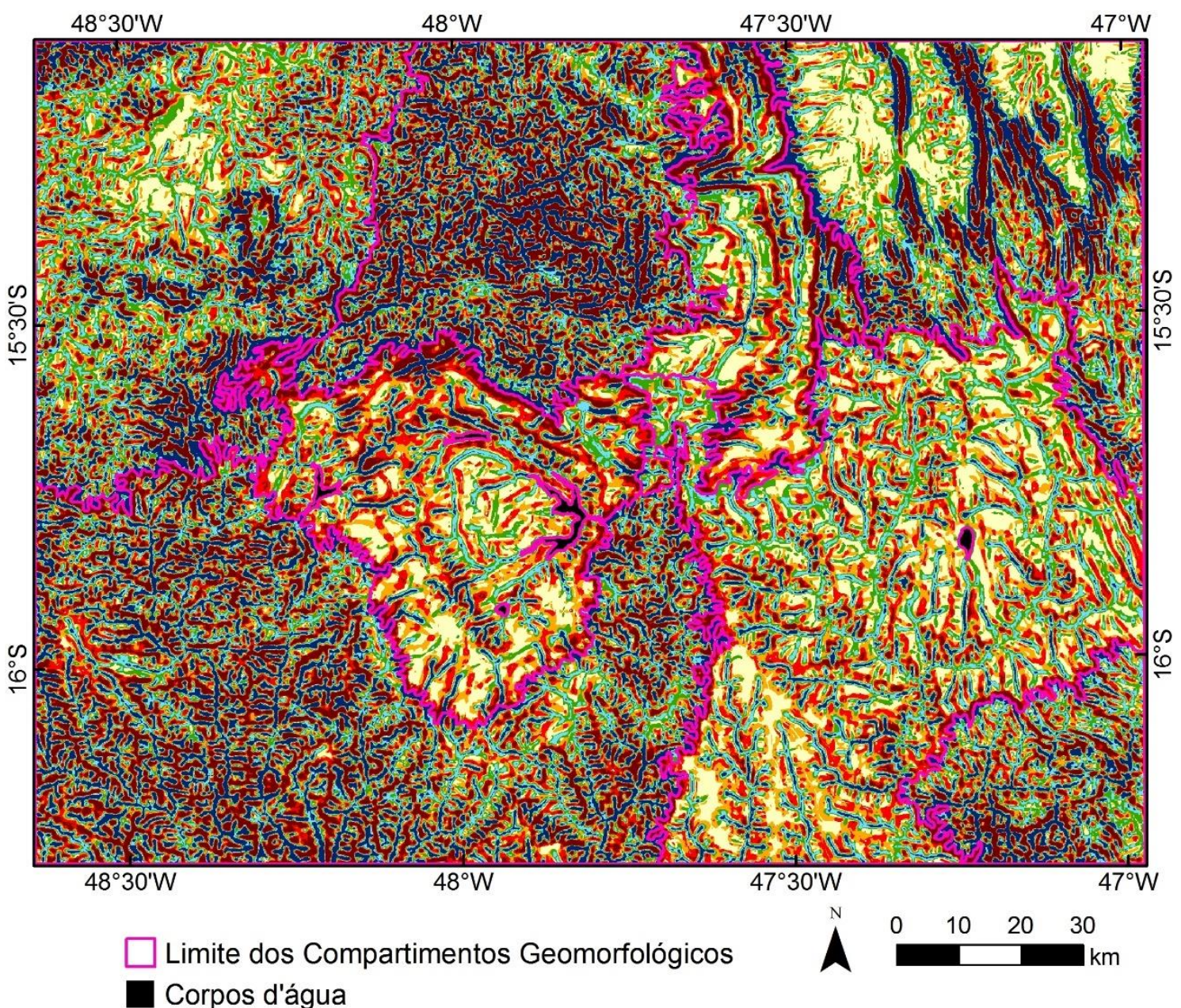

$\begin{array}{ccccc}\text { Residual } & \text { Residual/Denudado } & \text { Residual/Depositado } & \text { Dissecado/Depositado } & \text { Dissecado } \\ \square \mathrm{HiCx} & \mathbf{L O C x} & \mathrm{PI} & \text { LoCc } & \mathbf{H i C c}\end{array}$

Denudado
Cx-Cc
Cc-Cx

Figura 18 - Classificação das Formas de Terreno representada pelas setes assinaturas geométricas do contexto regional.

A curva de frequência do Planalto Retocado Bambuí-Canastra (Figura 17B) apresenta um equilíbrio entre as formas residuais e as que dissecam a paisagem. $\mathrm{A} \mathrm{HiCx}$ (Fr: 7\%) caracteriza interflúvios colinosos resistentes ao desenho hidrológico promovidos por canais e depressões classificados pela $\mathrm{HiCc}(\mathrm{Fr}: 6 \%)$. A HiCx está também localizada nas escarpas de quartzitos do Grupo Canastra que delimitam o contato deste planalto com o Planalto Dissecado Araxá-Canastra. Associada à HiCx, observa-se a LoCx (Fr: 16\%), posicionadas em cotas inferiores, formando um relevo mais denudado nos interflúvios. Conforme apresentado anteriormente, na Bacia do Rio Jardim se desenvolvem canais entalhados e mais abertos. As drenagens menos escavadas são classificadas pela LoCc (Fr: 13\%) associados a canais parcialmente dissecados e pequenas depressões 
classificadas pela Cc-Cx (Fr: 17\%). Ao contrário do Planalto Retocado do Paranoá, a LoCx é a forma mais representativa dos relevos convexos do Planalto Retocado BambuíCanastra. As formas Pl (Fr: 20\%) estão localizadas a porção sul do planalto como chapadas residuais dentro do limite da Bacia do Rio Paraná e nos planaltos mais elevados da Bacia do Rio São Francisco. Assim como no Planalto Retocado do Paranoá, rampas suaves se desenvolvem abaixo dos interflúvios sempre na margem direita dos rios, influenciado pelo controle estrutural promovido pelo cavalgamento do Bambuí sobre o Canastra. Juntamente com as formas P1, a Cx-Cc (Fr: 20\%) é a classe mais representativa desse planalto. A $\mathrm{Cx}-\mathrm{Cc}$ revela as frentes erosivas, seja localizado em um interflúvio denudado, formando colos, ou em cabeceiras de drenagem onde o processo de dissecação avança à montante.

Enquanto que nos Planaltos Retocados o padrão da curva de frequência apresenta os maiores valores nos relevos convexos ( $\mathrm{HiCx}, \mathrm{LoCx}$ e $\mathrm{Cx}-\mathrm{Cc})$ e nos planos $(\mathrm{Pl})$, nos Planaltos Dissecados prevalecem os côncavos (HiCc, LoCc e Cc-Cx) e a ausência dos planos (Pl) (Figura 17C e 17D). O Planalto Dissecado Araxá-Canastra apresenta mesas e chapadas residuais ligeiramente convexas caracterizadas pela $\mathrm{HiCx}$ (Fr: 21\%) e LoCx (Fr: 13\%). De oeste para leste observa-se a extensão dos interflúvios remanescentes marcado pela $\mathrm{HiCx}$, contribuindo para um desenho hidrológico com características dendríticas classificado pela HiCc (Fr: 21\%) (Figura 18). Algumas chapadas apresentam formas Pl (Fr: 3\%) preservada, mas esta classe é praticamente ausente nos Planaltos Dissecados. A resistência desses relevos residuais e a elevada amplitude entre estes e os fundos de vale determina os altos valores da curva de frequência dessas classes e em perfeito equilíbrio. Nos vales do Rio São Bartolomeu, o Grupo Canastra é caracterizado por xistos carbonosos e milonitos mais susceptíveis ao intemperismo e podem estar associados a rochas metassedimentares do Grupo Bambuí (Figura 18). Nessa porção do Planalto Dissecado Araxá-Canastra pode ser observado com mais frequência a forma P1 em rampas curtas. Nos setores onde os vales se tornam mais abertos, a drenagem é menos escavada caracterizando as formas LoCc (Fr. 15\%) associadas às $\mathrm{Cc}-\mathrm{Cx}$ (Fr: 15\%). Nesses setores ainda é observado com mais frequência as formas Cx-Cc (Fr: 13\%), normalmente em interflúvios denudados (Figura 18).

O Planalto Dissecado Paranoá-Canastra é um compartimento extremamente dissecado onde as formas $\mathrm{HiCx}$ (Fr: 23\%) e HiCc (Fr: 27\%) apresentam as maiores frequências registradas na área de estudo (Figura 17D). O relevo residual é formado por um conjunto de morros, colinas e serras. Não há presença de relevos residuais tabulares. 
Os interflúvios são mais curtos e a densidade de drenagem treliça ou retangular é alta (Dantas, 2002), o que respalda a frequência elevada de HiCc (Figura 18). É importante destacar que existe setores do planalto que realçam as classes $\mathrm{Cc}-\mathrm{Cx}$ (Fr: 14\%) e LoCc (Fr: 14\%). Provavelmente, o intemperismo diferencial influenciaram a esculturação de formas distintas e localizadas. As Unidades Pelíticas Carbonatadas do Paranoá no norte do Distrito Federal, por exemplo, são realçadas pela presença dessas classes, delimitando o contato com o Grupo Canastra. De maneira geral, os setores que apresentam maior frequência de Cc-Cx e LoCc, também são os que apresentam maior frequência de LoCx (Fr: 9\%) e Cx-Cc (Fr: 11\%), formando uma espécie de (topo)sequência de denudação. A forma Pl (Fr: 2\%) é praticamente inexistente nesse planalto, registrando as menores frequências da área de estudo.

A Depressão Cárstica Vazante-Bambuí é o compartimento que apresenta o padrão de curva mais próximo do padrão dos Planaltos Dissecados (Figura 17E). As formas se desenvolvem sobre dois níveis de bases diferentes. Adjacentes aos planaltos retocados mais à montante se desenvolve formas sobre um patamar estrutural alçado (Figura 18). Nesse nível de base, o relevo residual com formas $\mathrm{HiCx}$ (Fr: 15\%) é composto por cristas alinhadas de calcários silicificados do Grupo Bambuí com vergência para SE, assim como as Cristas de Unaí (Figura 18). A dissecação incipiente desse patamar configura um arranjo de FTs marcadas pela forma Cc-Cx (Fr: 19\%), a mais frequente da unidade, e vales pouco encaixados caracterizados por formas LoCc (Fr: 18\%). Observa-se ainda relevo residuais e denudados ligeiramente convexo caracterizado por formas LoCx (Fr: 12\%) e Cx-Cc (Fr: 13\%) em sequências abaixo das cristas, tendo como resultado final superfícies com formas Pl (Fr: 5\%) (Figura 18). No Grupo Vazante, localizado em degrau estrutural inferior, apresentam as maiores amplitudes entre o relevo residual e nível de base da Depressão Cárstica. Nessa porção da paisagem, as serras são caracterizadas por arenitos líticos resistentes ao intemperismo, formando vales encaixados representados pela HiCc (Fr: 18\%) (Figura 18).

O padrão da curva da Depressão Cárstica Paranoá-Canastra (Figura 17F) assinala um aumento da frequência da forma Pl (Fr: 10\%) decorrente da presença de rochas carbonáticas do Grupo Canastra. No sopé do Planalto Retocado, a Unidade Rítmica Quartzítica aflora caracterizando um relevo mais dissecado e de densidade de drenagem mais elevada (Dantas, 2000) (Figura 18). A amplitude entre o relevo residual e o fundo de vale caracteriza a forma $\mathrm{HiCx}(\mathrm{Fr}: 12 \%)$ e $\mathrm{HiCc}$ (Fr: 15\%). Nos limites do Grupo Canastra já é possível observar mudanças graduais entre o relevo convexo e côncavo, 
formado pelos LoCx (Fr: 12\%), Cx-Cc (Fr: 15\%), Cc-Cx (Fr: 19\%) e LoCc (Fr: 18\%). Nas superfícies aplainadas a drenagem é caracterizada pelas formas $\mathrm{Cc}-\mathrm{Cx}$ e LoCc, formando canais abertos de pouca erodibilidade (Figura 18).

O padrão da curva da Depressão Cárstica Paranoá-Bambuí (Figura 17G) apresenta o compartimento com mais forma Pl (Fr: 17\%) dentre as depressões, próximos dos valores encontrados nos Planaltos Retocados. Conhecido como Vão do Paranã, a região apresenta extensas superfícies aplainadas e relevo residual marcado por longas serras com vergência SE classificadas como HiCx (Fr: 12\%) (Figura 18). Os vales mais dissecados destacados pela HiCc (Fr: 18\%) ocorrem entre as serras e no contato oeste entre a depressão e o Planalto Retocado do Paranoá (Figura 18). Assim como na Depressão Cárstica Paranoá-Canastra, as superfícies aplainadas são cortadas por uma drenagem pouco entalhada caracterizada pelas Cc-Cx (Fr: 20\%) e a LoCc (Fr: 12\%) (Figura 18). A LoCx (Fr: 7\%) e o $\mathrm{Cx}-\mathrm{Cc}$ (Fr: 12\%) ocorrem com mais frequência nos patamares desenvolvidos no contato entre o limite sul da depressão e o Planalto Retocado Bambuí-Canastra caracterizados por serras mais curtas, fragmentadas e de baixa convexidade (Figura 18). Nos patamares as formas Pl são menos frequentes, mas aparecem nos sopés das serras, formando pequenas rampas retilíneas (Figura 18).

\subsubsection{Análise da Proporção de Patches das Formas de Terreno dos Compartimentos Geomorfológicos}

O Número de Patches (NP) é uma métrica simples de contagem de fragmentos que auxilia na identificação dos patches mais recorrentes da paisagem. $\mathrm{O}$ valor do número de patches absoluto pode levar interpretações tendenciosas e não ajuda a comparar compartimentos diferentes. Dessa forma, é utilizado a Proporção de Patches (PP). Assim como a Frequência (Fr), a Proporção de Patches varia de acordo com o estágio de evolução dos compartimentos. O seu valor pode ser interpretado de seis maneiras: (a) valores elevados significam que a classe é mais fragmentada; (b) os patches são mais numerosos em relação aos outros patches de FT dentro de um mesmo compartimento; (c) valores baixos significam que a paisagem é menos fragmentada; (d) os patches são menos numerosos em relação aos outros patches de FT dentro de um mesmo compartimento; (e) combinação da situação (a) e (b); (f) combinação da situação (d) e (e). Dessa forma é preciso do auxílio da frequência para uma melhor interpretação dos dados (Figura 19A). Para interpreta-los observa-se a diferença entre a Proporção de Patches e a Frequência (PP-Fr) de uma mesma classe de FT (Figura 19B). Ademais, a análise da Figura 19 é 
realizada observando as FTs em pares: o relevo mais residual ( $\mathrm{HiCx}$ ) com o relevo mais dissecado ( $\mathrm{HiCc}$ ); o relevo residual/denudado ( $\mathrm{LoCx}$ ) com o relevo dissecado/depositado ( $\mathrm{LoCc}$ ); o relevo denudado (Cx-Cc) com relevo denudado/depositado/dissecado (Cc-Cx). O relevo suave de baixa amplitude topográfica $(\mathrm{Pl})$ foi analisado individualmente.

Os valores mais baixos de proporção de patches são encontrados nos relevos residuais convexos $(\mathrm{HiCx})$ e nos relevos dissecados côncavos $(\mathrm{HiCc})$ em todos os compartimentos. Nestas formas, a proporção de patches é sempre menor do que a frequência o que indica que essas FTs não são tão fragmentadas (Figura 19A). Assim, quanto mais negativo for a diferença PP-Fr, menos fragmentada é a classe.

É possível inferir que os Planaltos Dissecados são as unidades que apresentam relevo residual HiCx menos fragmentados, pois apresentam os valores mais negativos com destaque para o Planalto Dissecado Paranoá-Canastra (PP-Fr: -21\%) (Figura 19B). Nos Planaltos Retocados, o Planalto Retocado Bambuí-Canastra apresenta a maior proporção de patches de $\mathrm{HiCx}$ (PP: 5\%) e a menor frequência (Fr: 7\%) (Figura 19A). Nesse sentido, o valor da PP-Fr indica que o relevo residual convexo além de ser menos frequente no Planalto Retocado Bambuí-Canastra ainda apresenta a maior proporção de patches dentre todos os compartimentos, indicando que a classe é mais fragmentada (Figura 19B). Nas Depressões Cársticas, destaca-se a Depressão Cárstica VazanteBambuí com o maior valor de frequência de $\mathrm{HiCx}$ (Fr: 15\%) e a menor proporção de patches para esta forma (PP: 2\%) (Figura 19A). A Depressão Cárstica Vazante-Bambuí é o compartimento menos aplainada com relevo residual serrano menos fragmentado do que os relevos residuais das outras depressões (Figura 17 e Anexo 1), o que influência no maior valor de PP-Fr (-13\%) (Figura 19B).

$\mathrm{O}$ balanço entre a proporção de patches e a frequência da $\mathrm{HiCx}$ reflete na $\mathrm{HiCc}$, apresentando padrões similares (Figura 19). Novamente é possível indicar o Planalto Dissecado Paranoá-Canastra e o Planalto Retocado Bambuí-Canastra como as unidades planálticas que mais se destacam. O Planalto Dissecado Paranoá-Canastra apresenta relevos dissecados menos fragmentados com frequência elevada e baixa proporção de patches de HiCc (Fr: 27\% e PP: 2\%), resultando nos valores mais negativos de PP-Fr (25\%) (Figura 19). O Planalto Retocado Bambuí-Canastra apresenta a menor frequência e a maior proporção de HiCc (Fr: 6\% e PP: 5\%) dentre todos os compartimentos, indicando maior fragmentação com o valor de PP-Fr próximo de zero (Figura 19). Nas Depressões Cársticas os PP-Fr apresentam valores próximos entre si (Figura 19B). A HiCc (Fr: 18\% e PP: 2\%) da Depressão Cárstica Paranoá-Bambuí é a forma menos 
fragmentada apresentando $\mathrm{PP}-\mathrm{Fr}$ de $-16 \%$. A HiCc nessa depressão margeia principalmente os rebordos das escarpas e o sopé das serras alinhadas sem interferência de outras classes de FTs (Figura 17 e Anexo 1) e por isso apresenta o valor mais negativo de PP-Fr dentre as depressões (Figura 19B).

Apenas nos relevos residuais convexos $(\mathrm{HiCx})$ e dissecados côncavos $(\mathrm{HiCc})$ que a frequência é sempre maior do que a proporção de patches. Nos outros pares de FTs (LoCx e LoCc; Cx-Cc e Cc-Cx) a proporção de patches tende a ser maior do que a frequência (Figura 19A). Isto acarreta em outra interpretação sobre as classes que são menos ou mais fragmentadas. Nesse caso, quanto mais próximo de zero for a diferença, PP-Fr, menos fragmentado será a classe de FT (Figura 19B). Na forma Pl essas medidas variam de posição e devem ser interpretadas das duas maneiras (Figura 19).

Nos pares LoCx e LoCc os valores entre a frequência e a proporção de patches se aproximam um dos outros e com valores de proporção de patches normalmente superior aos valores de frequência (Figura 19A). Assim, menor frequência e maior proporção de patches indicam que a forma dentro compartimento é mais fragmentada. Nos Planaltos Retocados, o PP-Fr apresenta pouca variação na LoCx (Figura 19B). Apesar da pouca diferença de PP-Fr entre esses planaltos, é possível dizer que a LoCx (PP-Fr: 3\%) do Planalto Retocado do Paranoá é ligeiramente mais fragmentado do que a LoCx (PP-Fr: 1\%) do Planalto Retocado Bambuí-Canastra. Em ambos os planaltos, essa forma representa relevos denudacionais adjacentes à $\mathrm{HiCx}$.

$\mathrm{Na}$ LoCc ocorre uma inversão de valores nos Planaltos Retocados. A LoCc é mais frequente e apresenta menor proporção de patches no Planalto Retocado BambuíCanastra, enquanto que no Planalto Retocado do Paranoá essa forma é menos frequente e apresenta maior proporção de patches. Nesse sentido a LoCc é menos fragmentada no Planalto Retocado Bambuí-Canastra com valores negativos de PP-Fr (-5\%) (Figura 19B). É importante lembrar que esse Planalto Retocado apresenta uma densidade de drenagem mais elevada (Dantas, 2002) com canais principais mais interligados com os tributários (Figura 17 e Anexo 1), tornando essa forma mais contínua na paisagem.

Nos Planaltos Dissecados, a proporção de patches apresenta valores superiores à frequência tanto para a LoCx quanto para a $\mathrm{LoCc}$ (Figura 19A). Essas formas no Planalto Dissecado Araxá-Canastra são menos fragmentadas, apresentando valores mais próximos de zero de PP-Fr (Figura 19B). Esse planalto é menos dissecado do que o Planalto Dissecado Paranoá-Canastra, apresentando vales mais abertos como o do São Bartolomeu 
(Figura 17 e Anexo 1) o que favorece maior frequência e menor proporção de patches da LoCc (PP-Fr: 5\%). Também apresenta fases mais denudadas e menos fragmentadas, representadas pelas formas LoCx, principalmente abaixo dos rebordos erosivas (Fr-PP: 7\%) (Figura 17 e Anexo 1). O relevo serrano e de morros do Planalto Dissecado ParanoáCanastra favorece a ocorrência das HiCx e HiCc e assim as formas LoCx (PP-Fr: 11\%) e LoCc (PP-Fr: 9\%) permanecem espalhadas, menos frequentes e menos numerosas no compartimento (Figura 17 e Anexo 1).

Nas Depressões Cársticas os valores de proporção de patches são superiores aos valores de frequência na $\mathrm{LoCx}$ e na LoCc (Figura 19A). A forma LoCx apresenta valores próximos de frequência e de proporção de patches na Depressão Cárstica VazanteBambuí (Fr: 12\% e PP: 17\%) e na Depressão Cárstica Paranoá-Canastra (Fr: 12\% e PP: 18\%). A Depressão Cárstica Paranoá-Canastra apresenta valor de PP-Fr ligeiramente superior e consequentemente mais fragmentado do que a Depressão Cárstica VazanteBambuí (Figura 19B). Dentre as Depressões Cársticas, a forma LoCx é mais fragmentada na Depressão Cárstica Paranoá-Bambuí com os valores mais positivos de PP-Fr (11\%). A LoCx neste compartimento está associada à denudação de relevos residuais do tipo inselberg ou colinas nas superfícies aplainadas da depressão, e também associadas à denudação do relevo serrano mais próximo do Planalto Retocado Bambuí-Canastra (Figura 17 e Anexo 1). A forma LoCc também não apresenta variações significativas entre a Depressão Cárstica Vazante-Bambuí (Fr: 18\% e PP: 19\%) e a Depressão Cárstica Paranoá-Canastra (Fr: 16\% e PP: 19\%), enquanto na Depressão Cárstica Paranoá-Bambuí apresentam as maiores diferenças (Fr: 12\% e PP: 22\%). A fragmentação da LoCc ganha mais destaque na Depressão Cárstica Paranoá-Bambuí decorrente da pouca frequência, mas da elevada proporção de patches (Figura 19A). Nesta depressão a LoCc disseca parcialmente a superfície aplainada formando uma rede drenagem pouco eficiente e mais fragmentada na paisagem (Figura 17 e Anexo 1).

As formas $\mathrm{Cx}-\mathrm{Cc}$ e $\mathrm{Cc}-\mathrm{Cx}$ apresentam geralmente proporção de patches superior à frequência (Figura 19A), indicando que quanto maior a diferença entre essas medidas, maior será a fragmentação. Analisando primeiramente a forma $\mathrm{Cx}-\mathrm{Cc}$, observa-se que apesar dos maiores valores de proporção e frequência estarem nos Planaltos Retocados, essa forma apresenta padrão de fragmentação muito similar em todas as unidades geomorfológicas, com um PP-Fr variando entre 13\% e 8\% (Figura 19B). 


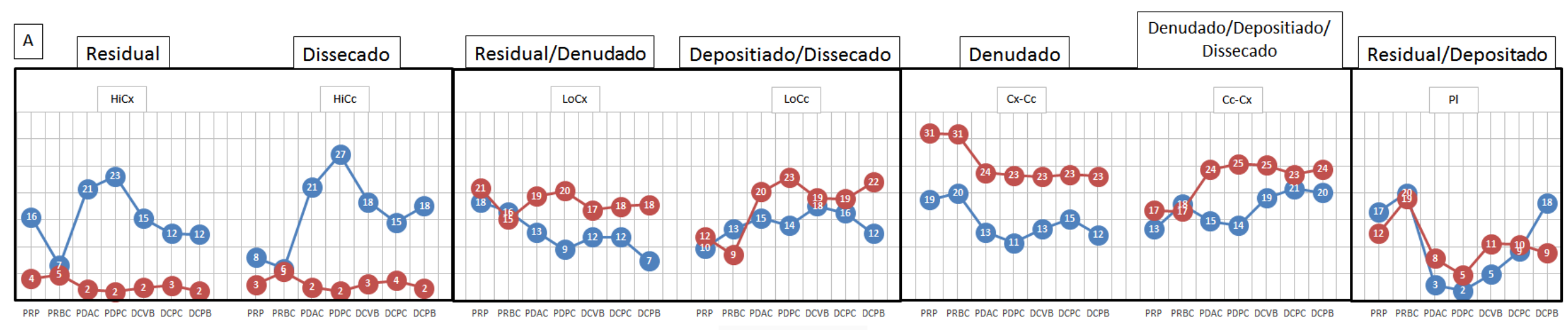

B

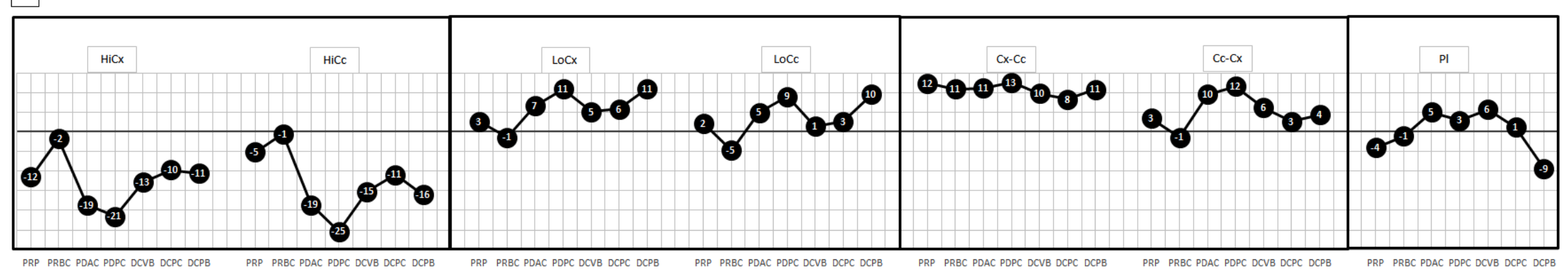

$\rightarrow$ (PP-Fr)

Figura 19 - Frequência (Fr \%) e Proporção de Patches (PP \%) das Formas de Terreno por Compartimento Geomorfológicos (A). Diferença entre a Proporção de Patches e Frequência (PP-Fr) das Formas de Terreno por Compartimento Geomorfológico (B). 
Nos Planalto Retocados, a Cx-Cc apresenta PP-Fr (12\%) no Planalto Retocado do Paranoá um pouco superior ao Planalto Retocado do Bambuí-Canastra (PP-Fr: 11\%), indicando mais fragmentos dessa forma no PRP (Figura 19B). Essa pequena variação é decorrente do avanço da denudação e dissecação que o Planalto Retocado BambuíCanastra (Figura 17) apresenta, aumentando assim a frequência dessa classe (Figura 19A). Nos Planaltos Dissecados, a Cx-Cc apresenta a maior variação entre a proporção de patches e a frequência, destacando o Planalto Dissecado Paranoá-Canastra (PP-Fr: 13\%) (Figura 19A). A Cx-Cc neste planalto está associada às fases mais denudadas da HiCx o que não é muito comum nesse compartimento decorrente da elevada dissecação do relevo com contato abrupto entre a HiCx e a HiCc.

Nas Depressões Cársticas, a Cx-Cc apresenta o mesmo valor de proporção de patches (23\%) para todos os compartimentos, variando apenas a frequência desta forma. Foi registrado o menor valor de PP-Fr na Depressão Cárstica Paranoá-Canastra (8\%), o maior valor de PP-Fr na Depressão Cárstica Paranoá-Bambuí (11\%) e o valor intermediário de PP-Fr na Depressão Cárstica Vazante-Bambuí (10\%) (Figura 19B). A fragmentação da $\mathrm{Cx}-\mathrm{Cc}$ está associada a denudação do relevo residual LoCx e ao avanço das frentes de recuo nas cabeceiras de drenagem (Figura 17 e Anexo 1). Na Depressão Cárstica Paranoá-Canastra a forma Cx-Cc é menos fragmentada decorrente da integração dos interflúvios denudados (Figura 17 e Anexo 1). Na Depressão Cárstica ParanoáBambuí, a forma $\mathrm{Cx}-\mathrm{Cc}$ está mais espalhada na superfície aplainada, ocorrendo pontualmente o que influencia na maior fragmentação (Figura 17 e Anexo 1). Em áreas mais serranas, próximas ao Planalto Retocado Bambuí-Canastra, a Cx-Cc aparece como interflúvios baixos e denudados com formas mais integradas. Na Depressão Cárstica Vazante-Bambuí, a forma Cx-Cc também está associada aos interflúvios mais denudados, porém mais fragmentado do que na Depressão Cárstica Paranoá-Canastra.

A Cc-Cx apresenta maior variação do comportamento de $\mathrm{PP}-\mathrm{Fr}$ em relação à CxCc (Figura 19B). Nos Planaltos Retocados a frequência e a proporção de patches apresentam valores próximos. Ambos compartimentos apresentam a mesma proporção de patches para a Cc-Cx (PP: 17\%). Entretanto, no Planalto Retocado Bambuí-Canastra o valor de PP-Fr (-1\%) é negativo decorrente da frequência superior à proporção de patches, o que resulta em formas menos fragmentadas. No Planalto Retocado do Paranoá essas formas são menos frequentes o que atesta valor positivo da PP-Fr (3\%). A Cc-Cx 
nos Planaltos Retocados são formas adjacente à LoCc conforme apresentado anteriormente, associadas aos canais menos encaixados ou pequenas depressões (Figura 17 e Anexo 1). O Planalto Retocado do Paranoá apresenta uma drenagem anelar pouco encaixada influenciada pelo domo estrutural e apresenta depressões pontuais, o que torna essa classe mais espalhada no compartimento. No Planalto Retocado Bambuí-Canastra essas formas são mais contínuas decorrente do nível de dissecação mais avançado promovendo uma $\mathrm{Cc}-\mathrm{Cx}$ menos fragmentada (Figura 17 e Anexo 1).

Nos Planalto Dissecados, a Cc-Cx apresenta a maior diferença entre a proporção de patches e a frequência, sempre com valores de proporção de patches superiores (Figura 19A). O Planalto Dissecado Paranoá-Canastra apresenta os valores mais positivos de PP-Fr (12\%), o que confere a maior fragmentação (Figura 19B). No Planalto Dissecado Araxá-Canastra, a forma Cc-Cx é mais frequente (Fr: 15\%) e apresenta a menor proporção de patches (PP: 24\%), resultando em PP-Fr menor (10\%). Nesse sentido, o Planalto Dissecado Araxá-Canastra apresenta forma Cc-Cx ligeiramente menos fragmentada dentre os Planaltos Dissecados. Esta forma está associada aos vales abertos, às rampas deposicionais que surgem abaixo das chapadas preservadas. No Planalto Dissecado Paranoá-Canastra, esses modelados são mais raros decorrentes da elevada frequência da HiCc caracterizando relevos dissecados (Figura 17 e Anexo 1).

Nas Depressões Cársticas, a proporção de patches apresenta valor superior a frequência, gerando sempre valores positivos de PP-Fr (Figura 19). A maior proporção de patches e a menor frequência são registradas na Depressão Cárstica Vazante-Bambuí. Assim, o compartimento apresenta $\mathrm{Cc}-\mathrm{Cx}$ mais fragmentado dentre as depressões com 6\% de PP-Fr (Figura 19B). Essa fragmentação está associada a denudação incipiente dos patamares adjacentes ao Planalto Retocado Bambuí-Canastra, tornando essa paisagem mais heterogênea (Figura 17 e Anexo 1). Essas formas se tornam mais contínuas na Depressão Cárstica Paranoá-Canastra, pois apresentam a menor variação de PP-Fr (3\%) (Figura 19B). Esse compartimento é mais dissecado com $\mathrm{Cc}-\mathrm{Cx}$ formando canais parciais interligados e longos depósitos no sopé de relevos residuais (Figura 17 e Anexo 1). Na Depressão Cárstica Paranoá-Bambuí a forma Cc-Cx apresenta PP-Fr de $4 \%$ com canais parcialmente dissecados que erodem principalmente as superfícies aplainadas. Essa forma também está fragmentada nos patamares próximos do Planalto Retocado Bambuí-Canastra, formando rampas curtas (Figura 17 e Anexo 1). 
A forma Pl está presente em todos compartimentos em arranjos específicos. A frequência apresenta valores superiores à proporção de patches no Planalto Retocado do Paranoá, Planalto Retocado Bambuí-Canastra e na Depressão Cárstica Paranoá-Bambuí (Figura 19A). Essa FT é mais fragmentada no Planalto Retocado Bambuí-Canastra onde a forma representa relevo residual e depósitos abaixo dos interflúvios (Figura 17 e Anexo 1). Nesse planalto PP-Fr apresenta a menor variação (-1\%) (Figura 19B). Na Depressão Cárstica Paranoá-Bambuí, a superfície aplainada apresenta a maior continuidade na paisagem (Figura 17 e Anexo 1). A frequência da forma Pl nessa depressão é menor do que nos Planaltos Retocados (Figura 19A), mas apresentam uma PP-Fr (-9\%) com a maior variação decorrente da menor proporção de patches (Figura 19B).

Nos Planaltos Dissecados, Araxá-Canastra e Paranoá-Canastra, e nas Depressões Cársticas, Vazante-Bambuí e Paranoá-Canastra, a proporção de patches apresenta valor superior a frequência. Nos planaltos, a forma Pl é mais fragmentada no Planalto Dissecado Araxá-Canastra onde a variação do PP-Fr (5\%) é maior do que no Planalto Dissecado Paranoá-Canastra (PP-Fr: 3\%) (Figura 19B). Apesar de mais frequente no Planalto Dissecado Araxá-Canastra (Figura 19A), essa forma está mais espalhada no compartimento, em relevo residual e depósitos abaixo dos rebordos (Figura 17 e Anexo 1). No Planalto Dissecado Paranoá-Canastra a forma Pl são menos frequentes (Figura 19A) mas ocorrem em setores pontuais decorrente da elevada dissecação desse planalto (Figura 17). A Depressão Cárstica Vazante-Bambuí apresenta forma Pl mais fragmentada dentre todos os compartimentos com valor de PP-Fr de 6\%. A forma Pl nessa depressão está ligada a denudação incipiente do relevo residual, aparecendo entre as serras alinhadas como pequenos depósitos associados à $\mathrm{Cx}-\mathrm{Cc}, \mathrm{Cc}-\mathrm{Cx}$ e LoCc (Figura 17 e Anexo 1). A Depressão Cárstica Paranoá-Canastra apresenta valor de proporção de patches ligeiramente superior a frequência o que resulta em um PP-Fr de 1\%, demonstrando que nesse compartimento o Pl é menos fragmentado quando comparada com os Planaltos Dissecados e com a Depressão Cárstica Vazante-Bambuí.

\subsection{3. Índice Geomorfométrico de Denudação}

No modelo de etchplanação (Thomas 1974, 1994), a denudação de um relevo aplainado pode gerar diversos conjuntos de FT. De maneira geral, esses conjuntos são formados por relevos convexos, planos, côncavos e convexo-côncavo (Eschenbrenner, 
1988) a depender do estágio de evolução do etchplano e dos fatores que compõe a equação do manto de intemperismo (Migon, 2013). Thomas (1994) apresenta um modelo que varia entre um etchplano com manto de intemperismo preservado e uma etchsuperfície onde o perfil foi totalmente removido. $\mathrm{Na}$ representação do modelo é possível inferir que a remoção constante do manto de intemperismo torna a paisagem cada vez mais dissecada, consequentemente fragmentada decorrente do balanço que existe entre o relevo residual e as porções mais denudadas.

A morfologia do relevo residual no processo de etchplanação será sempre um relevo suave de baixa amplitude topográfica ou um relevo ligeiramente convexo. O relevo suave como um residual está associado às porções que remetem aos Etchplanos Mantados ou Laterizados ou até mesmo os Etchplanos Dissecados, quando apresentam mesas e chapadas residuais (Thomas, 1974). Esse relevo de baixa amplitude topográfica ainda pode ser produto da denudação, formando rampas abaixo de relevo residual convexo em concordância com Etchplanos Parcialmente Denudados. Além disso, também pode formar superfícies aplainadas em depressões que podem estar relacionadas com Etchplanos Pedimentados e/ou Etchplanos Cobertos. Dentro desse contexto, relevos suaves serão sempre matrizes (chapadas, mesas, depressão aplainada, rampas aplainadas) da dissecação enquanto que a sua ausência sugere taxas elevadas de dissecação, revelando uma alternância entre relevos convexos e côncavos nos planaltos dissecados. Essa dinâmica pode ser avaliada pela frequência e pela proporção de número de patches de FTs de cada compartimento, considerando a diferença entre as duas medidas.

A diferença apenas indica quais são as FTs mais fragmentadas em um determinado compartimento. Para avaliar os estágios que se encontram os compartimentos é preciso elaborar um índice que considere a relação entre o relevo residual plano ou convexo e o relevo dissecado composto por formas côncavas. Nesse sentido, é proposto o Índice Geomorfométrico de Denudação (IGD) construído a partir da relação entre os relevos convexos $(\mathrm{Cx}=\mathrm{HiCx}, \mathrm{LoCx}, \mathrm{Cx}-\mathrm{Cc})$ e côncavos $(\mathrm{Cc}=\mathrm{HiCc}, \mathrm{LoCc}$ e Cc-Cx) e entre os relevos planos $(\mathrm{Pl})$ e côncavos $(\mathrm{Cc})$ tanto para a frequência quanto para a proporção de patches (Figura 20). 


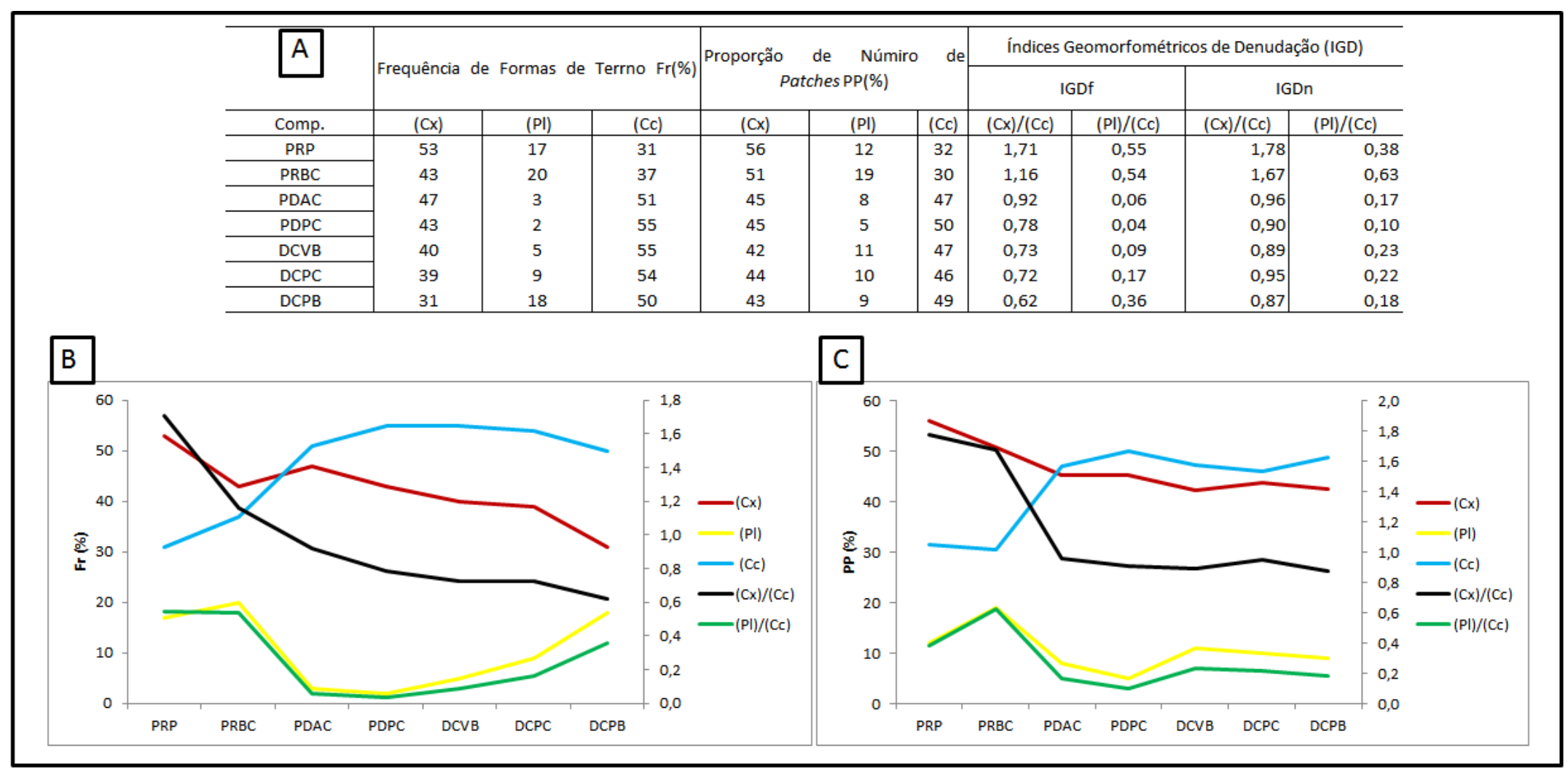

Figura 20 - Tabela de Frequência (Fr \%) e de Proporção de Patches (PP \%) de relevos convexos (Cx), planos (Pl) e côncavos (Cc) e Índice Geomorfométrico de Denudação (IGD) calculada pela razão entre o Cx e Cc da frequência (f) e da proporção de patches (n) e pela razão entre o Pl e Cc da frequência (f) e da proporção de patches (n) por compartimento (A). Gráfico de frequência (Fr \%) de relevos Cx, Pl e Cc; IGDf Cx/Cc; e IGDf Pl/Cc por compartimento (B). Gráfico de proporção de patches (PP\%) de relevos $\mathrm{Cx}, \mathrm{Ple} \mathrm{Cc}$; IGDn Cx/Cc; e IGDn Pl/Cc por compartimento (C). 
As formas convexas são mais frequentes nos planaltos retocados (relevos menos denudados) enquanto que as formas côncavas são mais frequentes nos planaltos dissecados e nas depressões cársticas (relevos mais denudados). O IGD da frequência da relação entre relevos convexos e relevos côncavos (IGDf $\mathrm{Cx} / \mathrm{Cc}$ ) apresenta constante queda entre o Planalto Retocado do Paranoá e o Depressão Cárstica Paranoá-Bambuí (Figura 20A e 20B). A frequência de Pl será elevada nos planaltos retocados, baixa nos planaltos dissecados e elevada nas depressões cársticas (Figura 20A e 20B). É importante ter atenção na interpretação da frequência de $\mathrm{Pl}$, pois sua porcentagem apresenta grande variação de ganho e perda nos diferentes compartimentos. No estágio inicial (Etchplanos Mantados) e no estágio final (Etchplanos Pedimentados ou Cobertos), a porcentagem de formas Pl tende a ser próximas. Dessa forma, a curva do IGD da frequência da relação entre relevos planos e côncavos (IGDf $\mathrm{Pl} / \mathrm{Cc}$ ) apresenta a mesma tendência da curva de frequência do P1, porém com o aumento da frequência do $\mathrm{Cc}$, a curva IGDf $\mathrm{Pl} / \mathrm{Cc}$ revela a dissecação das depressões promovida pelos relevos côncavos.

Assim como a frequência, existe uma relação entre a proporção de patches e os relevos convexos, côncavos e planos (Figura 20A e 20C). A proporção de patches dos relevos convexos diminui progressivamente entre o Planalto Retocado do Paranoá e a Depressão Cárstica Vazante-Bambuí que em seguida volta a apresentar um ligeiro aumento (Figura 20A e 20C). Diferentemente do gráfico da frequência, a curva do relevo côncavo aumenta abruptamente a partir dos Planaltos Dissecados em direção às depressões, que em seguida se mantem constante com valores maiores do que os valores de proporção de patches do relevo convexo (Figura 20A e 20C). Esse contraste entre relevos convexos e côncavos dos Planaltos Retocados e Dissecados influencia diretamente o IGD de proporção de patches desses relevos (IGDn $\mathrm{Cx} / \mathrm{Cc}$ ), apresentando queda brusca entre essas unidades. Já o relevo plano apresenta uma curva de proporção de patches similar à curva da frequência. A única diferença está na diminuição da proporção de patches do relevo plano entre a Depressão Cárstica Vazante-Bambuí e a Depressão Cárstica Paranoá-Bambuí, enquanto que a frequência desse relevo aumenta (Figura 20). Essa diferença influencia o IGD da proporção de patches da relação entre o relevo plano e côncavo (IGDn Pl/Cc) que tende a diminuir entre a Depressão Cárstica Vazante-Bambuí e a Depressão Cárstica Paranoá-Bambuí, indicando que os relevos suaves de baixa amplitude topográfica estão cada vez menos fragmentados. 
O estágio de evolução geomorfológica está intrinsicamente relacionado com a proporção de patches de relevo plano, convexo e côncavo. Diferentemente da frequência que é determinada a partir do tamanho de sua área em relação à área do compartimento, o número de patches se baseia na contagem simples de fragmentos das classes FTs, independente do seu tamanho, perímetro e área. Contudo o seu resultado serve de base para uma compreensão mais complexa do arranjo das FTs, considerando o tamanho (MPS, PSSD e MPE), densidade (PD), complexidade (MPAR) e diversidade (SHDI). Apenas o ED não utiliza o número de patches para sua medida.

\subsubsection{Análise Multivariada das Landscape Metrics}

A Tabela 3 apresenta o resultado das Landscape Metrics. As interpretações da ACP foram feitas com os dados desse resultado baseado na $1^{\circ}$ e $2^{\circ}$ componente principal, que explicam 86,95\% da variância dos 6 parâmetros dos 7 compartimentos em diferentes estágios de evolução geomorfológica. De acordo com a literatura, o ideal é que as componentes interpretadas expliquem um mínimo de $80 \%$ da variância dos dados (Manly, 2008). As métricas com maior porcentagem de contribuição nas componentes são em ordem decrescente: PD (13,95\%), MPS (13,62\%), ED (13,34\%), SHDI (12,80\%), MPE, (12,37\%), MPAR (10,79\%) e PSSD (10,09\%). As métricas MPS, MPE, MPAR e PSSD determinam os Planaltos Retocados (PRP e PRBC), as métricas PD e ED os Planaltos Dissecados (PDAC, PDPC) e a métrica SHDI as Depressões Cársticas (DCVB, DCPC e DCPB) (Figura 21).

Tabela 3 - Variação das Landscape Metrics por Unidade Geomorfológica (Unit. Geo.) e por Compartimento Geomorfológico (Comp. Geo.).

\begin{tabular}{c|c|c|c|c|c|c|c|c}
\hline Unit. Geo. & Comp. Geo. & SHDI & MPAR (ha) & ED (m/ha) & PD (patch/100ha) & MPE (m/patch) & MPS (ha) & PSSD (ha) \\
\hline Planalto & PRP & 1,91 & 831,1 & 97,2 & 4,4 & 2222,2 & 22,9 & 106,2 \\
Retocado & PRBC & 1,86 & 599,2 & 100,5 & 3,3 & 3051,3 & 30,4 & 116,3 \\
\hline Planalto & PDAC & 1,85 & 342,5 & 136,9 & 10,3 & 1367,0 & 10,0 & 48,6 \\
Dissecado & PDPC & 1,78 & 432,5 & 140,4 & 14,4 & 1020,1 & 7,3 & 57,1 \\
\hline \multirow{2}{*}{ Depressão } & DCVB & 1,88 & 333,4 & 137,5 & 9,9 & 1422,6 & 10,3 & 47,6 \\
Cásrtica & DCPC & 1,92 & 357,7 & 125,1 & 7,8 & 1644,2 & 13,1 & 67,3 \\
& DCPB & 1,90 & 342,0 & 102,5 & 6,5 & 1602,5 & 15,6 & 136,8 \\
\hline
\end{tabular}

$\mathrm{O}$ resultado da $\mathrm{ACP}$ apresenta a tendência das métricas baseadas em tamanho (size) do fragmento (MPS, MPE, PSSD) e em complexidade (MPAR) na compreensão dos planaltos retocados enquanto que as métricas baseadas em densidade (density) (PD e 
ED) na compreensão dos planaltos dissecados. As métricas que representam tamanho e densidade estão localizados em extremos (Figura 21). A métrica que expressa diversidade (diversity) (SHDI) explica quase que exclusivamente as depressões cársticas, principalmente a Depressão Cárstica Paranoá-Bambuí. Observa-se que em depressões mais dissecadas e menos aplainadas (Depressão Cárstica Vazante-Bambuí e Depressão Cárstica Paranoá-Canastra), também se associam as métricas de densidade (Figura 21).

Essa organização dos parâmetros indica a pré-disposição da métrica de fragmentação em explicar diferentes estágios de evolução geomorfológica. Cada métrica estimada dos compartimentos geomorfológicos (Landscape Metrics) tem sua base de cálculo nas formas convexas ( $\mathrm{HiCx}$, LoCx e Cx-Cc), nas formas côncavas (HiCc, $\mathrm{LoCc}$ e $\mathrm{Cc}-\mathrm{Cx}$ ) e na forma plana (Pl). Nesse sentido é possível entender qual o conjunto de formas contribui mais para as Landscape Metrics por meio das Class Metrics.

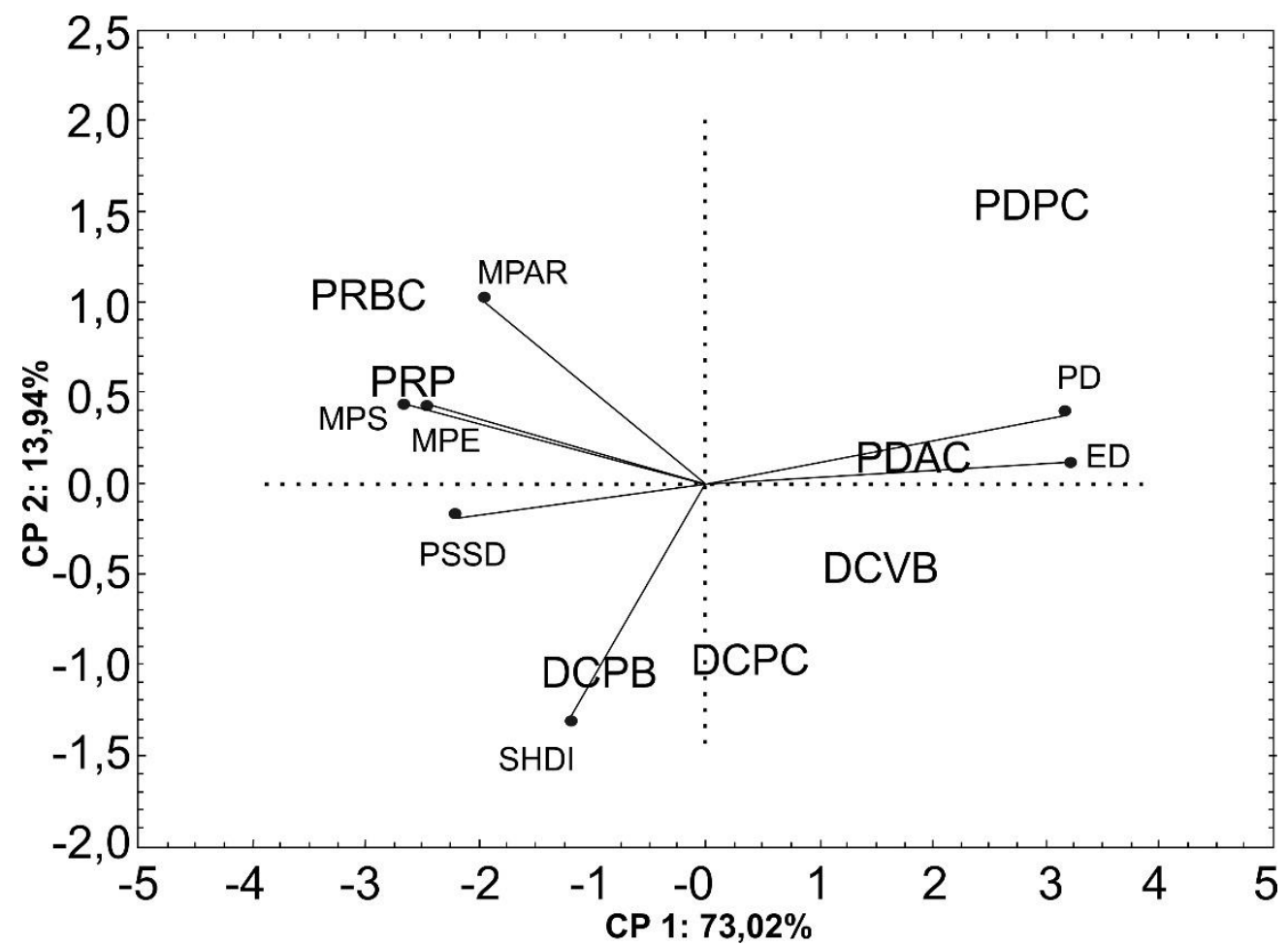

Figura 21 - Resultado da Análise de Componentes Principais das Landscape Metric de fragmentação por compartimento geomorfológico.

O cálculo do SHDI é baseado em Shannon e Weaver (1949). A métrica é usada como um índice relativo para comparar diferentes paisagens ou a mesma paisagem em 
diferentes épocas (McGarigal, 2014). É a única métrica utilizada na ACP que compõe exclusivamente as Landscape Metrics. O valor deste índice representa a variação da diversidade por patch, ou seja, quanto maior é o valor, maior é a diversidade de patches (diferentes tipos de FTs) no compartimento, ou, por outro lado, a distribuição proporcional entre os tipos de patches torna-se mais equitativa. A ACP sugere que essa métrica determina as Depressões Cársticas. Entretanto, também foram registrados altos valores SHDI nos Planaltos Retocados, em especial no Planalto Retocado do Paranoá. A Depressão Cárstica Paranoá-Canastra é o compartimento que apresenta o maior valor $(1,92)$ seguido pelo Planalto Retocado do Paranoá $(1,91)$, Depressão Cárstica ParanoáBambuí $(1,90)$, Depressão Cárstica Vazante-Bambuí $(1,88)$ (Tabela 3). Essa métrica indica que nos extremos da evolução geomorfológica, ou seja, no etchplano mais preservado e no mais denudado existe mais diversidade de patches.

\subsubsection{Fragmentação das Classes Metrics}

A Tabela 4 apresenta o resultado de fragmentação das classes de FTs, além da Proporção de Patches e da Frequência já explanadas. Primeiramente, é possível determinar qual relevo (convexo ou côncavo) contribui mais para a complexidade, tamanho, e densidade ao ser conferida a soma de todas as formas convexas $(\mathrm{Cx}=\mathrm{HiCx}$, LoCx, $\mathrm{Cx}-\mathrm{Cc})$ e côncavas $(\mathrm{Cc}=\mathrm{HiCc}$, LoCc e $\mathrm{Cc}-\mathrm{Cx})$. Observa-se, também, que o resultado das Class Metrics apresenta geralmente um padrão de distribuição de valores máximos e mínimos de acordo com os pares de FTs: HiCx e HiCc; LoCx e LoCc; Cx-Cc e Cc-Cx.

O MPAR representa uma das medidas mais comuns de complexidade de forma. Baseiam-se na quantidade relativa de perímetro por unidade de área, geralmente indexado na relação perímetro-área. De maneira geral, os valores mais elevados significam maior complexidade de forma ou menor equivalência com a geometria euclidiana (McGarigal, 2014).

A complexidade das formas tende a ser maior nos relevos côncavos. Apenas na Depressão Cárstica Paranoá-Canastra o valor de MPAR dos convexos (943 ha) supera o valor de MPAR dos côncavos (907 ha) (Tabela 4). Nos Planaltos Retocados e Dissecados, na Depressão Cárstica Vazante-Bambuí e na Depressão Cárstica Paranoá- 
Canastra a forma que apresenta os maiores e os menores valores de MPAR estão sempre localizados respectivamente nos pares $\mathrm{Cx}-\mathrm{Cc}$ e $\mathrm{Cc}-\mathrm{Cx}$, e HiCx e $\mathrm{HiCc}$.

As formas $\mathrm{Cx}-\mathrm{Cc}$ e $\mathrm{Cc}-\mathrm{Cx}$ são as classes de transição entre o relevo residual e o relevo dissecado. Nesse sentido, podem representar diversas formas denudadas, dissecadas, deposicionais em diferentes posições topográficas do compartimento e aumentar a complexidade do desenho do polígono. A HiCx e a HiCc representam um par de extremos geomorfológicos. A primeira representando o relevo residual que ainda não foi denudado e dissecado e a segunda apresenta a forma resultante do processo de denudação e dissecação (Figura 17 e Anexo 1).

Na Depressão Cárstica Paranoá-Bambuí, os pares que apresentam os maiores e os menores valores de MPAR, respectivamente, são as LoCx e LoCc, e as HiCx e HiCc. A LoCx representa tanto as porções denudadas do relevo residual quanto um relevo local dentro da superfície aplainada, elevando a complexidade dessa forma. A LoCc representa depósitos no sopé das escarpas no contato com o Planalto Retocado do Paranoá, canais parcialmente dissecados na superfície aplainada e nos setores mais dissecados adjacentes ao Planalto Retocado Bambuí-Canastra (Figura 17 e Anexo 1).

A complexidade da forma P1 aumenta dos Planaltos Retocados aos Planaltos Dissecados (Tabela 4). No Planalto Retocado do Paranoá essa forma é representada em grande parte pelo relevo residual de chapadas nos flancos do semidomo de Brasília. No Planalto Retocado Bambuí-Canastra as chapadas também são representadas por estas formas, porém estão presentes nas rampas retilíneas abaixo dos interflúvios, normalmente nas vertentes mais extensas do Rio Jardim. Nos Planaltos Dissecados, a forma Pl não é representativa. No Planalto Dissecado Araxá-Canastra é encontrada em chapadas residuais e como produto da denudação diferencial, formando superfícies aplainadas abaixo dos rebordos, principalmente ao longo do Rio São Bartolomeu. No Planalto Dissecado Paranoá-Canastra ocorre principalmente em vales abertos no setor NE do compartimento. Além disso, pequenos patches são identificados em todo compartimento (Figura 17 e Anexo 1). Nas Depressões Cársticas, a forma Pl é mais complexa na Depressão Cárstica Vazante-Bambuí e apresenta valores próximos de MPAR na Depressão Cárstica Paranoá-Canastra e na Depressão Cárstica Paranoá-Bambuí. A maior complexidade desta forma na Depressão Cárstica Vazante-Bambuí pode estar relacionada ao aplainamento pouco expressivo do relevo. 
As métricas de densidade (PD e ED) determinam os Planaltos Dissecados de acordo com a análise de principal componente (Figura 21). Entretanto, apresentam o mesmo padrão para todos os compartimentos com os maiores valores nos pares $\mathrm{Cx}-\mathrm{Cc} \mathrm{e}$ $\mathrm{Cc}-\mathrm{Cx}$, e os menores valores no $\mathrm{HiCx}$ e $\mathrm{HiCc}$ (Tabela 4). Algumas diferenças ainda podem ser verificadas. Os Planaltos Retocados constituem a única unidade geomorfológica que apresenta a métrica ED com maior contribuição de relevos convexos decorrente do valor de $\mathrm{Cx}-\mathrm{Cc}$ superior ao valor de $\mathrm{Cc}-\mathrm{Cx}$ (Tabela 4). Nos Planaltos Dissecados e Depressões Cársticas a contribuição dos relevos côncavos sempre será maior, tanto para o PD, quanto para o ED. Essa informação está diretamente ligada com a frequência e a proporção de patches que são sempre maiores nos relevos côncavos dos Planaltos Dissecados e das Depressões Cársticas, e sempre maiores nos relevos convexos dos Planaltos Retocados (Tabela 4). Entretanto, é importante esclarecer que os maiores valores de $\mathrm{PD}$ e $\mathrm{ED}$ nos pares $\mathrm{Cx}-\mathrm{Cc}$ e $\mathrm{Cc}-\mathrm{Cx}$ refletem a fragmentação dessas formas nos Planaltos Dissecados decorrente dos contatos abruptos entre o HiCx e HiCc (Figura 17 e Anexo 1). Os pares $\mathrm{Cx}-\mathrm{Cc}$ e $\mathrm{Cc}-\mathrm{Cx}$ são as formas menos frequentes, mas as que apresentam a maior proporção de patches para essas unidades (Tabela 4).

A métrica PSSD é a que menos contribui para a análise de principal componente (Figura 21), mas ainda assim, é um importante parâmetro a ser observado. Representa o quanto de variação ocorre no tamanho dos polígonos em relação à média da população para um compartimento geomorfológico. Um baixo PSSD indica que os polígonos possuem tamanhos similares dentro do mesmo compartimento com possível equilíbrio entre as classes de formas, enquanto que altos valores de PSSD indicam alta variação no tamanho dos polígonos dentro do compartimento. Essa métrica, conjuntamente com as métricas MPE e MPS, registram a variação do tamanho do patch (MPS e PSSD) e do contorno (MPE).

Essas métricas apresentam um padrão inverso à complexidade no Planalto Retocado do Paranoá e nos Planaltos Dissecados. Os maiores valores estão localizados no relevo residual $\mathrm{HiCx}$ e no relevo dissecado $\mathrm{HiCc}$, enquanto que os menores valores estão nos pares $\mathrm{Cx}-\mathrm{Cc}$ e $\mathrm{Cc}-\mathrm{Cx}$. Ou seja, o relevo residual e dissecado apesar de menos complexo, registram a maior variação de tamanho (PSSD) com média elevada tanto para o tamanho do polígono (MPS) quanto para o seu contorno (MPE). A $\mathrm{Cx}-\mathrm{Cc}$ e a $\mathrm{Cc}-\mathrm{Cx}$ representam polígonos menores e com pequena variação do desvio padrão, medido pelo PSSD. 
O Planalto Retocado Bambuí-Canastra apresenta um arranjo específico das formas que mais contribuem para as métricas de tamanho. Nos relevos convexos a forma LoCx apresenta os maiores valores de PSSD e MPE. Destaca-se nesse compartimento o processo de denudação do relevo residual, caracterizando o desenvolvimento da LoCx abaixo da HiCx quando este está presente. Nesse sentido, quanto maior for a denudação de uma colina ou de um interflúvio, por exemplo, mais isolado e menor será o polígono do relevo residual HiCx, favorecendo o desenvolvimento da LoCx.

Nos relevos côncavos, destaca-se as formas $\mathrm{Cc}-\mathrm{Cx}$, LoCc e HiCc. A forma Cc-Cx apresenta o maior valor de PSSD e a forma $\mathrm{HiCc}$ o menor valor, exatamente o contrário do que ocorre no Planalto Retocado do Paranoá e nos Planaltos Dissecados. A variação de tamanho da $\mathrm{Cc}-\mathrm{Cx}$ e da HiCc está intimamente relacionada com o estágio de evolução desse planalto. O Planalto Retocado Bambuí-Canastra apresenta uma drenagem pouco encaixada o que favorece a baixa fragmentação da Cc-Cx (valor de 17,930\% para frequência, superior ao valor de $16,5 \%$ para a proporção de patches). Além disso, essa forma está presente no Planalto Retocado Bambuí-Canastra classificando relevos variados de diferentes tamanhos, que promove o aumento dos valores de PSSD. Apesar do maior valor de PSSD, observa-se que a $\mathrm{Cc}-\mathrm{Cx}$ apresenta o menor tamanho médio (MPS).

A HiCc representa a porção do relevo dissecado mais confinado, porém menos frequente, o que contribui para a explicação do menor valor de PSSD. Essa configuração setorizada da HiCc e formada por pequenos polígonos ainda influencia no menor valor de MPE (Tabela 4). Os maiores valores de MPE e MPS são registrados na LoCc. Esta forma está associada às drenagens pouca escavadas e aos vales abertos recorrentes no Planalto Retocado Bambuí-Canastra. Apresenta ainda baixa fragmentação (valor de $13,244 \%$ para frequência, superior ao valor de $8,5 \%$ para a proporção de patches), influenciando assim nos valores de MPE e MPS.

A forma Pl apresenta os maiores valores nos Planaltos Retocados (Tabela 4). A maior variação de PSSD está registrada no Planalto Retocado do Paranoá, e os maiores valores de MPS e MPE estão registrados no Planalto Retocado Bambuí-Canastra. Essa configuração atesta os diferentes estágios de evolução geomorfológica. O Planalto Retocado do Paranoá é o compartimento mais elevado e o menos dissecado, e por isso apresenta relevo residual plano de chapadas, mas ao mesmo tempo também apresenta 
localmente rampas retilíneas abaixo dos interflúvios, que influencia no valor de PSSD (Tabela 4). O Planalto Retocado Bambuí-Canastra é um compartimento mais denudado que o Planalto Retocado do Paranoá. As rampas são mais extensas e formam polígonos maiores (MPS) e com maiores contornos (MPE), alterando o valor de PSSD. Mesmo não sendo uma forma representativa nos Planaltos Dissecados, verifica-se que a forma Pl apresenta os maiores valores no Planalto Dissecado Araxá-Canastra (Tabela 4). Nesse caso deve-se à diferença de frequência dessa forma nesses compartimentos como já observado na análise da MPAR.

Nas depressões, os relevos convexos contribuem mais para o valor total de MPS na Depressão Cárstica Vazante-Bambuí e na Depressão Cárstica Paranoá-Canastra, e os relevos côncavos contribuem mais para o valor total de MPE em todos os compartimentos e para o valor total de MPS na Depressão Cárstica Paranoá-Bambuí (Tabela 4). Observase uma mudança no padrão dos pares de formas que contribuem mais para as métricas de tamanho com o avanço do aplainamento. A diferença se concentra sempre nos menores valores das métricas (Tabela 4). A Depressão Cárstica Vazante-Bambuí é a depressão menos aplainada e apresenta um padrão similar ao Planalto Retocado do Paranoá e aos Planaltos Dissecados, apenas diferindo no menor valor de PSSD para os relevos côncavos com destaque da LoCc (Tabela 4). A Depressão Cárstica Paranoá-Canastra apresenta o menor valor de MPE dos relevos convexos na forma LoCx (Tabela 4). A Depressão Cárstica Paranoá-Bambuí é o compartimento mais aplainado e apresenta os menores valores de PSSD, MPE, MPS registrados na LoCx para relevos convexos e na LoCc para os relevos côncavos (Tabela 4).

Nesse sentido, a LoCx e a LoCc nessas depressões parecem ser as formas mais susceptíveis ao aplainamento. A evolução desses compartimentos difere dos planaltos por apresentarem superfície plana no mesmo ou próximo do nível de base local do compartimento. A formação dessas superfícies resulta na denudação quase que completa do relevo residual menos resistente ao intemperismo onde se concentra a forma LoCx. No caso da LoCc é preciso lembrar que relevos côncavos necessitam de amplitude de relevo para serem classificados, nesse sentido a denudação completa do relevo residual influencia diretamente na presença/ausência do relevo côncavo. Com relação a forma $\mathrm{Pl}$, observa-se um aumento progressivo de todas as métricas que medem o tamanho do polígono (PSSD e MPS) o do contorno (MPE) da Depressão Cárstica Vazante-Bambuí à Depressão Cárstica Paranoá-Bambuí (Tabela 4). 
Tabela 4 - Class Metrics dos Compartimentos Geomorfológico. Maiores e menores valores das métricas dos relevos convexos $(\mathrm{Cx})$ e de relevo côncavos $(\mathrm{Cc})$ realçados. Valor total (TOTAL) do resultado das Class Metrics por compartimento. Valor total do resultado das Class Metrics dos relevos convexos (Total (Cx)) e côncavos (Total (Cc)) por compartimento.

\begin{tabular}{|c|c|c|c|c|c|c|c|c|c|c|c|}
\hline Unid. Geo. & Comp. Geo. & FT & NP & PP (\%) & $\operatorname{Fr}(\%)$ & $\operatorname{MPAR}(\mathrm{m} / \mathrm{ha})$ & PD(patch/100ha) & $\mathrm{ED}(\mathrm{m} / \mathrm{ha})$ & PSSD (ha) & MPE (m/patch) & MPS (ha) \\
\hline \multirow{20}{*}{$\begin{array}{c}\text { Planaltos } \\
\text { Retocados }\end{array}$} & \multirow{10}{*}{ PRP } & HiCx & 655 & 4,0 & 15,516 & 183 & 1742 & 8,3 & 256,6 & 4753 & 89,1 \\
\hline & & LoC $x$ & 3438 & 20,9 & 18,283 & 423 & 9146 & 19,0 & 98,0 & 2074 & 20,0 \\
\hline & & $C x-C c$ & 5107 & 31,1 & 18,718 & 581 & 13585 & 22,9 & 48,0 & 1687 & 13,8 \\
\hline & & $\mathrm{Cc}-\mathrm{Cx}$ & 2750 & 16,7 & 13,242 & 2612 & 7315 & 16,9 & 70 & 2315 & 18,1 \\
\hline & & LoCc & 1954 & 11,9 & 9,728 & 618 & 5198 & 12,8 & 95,4 & 2471 & 18,7 \\
\hline & & HiCc & 478 & 2,9 & 8,012 & 212 & 1272 & 5,5 & 137,1 & 4360 & 63,0 \\
\hline & & $\mathrm{PI}$ & 2054 & 12,5 & 16,500 & 304 & 5464 & 11,7 & 160,9 & 2136 & 30,2 \\
\hline & & TOTAL & 16436 & 100 & 100 & 4935 & 38258 & 97,2 & N/A & 19796 & 252,8 \\
\hline & & Total (Cx) & 9200 & 56 & 53 & 1187 & 10888 & 50 & N/A & 8514 & 123 \\
\hline & & Total (Cc) & 5182 & 32 & 31 & 3443 & 26099 & 35 & N/A & 9146 & 100 \\
\hline & \multirow{10}{*}{ PRBC } & HiCx & 752 & 4,8 & 6,531 & 198 & 1566 & 4,9 & 80,0 & 3160 & 41,7 \\
\hline & & LoC $x$ & 2382 & 15,1 & 16,448 & 468 & 4960 & 15,8 & 85,8 & 3190 & 33,2 \\
\hline & & $C x-C c$ & 4889 & 30,9 & 19,974 & 690 & 10180 & 22,6 & 65,7 & 2223 & 19,6 \\
\hline & & $\mathrm{Cc}-\mathrm{Cx}$ & 2615 & 16,5 & 17,930 & 1262 & 5445 & 21,3 & 168,9 & 3916 & 32,9 \\
\hline & & LoCc & 1345 & 8,5 & 13,244 & 297 & 2801 & 15,0 & 153,4 & 5368 & 47,3 \\
\hline & & HiCc & 844 & 5,3 & 5,906 & 223 & 1757 & 5,4 & 60,8 & 3077 & 33,6 \\
\hline & & $\mathrm{Pl}$ & 2989 & 18,9 & 19,968 & 318 & 6224 & 15,3 & 141,5 & 2462 & 32,1 \\
\hline & & TOTAL & 15816 & 100 & 100 & 3456 & 26708 & 100,5 & N/A & 23396 & 240 \\
\hline & & Total $(\mathrm{Cx})$ & 8023 & 51 & 43 & 1356 & 6526 & 43 & N/A & 8574 & 94 \\
\hline & & Total (Cc) & 4804 & 30 & 37 & 1781 & 18425 & 42 & N/A & 12360 & 114 \\
\hline \multirow{20}{*}{$\begin{array}{c}\text { Planaltos } \\
\text { Dissecados }\end{array}$} & \multirow{10}{*}{ PDAC } & HiCX & 1067 & 2,1 & 20,693 & 138 & 2066 & 11,6 & 166,8 & 5605 & 100,2 \\
\hline & & LoC $x$ & 10013 & 19,4 & 12,701 & 342 & 19388 & 23,2 & 24,3 & 1197 & 6,6 \\
\hline & & $C x-C c$ & 12289 & 23,8 & 12,675 & 358 & 23795 & 25,4 & 12,8 & 1069 & 5,3 \\
\hline & & $\mathrm{Cc}-\mathrm{Cx}$ & 12577 & 24,3 & 14,761 & 356 & 24353 & 29,1 & 28,0 & 1194 & 6,1 \\
\hline & & LoCC & 10454 & 20,2 & 15,297 & 341 & 20242 & 27,7 & 32,1 & 1368 & 7,6 \\
\hline & & $\mathrm{HiCc}$ & 1274 & 2,5 & 21,045 & 171 & 2467 & 14,0 & 191,4 & 5673 & 85,3 \\
\hline & & $\mathrm{Pl}$ & 4052 & 7,8 & 2,828 & 367 & 7846 & 5,9 & 12,0 & 754 & 3,6 \\
\hline & & TOTAL & 51726 & 100 & 100 & 2073 & 92311 & 136,9 & N/A & 16860 & 214,6 \\
\hline & & Total $(C x)$ & 23369 & 45 & 46 & 838 & 21454 & 60 & N/A & 7871 & 112 \\
\hline & & Total (Cc) & 24305 & 47 & 51 & 868 & 68390 & 71 & N/A & 8235 & 99 \\
\hline & \multirow{10}{*}{ PDPC } & HiCX & 603 & 1,6 & 23,096 & 116 & 2214 & 12,6 & 171,9 & 5689 & 104,3 \\
\hline & & LoC $x$ & 7635 & 20,4 & 9,489 & 366 & 28030 & 22,4 & 7,9 & 798 & 3,4 \\
\hline & & $\mathrm{Cx}-\mathrm{Cc}$ & 8734 & 23,3 & 10,719 & 466 & 32065 & 25,3 & 7,6 & 790 & 3,3 \\
\hline & & $\mathrm{Cc}-\mathrm{Cx}$ & 9531 & 25,4 & 13,895 & 535 & 34991 & 30,3 & 16,4 & 867 & 4,0 \\
\hline & & LoCc & 8587 & 22,9 & 13,901 & 388 & 31525 & 29,4 & 18,9 & 931 & 4,4 \\
\hline & & $\mathrm{HiCc}$ & 654 & 1,7 & 27,114 & 154 & 2401 & 16,2 & 359,3 & 6749 & 112,9 \\
\hline & & $\mathrm{PI}$ & 1746 & 4,7 & 1,786 & 428 & 6410 & 4,2 & 7,6 & 655 & 2,8 \\
\hline & & TOTAL & 37490 & 100 & 100 & 2453 & 131226 & 140,4 & N/A & 16479 & 235,2 \\
\hline & & Total $(C x)$ & 16972 & 45 & 43 & 948 & 30244 & 60 & N/A & 7277 & 111 \\
\hline & & Total (Cc) & 18772 & 50 & 55 & 1077 & 98581 & 76 & N/A & 8547 & 121 \\
\hline \multirow{30}{*}{$\begin{array}{c}\text { Depressões } \\
\text { Cársticas }\end{array}$} & \multirow{10}{*}{ DCVB } & HiCx & 216 & 2,4 & 15,244 & 159 & 2274 & 9,4 & 121,0 & 4155 & 67,0 \\
\hline & & LoC $x$ & 1548 & 16,9 & 11,765 & 347 & 16297 & 20,3 & 24,6 & 1244 & 7,2 \\
\hline & & $\mathrm{Cx}-\mathrm{Cc}$ & 2110 & 23,0 & 13,257 & 337 & 22214 & 25,1 & 13,5 & 1128 & 6,0 \\
\hline & & $\mathrm{Cc}-\mathrm{Cx}$ & 2311 & 25,2 & 19,059 & 345 & 24330 & 32,5 & 45,1 & 1336 & 7,8 \\
\hline & & LoCc & 1747 & 19,0 & 17,566 & 338 & 18392 & 28,1 & 40,0 & 1526 & 9,6 \\
\hline & & $\mathrm{HiCc}$ & 285 & 3,1 & 18,291 & 191 & 3000 & 12,8 & 159,2 & 4261 & 61,0 \\
\hline & & $\mathrm{Pl}$ & 967 & 10,5 & 4,819 & 348 & 10180 & 9,4 & 9,6 & 924 & 4,7 \\
\hline & & TOTAL & 9184 & 100 & 100 & 2065 & 86507 & 137,5 & N/A & 14574 & 163 \\
\hline & & Total $(C x)$ & 3874 & 42 & 40 & 843 & 18571 & 55 & N/A & 6527 & 80 \\
\hline & & Total (Cc) & 4343 & 47 & 55 & 873 & 64936 & 73 & N/A & 7124 & 78 \\
\hline & & HiCx & 735 & 2,8 & 12,440 & 160 & 2135 & 7,8 & 100,0 & 3642 & 58,3 \\
\hline & & LoC $x$ & 4586 & 17,5 & 11,748 & 376 & 13324 & 18,0 & 27,5 & 1350 & 8,8 \\
\hline & & $C x-C c$ & 6131 & 23,4 & 15,159 & 407 & 17813 & 24,2 & 22,3 & 1359 & 8,5 \\
\hline & & $\mathrm{Cc}-\mathrm{Cx}$ & 6127 & 23,4 & 20,782 & 381 & 17801 & 30,1 & 87,5 & 1691 & 11,7 \\
\hline & DCPC & LoCc & 4939 & 18,9 & 16,237 & 339 & 14350 & 24,0 & 41,1 & 1674 & 11,3 \\
\hline & dere & HiCc & 955 & 3,6 & 14,516 & 187 & 2775 & 10,2 & 149,2 & 3691 & 52,3 \\
\hline & & $\mathrm{Pl}$ & 2706 & 10,3 & 9,117 & 310 & 7862 & 10,7 & 95,8 & 1365 & 11,6 \\
\hline & & TOTAL & 26179 & 100 & 100 & 2160 & 76061 & 125,1 & N/A & 14771 & 162 \\
\hline & & Total (Cx) & 11452 & 44 & 39 & 943 & 33273 & 50 & N/A & 6351 & 76 \\
\hline & & Total (Cc) & 12021 & 46 & 52 & 907 & 34926 & 64 & N/A & 7056 & 75 \\
\hline & & HiCx & 294 & 1,7 & 12,254 & 136 & 1095 & 5,9 & 267,1 & 5361 & 111,9 \\
\hline & & LoC $x$ & 3055 & 17,8 & 7,309 & 358 & 11379 & 11,9 & 20,6 & 1044 & 6,4 \\
\hline & & $C x-C c$ & 3963 & 23,1 & 12,232 & 341 & 14761 & 18,1 & 22,2 & 1229 & 8,3 \\
\hline & & $\mathrm{Cc}-\mathrm{Cx}$ & 4194 & 24,4 & 20,069 & 355 & 15621 & 25,5 & 95,7 & 1633 & 12,8 \\
\hline & DCPB & LoCc & 3778 & 22,0 & 12,405 & 356 & 14072 & 19,4 & 36,6 & 1375 & 8,8 \\
\hline & & HiCc & 386 & 2,2 & 17,564 & 200 & 1438 & 9,3 & 376,6 & 6477 & 122,2 \\
\hline & & $\mathrm{PI}$ & 1509 & 8,8 & 18,166 & 316 & 5621 & 12,5 & 355,5 & 2219 & 32,3 \\
\hline & & TOTAL & 17179 & 100 & 100 & 2063 & 58366 & 103 & N/A & 19338 & 303 \\
\hline & & Total (Cx) & 7312 & 43 & 32 & 836 & 27235 & 36 & N/A & 7634 & 127 \\
\hline & & Total (Cc) & 8358 & 49 & 50 & 912 & 44454 & 54 & N/A & 9486 & 144 \\
\hline
\end{tabular}

\begin{tabular}{c|c|c|c}
$C x$ & Maiores valores $\quad C x$ & Menores valores
\end{tabular}

Cc Menores valores $\quad$ Cc $\quad$ Maiores valores 


\section{Capítulo 5 - DISCUSSÃO}

Diante do exposto, é possível traçar um paralelo entre os dados analisados e a evolução geomorfológica. Nos planaltos, o processo de denudação química foi elevado para que se chegasse a um aplainamento durante a primeira metade do Terciário (Braun, 1970; Ab'Saber, 1965; Noves Pinto, 1994; Martins et al., 2004b), onde o relevo permaneceu preservado com manto de intemperismo capeado por coberturas lateríticas (Naime et al., 2002; CPRM, 2008; Reatto et al., 2004), o que indica a presença de perfil de intemperismo profundo e desenvolvido (Büdel, 1957, Millot, 1983, Thomas, 1994). Na segunda metade do Terciário um novo ciclo de aplainamento teria sido desenvolvido associado ao aplainamento das superfícies abaixo dos interflúvios (Braun, 1970; CODEPLAN, 1984; Ab'Saber, 1965; Noves Pinto, 1994). A incisões das drenagens e a formação de canais são parte do processo erosivo atuou com maior velocidade que o processo químico no Cenozoico (Summerfield e Hulton, 1994; Galiart et al., 1999) mas que não foi capaz de dissecar completamente a superfície aplainada.

Nesse sentido, observa-se níveis de dissecação (incisão da drenagem) e denudação (remoção do manto de intemperismo) distinta para cada etchplano. Para Novaes Pinto (1987; 1994) o Planalto Retocado do Paranoá seria um Etchplano Paleogênico com relevo residual mais antigo. O Planalto Retocado Bambuí-Canastra apresentaria uma fase de etchplanação e outra de pedimentação. O relevo residual do Planalto Retocado BambuíCanastra seria um Etchplano Neogênico localizado predominantemente dentro da Bacia do Paraná, e as rampas aplainadas abaixo dos interflúvios dentro da Bacia do São Francisco são parte de Pedimentos Pleistocênicos. O Planalto Dissecado Araxá-Canastra representaria um Etchplano Neogênico decorrente da presença de chapadas e mesas residuais e abaixo dos rebordos, Pediplanos Pliopleistocênico e Pedimentos Pleistocênicos. Como o Planalto Dissecado Paranoá-Canastra não apresenta chapadas residuais, o relevo teria sido elaborado por pediplanação, guardando registros de Pediplano Pliopleistocênico e Pedimentos Pleistocênicos (Novaes Pinto, 1987; 1994). Martins et al., (2004b) baseado em Thomas (1974) interpreta a evolução como apenas um etchplano que teria sido denudado por intemperismo diferencial deixando os etchplanos em cotas distintas. As rampas aplainadas formadas abaixo dos interflúvios seriam antigos pedimentos pedogenizados. Nesse sentido, o aplainamento teria cessado na primeira 
metade do Terciário para que a denudação física atuasse de maneira predominante. Assim, o estágio de evolução que os compartimentos estudados, Planalto Retocado do Paranoá, Planalto Retocado Bambuí-Canastra, Planalto Dissecado Araxá-Canastra, Planalto Dissecado Paranoá-Canastra, Depressão Cárstica Vazante-Bambuí, Depressão Cárstica Paranoá-Canastra e Depressão Cárstica Paranoá-Bambuí, se encontram atualmente seria decorrente da denudação diferencial e do controle estrutural que a região está submetida com alternância de domos (Planaltos Retocados) e bacias estruturais (Planaltos Dissecados) e litologia mais susceptível ao intemperismo químico (Depressões Cársticas).

As depressões, Paranoá-Canastra e Paranoá-Bambuí, localizadas às margens do Planalto Retocado do Paranoá e a Depressão Cárstica Vazante-Bambuí a sul do Planalto Retocado Bambuí-Canastra também são explicadas por aplainamento do Terciário. Para Dantas et al., (2003) a Depressão Cárstica Paranoá-Canastra está relacionado com o aplainamento recente do Neógeno denominado de Pediplano Retocado com inselbergs (Dantas, 2002). Latrubesse e Carvalho, (2006) acreditam que a superfície da Depressão Cárstica Paranoá-Bambuí exibe extenso aplainamento com presença de crostas ferruginosas e sedimentos friáveis na forma de manto de lavagem da superfície de etchplanação. A Depressão Cárstica Vazante-Bambuí é composta por uma sucessão de superfícies aplainadas com diferentes estágios de dissecação decorrente da sua proximidade com o Planalto Retocado Bambuí-Canastra (Baptista et al., 2010).

Cada compartimento estudado apresenta especificidades do ponto de vista geológico, pedológico e de dissecação o que imprime uma dinâmica própria na taxa de denudação (von Blanckenburg, 2006). É importante salientar que na região o manto de intemperismo é poligenético, resultado da associação das condições paleoclimáticas e dos diferentes tipos de material de origem. Dessa maneira, a evolução do relevo parece se adequar a ideia de Martins (2000) e Martins et al., (2004b) que consideram o balanço entre o relevo convexo, plano e côncavo (Eschenbrenner, 1988) como estágios de denudação e dissecação a partir de apenas evento de etchplanação. Assim, a classificação das FTs é uma resultante do processo de denudação conjuntamente com a dissecação atrelada à resistência dos diferentes tipos de mantos de intemperismo elaborados em Período anterior (Thomas, 1974). 
Quando o intemperismo físico e químico está em equilíbrio, essa taxa de denudação é mediada pelo balanço da taxa de formação de solos (von Blanckenburg, 2006). Dentro desse contexto, é possível traçar uma hierarquia entre os estágios de evolução dos etchplanos de cada compartimento baseada nas especificidades geológicas, pedológicas e de dissecação, considerando o conjunto de regras de Thomas (1974; 1994), mas parametrizados pela PP-Fr, IGD e métricas de fragmentação (Figura 22). Para compreender os estágios de evolução é preciso comparar os compartimentos (Planalto Retocado do Paranoá, Planalto Retocado Bambuí-Canastra, Planalto Dissecado AraxáCanastra, Planalto Dissecado Paranoá-Canastra, Depressão Cárstica Vazante-Bambuí, Depressão Cárstica Paranoá-Canastra, Depressão Cárstica Paranoá-Bambuí) dentro de uma mesma unidade geomorfológica (Planaltos Retocados, Dissecados e Depressões Cársticas).

Assim colocado, os Planaltos Retocados são os etchplanos mais preservados da área de estudo. Localizados em cotas distintas apresentam diferenças geológicas, pedológicas e de dissecação, indicando diferentes níveis de denudação. O Planalto Retocado do Paranoá é o etchplano mais residual, pois é caracterizado por rochas psamíticas (Freitas-Silva e Campos, 1999) resistentes à denudação e está coberto por Latossolos Vermelhos (Reatto et al. 2004, Naime et al., 2002) nas chapadas residuais planas e convexas, e nas rampas retilíneas localizadas na parte interna do semidomo o que atesta a estabilidade desse etchplano (von Blanckenburg, 2006). Nesse estágio de evolução, o etchplano apresenta frequência de relevos convexos e planos muito superior aos relevos côncavos, resultando nos maiores valores de IGDf (Figura 22). Também apresenta maior proporção de patches de relevos convexos em relação aos côncavos com o maior IGDn (Figura 22), mas lembrando que os relevos residuais HiCx são mais contínuos na paisagem sempre com frequência maior do que a proporção de patches, resultando em valor negativo de PP-Fr e atestando a baixa fragmentação (Figura 19).

O Planalto Retocado Bambuí-Canastra é caracterizado por rochas pelíticas, menos resistentes ao intemperismo e capeado por coberturas lateríticas (Scislewski et al., 2002). Nos relevos residuais encontram-se Latossolos Vermelho-Amarelos (Reatto et al., 1999; 2004; Naime et al., 2002) mais sensíveis às oscilações do lençol freático, indicando que o perfil de solos dessas chapadas é menos profundo do que nas chapadas residuais do Planalto Retocado do Paranoá. Esse planalto teria perdido parte da sua cobertura pedológica pela denudação e depositado nas rampas retilíneas abaixo dos interflúvios. 
Esses depósitos profundos em ambiente estável foram pedogenizados (Martins et al., 2004b) e atualmente são classificados como Latossolos Vermelhos (Reatto et al., 1999; 2004; Naime et al., 2002). Essa hipótese parece ser coerente pelo fato do compartimento apresentar maior densidade de drenagem do que o Planalto Retocado do Paranoá (Dantas, 2002) abaixo das chapadas residuais nos limites da Bacia do Rio São Francisco.

O fato do Planalto Retocado Bambuí-Canastra estar mais denudado do que o Planalto Retocado do Paranoá reflete na baixa frequência do relevo residual HiCx com valor de proporção de patches próximo ao da frequência, resultando em uma PP-Fr negativa próxima de zero, o que influencia na fragmentação dessa classe. A denudação do relevo residual, $\mathrm{HiCx}$, reflete no aumento da continuidade da forma $\mathrm{LoCx}$ e $\mathrm{Cx}$-Cc no compartimento. A LoCx apresenta apenas no Planalto Retocado Bambuí-Canastra frequência superior à proporção de patches gerando um número negativo de PP-Fr (Figura 19). Quanto mais denudado e dissecado for o relevo residual em Planaltos Retocados mais frequente será o $\mathrm{Cx}-\mathrm{Cc}$ e nesse caso menos fragmentado conforme a PPFr para essa classe (Figura 19).

Além disso, a dissecação desse relevo é mais elevada, o que reflete no IGDf dos relevos convexos e planos em relação aos côncavos (IGDf $\mathrm{Cx} / \mathrm{Cc}$ e IGDf $\mathrm{Pl} / \mathrm{Cc}$ ) menor do que no Planalto Retocado do Paranoá (Figura 22). As formas côncavas nesse compartimento são destacadas pela LoCc associada à $\mathrm{Cc}-\mathrm{Cx}$ com proporção de patches menor que a sua frequência atestando a continuidade de canais e depressões nesse planalto. Fazendo um balanço da proporção de patches de todos os relevos convexos e côncavos, o IGDn com valor menor, mostra que esses relevos são menos fragmentados do que no Planalto Retocado do Paranoá. Ainda é importante destacar que o Planalto Retocado Bambuí-Canastra apresenta relevos residuais suaves e de baixa ampitide e depósitos localizados nas rampas retilíneas. Há um aumento da frequência e da proporção de patches com uma PP-Fr, mostrando que a Pl é ligeiramente mais fragmentada quando comparada com a do Planalto Retocado do Paranoá. Contudo, a proporção de patches de relevos côncavos diminui nesse compartimento, uma vez que a rede de drenagem está mais interligada. Assim, o IGDn da relação plano e côncavo (IGDn P1/Cc) é mais elevado do que o encontrado no Planalto Retocado do Paranoá.

O estágio de denudação e dissecação de cada etchplano dos Planaltos Retocados influencia na fragmentação das classes de FTs em arranjos específicos. Para esses 
etchplanos o tamanho do patch e do edge (MPS e PSSD, MPE) e a complexidade (MPAR) são as métricas mais determinantes (Tabelas 3 e Figura 21). As diferenças observadas entre o padrão dos valores máximos e mínimos na composição da métrica revelam o avanço da denudação, principalmente quando se é observado o aumento do valor de PSSD e MPE nas formas denudadas LoCx, e nas formas dissecadas/depositadas LoCc, ambas, do Planalto Retocado Bambuí-Canastra. Os relevos residuais HiCx se encontram com interflúvios mais estreitos, dando espaço para o desenvolvimento da LoCx abaixo topograficamente. Além disso, o avanço da dissecação corrobora para a formação de LoCc.

As classes que apresentam os maiores tamanhos são as formas residuais convexas, HiCx, e o relevo de dissecação, HiCc, no Planalto Retocado do Paranoá, tanto para o MPS, quanto para o MPE. No Planalto Retocado Bambuí-Canastra a forma denudada LoCx e a forma de dissecada/depositada LoCc são as maiores classes decorrentes da pouca fragmentação que essas formas têm nesse estágio de evolução. A Cx-Cc e a Cc-Cx são as classes que detém a maior complexidade nos Planaltos Retocados. Isso é decorrente dos relevos variados que essas classes podem representar.

Com todos esses parâmetros é possível dizer que o Planalto Retocado do Paranoá e o Planalto Retocado Bambuí-Canastra estão associados aos Etchplanos Laterizados ou Mantados decorrente de suas características residuais com pouca remoção do manto de intemperismo, mas levemente dissecados. Nesse caso, o Planalto Retocado BambuíCanastra apresenta um estágio de denudação mais avançado e com maior dissecação. Assim, o Planalto Retocado do Paranoá é classificado como Etchplano Mantado levemente dissecado e o Planalto Retocado Bambuí-Canastra como Etchplano Mantado dissecado.

Os Planaltos Dissecados são unidades mais denudadas do que os Planaltos Retocados. É composto basicamente da alternância entre HiCx e HiCc com frequências equiparadas (Figura 22). O Planalto Dissecado Araxá-Canastra é caracterizado por rochas pelíticas predominantemente. A cobertura laterítica que ocorre sobre chapadas e mesas residuais planas e convexas (Scislewski et al., 2002) apresentam Latossolos Vermelhos (Reatto et al., 1999; 2004; Mota et al., 2002). Abaixo dos rebordos erosivos, rampas retilíneas ou levemente convexas com transições mais suaves entre as FTs estão associadas aos Latossolos Vermelho-Amarelos (Reatto et al., 1999; 2004; Mota et al., 
2002). Onde o relevo é caracterizado por um contato abrupto entre as formas $\mathrm{HiCx}$ e HiCc normalmente ocorrem Cambissolos. Nesse contexto, observa-se uma relação solo-relevo que está submetida a uma denudação diferencial. Essa configuração indica que o Planalto Dissecado Araxá-Canastra é o estágio do etchplano mais preservado em relação ao Planalto Dissecado Paranoá-Canastra e por isso apresenta maior IGDf de convexos e planos em relação aos côncavos (IGDf Cx/Cc e IGDf P1/Cc). Entretanto, o relevo residual HiCx e o relevo dissecado HiCc do Planalto Dissecado Araxá-Canastra são mais fragmentados, pois apresentam os maiores valores de PP-Fr (menos negativos) dentre os Planaltos Dissecados (Figura 19). Isso é decorrente da influência das outras FTs que aparecem no compartimento mais pontualmente entre a HiCx e a HiCc. Se de um lado as formas HiCx e a HiCc são mais fragmentadas no Planalto Dissecado Araxá-Canastra em relação ao Planalto Dissecado Paranoá-Canastra, de outra, as formas LoCx, LoCc, Cx-Cc e Cc-Cx são mais contínuas no compartimento com menor valor de PP-Fr (Figura 19). Por fim, a pouca presença de forma Pl influencia em valores baixos de IGDf e IGDn, mas superiores aos valores apresentados no Planalto Dissecado Paranoá-Canastra (Figura 22). 


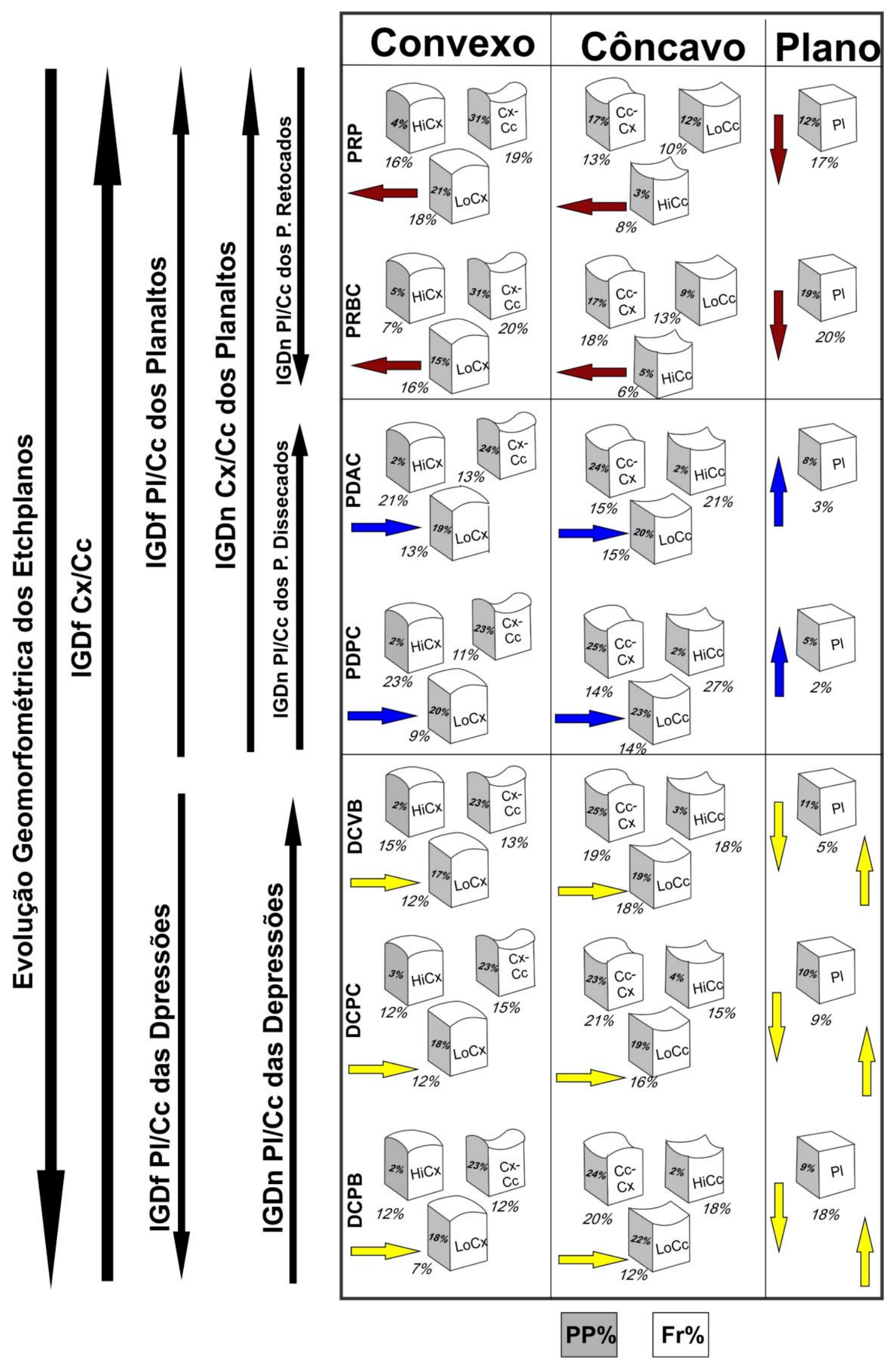

Figura 22 - Esquema apresentando a variação geomorfométrica dos etchplanos a partir do compartimento mais residual, Planalto Retocado do Paranoá (PRP), até a depressão 
mais aplainada, Depressão Cárstica do Paranoá-Bambuí (DCPB). Índice Geomorfométrico de Denudação (IGDf e IGDn) representado com setas verticais (cor preta) apontadas em direção aos maiores valores. Frequência (Fr\%) e Proporção de Patches (PP\%) dos relevos convexos e côncavos por compartimento representados com setas horizontais. Setas horizontais vemelhas apontadas para os relevos convexos com os maiores valores de Frequência (Fr\%) e Proporção de Patches (PP\%) no PRP e no PRBC. Setas verticais vermelhas indicando o aumento da Frequência (Fr\%) e da Proporção de Patches (PP\%) do PRP ao PRBC. Setas horizontais azuis apontadas para os relevos côncavos com os maiores valores de Frequência (Fr\%) e Proporção de Patches (PP\%) no PDAC e no PDPC. Setas verticais azuis indicando o aumento da Frequência (Fr\%) e Proporção de Patches (PP\%) do PDPC ao PDAC. Setas horizontais amarelas apontadas para os relevos côncavos com os maiores valores de Frequência (Fr\%) e Proporção de Patches (PP\%) nas DCVB, DCPC e DCPB. Setas verticais amarelas indicando o aumento da Frequência (Fr\%) do DCVB ao DCPB. Setas verticais amarelas indicando o aumento da Proporção de Patches (PP\%) do DCPB ao DCVB.

O Planalto Dissecado Paranoá-Canastra é caracterizado por rochas psamopelítica-carbonatadas, onde praticamente não existe coberturas lateríticas. Naime et al., (2002) mapeiam na região Cambissolos Háplicos e localmente Argissolos Vermelhos e Vermelho-Amarelos e pontualmente em vales abertos, Latossolos Vermelhos oriundos de depósitos. A presença de solos pouco desenvolvidos está associada ao relevo movimentado do compartimento com residuais serranos e de morros. Não há aplainamento nesse compartimento, apenas denudação e dissecação da paisagem.

Esse planalto ainda apresenta uma relação com as formas oposta do que foi apresentado no Planalto Dissecado Araxá-Canastra. A HiCx e a HiCc são mais frequentes e mais contínuas na paisagem decorrente dos valores mais negativos de PP-Fr. As outras formas ( $\mathrm{LoCx}$, LoCc, $\mathrm{Cx}-\mathrm{Cc}$ e $\mathrm{Cc}-\mathrm{Cc}$ ), além de serem menos frequentes estão espalhadas na paisagem com maior representatividade em setores específicos decorrente da denudação diferencial do relevo, principalmente na Unidade Pelito-Carbonatada do Grupo Paranoá às margens do Planalto Retocado do Paranoá. A fragmentação dessas formas influencia nos valores de IGDn de convexos em relação aos côncavos (IGDn $\mathrm{Cx} / \mathrm{Cc}$ ) que são menores no Planalto Dissecado Paranoá-Canastra quando comparadas ao Planalto Dissecado Araxá-Canastra. A forma Pl é praticamente inexistente no Planalto Dissecado Paranoá-Canastra e assim, apresenta os menores valores de IGDf e IGDn da 
relação de relevo plano com côncavos (IGDf Pl/Cc e IGDn Pl/Cc) dentre todos os compartimentos (Figura 22).

Esses etchplanos apresentam um arranjo de formas que é melhor determinada por métricas que representam densidade (PD e ED). As formas que mais contribuíram foram aquelas que apresentaram maior fragmentação de acordo com PP-Fr, que nesse caso são representados pela $\mathrm{Cx}-\mathrm{Cc}$ e a Cc-Cx, em seguida pela LoCx e a LoCc. A HiCx e a HiCc são as formas menos densas desse compartimento decorrente da continuidade que elas têm na paisagem. A HiCx não apresenta dissecação ou denudação interna que promova a formação das outras FTs, assim como a HiCc representa um relevo côncavo bastante homogêneo de vales encaixados. Diante dessas características, o Planalto Dissecado Araxá-Canastra pode ser classificado como um Etchplano Parcialmente Denudado de acordo com Thomas (1994) decorrente das suas chapadas residuais sustentadas por couraças lateríticas. O Planalto Dissecado Paranoá-Canastra seria um Etchplano Denudado por seu relevo residual ser composto principalmente por serras e morros sem coberturas lateríticas e pela maior parte do manto de intemperismo ter sido denudado.

As Depressões Cársticas são unidades denudadas que geraram superfícies aplainadas. O estágio de dissecação dessas unidades está relacionado com o relevo residual que não foi completamente denudado ou com a dissecação da própria superfície aplainada. Diferentemente dos Planaltos Retocados, as coberturas lateríticas fazem parte de um processo pedogenético pós-pedimentação.

Essa ideia é corroborada pelos estudos de Reatto et al., (2008) que apresentam um padrão mineralógico dos Latossolos diferentes para planaltos e depressões. Nos planaltos os Latossolos são mais gibbsíticos, ou seja, mais intemperizados quimicamente do que nas depressões, onde ocorrem Latossolos mais cauliníticos. Essa unidade apresenta características similares aos Planaltos Retocados decorrente da frequência dos relevos planos que aumentam nas depressões, e, ao mesmo tempo, apresenta características similares aos Planaltos Dissecados, decorrente da frequência dos relevos côncavos que varia pouco em relação a estes planaltos. Com relação à proporção de patches, as depressões apresentam valores de relevos convexos e côncavos próximos aos valores encontrados nos Planaltos Dissecados, mas com aumento da proporção de patches de formas Pl. No entanto, a Análise de Principais Componentes mostra que as depressões 
estão mais próximas dos Planaltos Dissecados do que dos Planaltos Retocados (Figura 19).

A Depressão Cárstica Vazante-Bambuí é caracterizado por ser a depressão menos aplainada composta por rochas psamo-pelítica-carbonatadas. É a depressão que apresenta a menor cobertura laterítica e com predominância de Cambissolos (Batista et al., 2010). O relevo residual HiCx e o relevo denudado LoCx são os menos fragmentados do que nas outras depressões de acordo com o PP-Fr (Figura 19), justamente por não apresentar frequência elevada de formas Pl (Figura 22). É preciso compreender que em depressões, o avanço do aplainamento separa o relevo mais resistente ao intemperismo, fragmentando-o. Além disso, a Depressão Cárstica Vazante-Bambuí, por ser menos aplainada apresenta características próxima dos planaltos dissecados, com frequência de relevo côncavo equiparado aos do Planalto Dissecado Paranoá-Canastra, o que favorece obter o maior IGDf de convexos em relação aos côncavos (IGDf Cx/Cc) e o menor IGDf de planos em relação aos côncavos (IGDf $\mathrm{Pl} / \mathrm{Cc}$ ). A similaridade com os Planaltos Dissecados ainda reflete no IGDn. A relação de convexos e côncavos (IGDn Cx/Cc) não sugere uma hierarquia entre as depressões, mas o IGDn da relação entre planos e côncavos (IGDn Pl/Cc) mostra os menores valores para essa depressão decorrente da fragmentação da forma $\mathrm{Pl}$, registrando os maiores valores de proporção de patches.

A Depressão Cárstica Paranoá-Canastra é caracterizada por rochas psamopelítica-carbonatadas. De acordo com o mapeamento de solos do SIEG (2005) o compartimento apresenta predominantemente Latossolos e Cambissolos, e localmente Neossolos. Naime et al., (2002) mapearam Latossolos Vermelhos e Latossolos VermelhoAmarelos em hidrossequências e Cambissolos Háplicos nos relevos mais ondulados. Os Latossolos estão localizados principalmente no relevo plano. O relevo residual $\mathrm{HiCx}$ e dissecado HiCc se tornam cada vez mais fragmentados de acordo com PP-Fr que mostra que essas formas não são tão frequentes quanto na Depressão Cárstica Vazante-Bambuí, mas apresentam maior proporção de patches. A fragmentação ainda é maior no relevo denudado, LoCx e nos relevos depositados/dissecados, LoCc. A fragmentação destas formas está associada ao aumento do relevo plano que espalha os relictos e os inselbergs na depressão e ao mesmo tempo está atualmente em processo de dissecação, formando canais. 
A denudação avançada da LoCx em interflúvios favorece e torna a $\mathrm{Cx}-\mathrm{Cc}$ a forma denudada mais contínua na paisagem dos ambientes cársticos do Grupo Canastra. Ao mesmo tempo que o relevo convexo denuda a superfície plana abaixo dos interflúvios está sendo levemente dissecada pela LoCc associada à $\mathrm{Cc}-\mathrm{Cx}$, tornando essas formas fragmentadas na depressão. A denudação elevada e o aplainamento refletem em ambos IGDf. Dos convexos em relação aos côncavos (IGDf $\mathrm{Cx} / \mathrm{Cc}$ ), apresenta valor inferior ao da Depressão Cárstica Vazante-Bambuí decorrente da frequência dos convexos e côncavos serem menores na Depressão Cárstica Paranoá-Canastra. O IGDf do plano em relação aos côncavos (IGDf $\mathrm{Pl} / \mathrm{Cc}$ ) apresenta valor maior do que o da Depressão Cárstica Vazante-Bambuí decorrente da frequência mais elevada de planos na Depressão Cárstica Paranoá-Canastra. Ainda com as formas P1, o IGDn apresenta valores inferiores ao IGDn da Depressão Cárstica Vazante-Bambuí decorrente da diminuição da proporção de patches da forma $\mathrm{Pl}$ que se torna mais frequente e mais continua na Depressão Cárstica Paranoá-Canastra.

A Depressão Cárstica Paranoá-Bambuí é caracterizada por rochas psamo-pelíticacarbonatadas. A cobertura laterítica ocorre principalmente no sopé do relevo residual HiCx, formando rampas em direção ao centro da depressão. Esta depressão ainda apresenta Neossolos nas serras e Cambissolos associado ao relevo denudado adjacente ao Planalto Retocado Bambuí-Canastra e nos canais que se formam como parte da dissecação da superfície aplainada representadas pela $\mathrm{Cc}-\mathrm{Cx}$. Localmente se formam Argissolos e Planossolos (SIEG, 2005). O relevo residual HiCx das serras e cristas não apresenta influência das outras FTs e por isso são relevos residuais menos fragmentados do que o relevo residual HiCx encontrado na Depressão Cárstica Paranoá-Canastra de acordo com a PP-Fr (Figura 19). O mesmo acontece com o relevo dissecado HiCc que ocorre entre as serras e nos sopés das escarpas, resultando na menor fragmentação dentre as depressões analisadas de acordo com a PP-Fr (Figura 19). Entretanto, o relevo denudado LoCx e o relevo dissecado/depositado LoCc são os mais fragmentados. A PPFr dessas classes mostra que essas FTs são menos frequentes e com maior proporção de patches dentre as depressões. Assim como no Planalto Dissecado Paranoá-Canastra, a fragmentação dessas formas está associada a elevada denudação do relevo residual por intemperismo diferencial, mas ao mesmo tempo, a depressão está sendo dissecada formando LoCc e Cc-Cx de maneira fragmentada na paisagem. Essa configuração das formas influencia ambos IGDf. Da relação convexa com côncavo (IGDf $\mathrm{Cx} / \mathrm{Cc}$ ), 
apresenta o menor valor, e da relação plano com côncavo (IGDf Pl/Cc), apresenta o maior valor dentre as Depressões Cársticas. A diminuição da fragmentação do relevo plano favorece um IGDn da relação plano com côncavo (IGDn $\mathrm{Pl} / \mathrm{Cc}$ ) com o menor valor, mesmo com aumento da fragmentação da LoCc e da Cc-Cx.

Para a unidade de Depressões Cársticas, a métrica que representa diversidade (SHDI) de FTs foi a que melhor determinou o arranjo dos fragmentos. Análise de Principais Componentes mostra que no DPCB o SHDI atinge os maiores valores seguido pela Depressão Cárstica Paranoá-Canastra e Depressão Cárstica Vazante-Bambuí. Com o aumento do aplainamento, os compartimentos de depressão se distanciam das métricas que medem densidade (PD e ED). Ainda foi verificado que as métricas de tamanho (PSSD, MPE e MPS) apresentam um arranjo específico para as formas LoCx e LoCc que diferenciam cada uma das depressões.

As depressões analisadas mostram diferentes níveis de aplainamento e dissecação. Decorrente da proximidade dos dados apresentados da Depressão Cárstica VazanteBambuí com os Planaltos Dissecados, classifica-se essa depressão como um Etchplano Denudado por não apresentar predomínio de cobertura laterítica e ser formado por um relevo residual de serras e cristas. A Depressão Cárstica Paranoá-Canastra, por apresentar uma cobertura laterítica oriunda de depósitos pode ser classificado como um Etchplano Coberto, mas com algumas fases de Etchplano Denudado decorrente das rochas psamíticas do Grupo Paranoá nas serras próximas aos Planaltos Retocados. A Depressão Cárstica Paranoá-Bambuí é um Etchplano Exumado, pois exibe rocha fresca principalmente abaixo dos Neossolos das serras do Grupo Paranoá, mas também apresentam fases de Etchplano Coberto decorrente da cobertura laterítica que capeia o aplainamento. 


\section{Capítulo 6 - CONCLUSÃO}

- O método proposto superou as limitações das abordagens anteriores no mapeamento das Formas de Terreno em relevos suaves de baixa amplitude topográfica com assinaturas geométricas formadas pelas curvaturas longitudinal, transversal, mínima e máxima.

- A classificação das formas de terreno pelas assinaturas mostrou pequenas diferenças no terreno: topos levemente abalados, depressões rasas, canais ligeiramente côncavos.

- O método também apresenta pontencial para classificar regiões de elevada declividade como nos Planaltos Dissecados

- As formas de terreno classificadas estão organizadas em sequência topográficas e por isso o método demonstra um potencial para estudos da relação solo-paisagem e da dinâmica da água.

- O estudo da fragmentação das formas de terreno permitiu mostrar a evolução geomorfológica de etchplanos por meio da configuração dos seus polígonos avaliados por métricas.

- Essa abordagem aproxima a análise geomorfométrica com a geomorfogênese e consequentemente com os estudos de evolução geomorfológica.

- A evolução geomorfológica em ampla escala temporal e espacial podem ser avaliadas por fragmentação de formas de terreno onde seu arranjo caracterizam estágios denudacionais.

- A fragmentação das formas de terreno pode representar um retrato da taxa de formação de solos em ampla escala tempora e espacial decorrente da relação solopaisagem, controlada por processos denudaciaonais. 


\section{Capítulo 7 - CONSIDERAÇÕES FINAIS}

As contribuições desse trabalho abarcam o desenvolvimento de um procedimento metodológico para classificar Formas de Terreno em superfícies aplainadas de regiões tropicais cratonizadas e a organização dessas formas em relação à evolução geomorfológica.

A área de estudo escolhida dentro da Faixa Brasília de Dobramentos representa o relevo residual de etchplanos com diferentes níveis de denudação desenvolvido a partir da transição entre o Cretáceo e o Terciário. A continuidade do relevo e com predomínio de formas aplainadas são critérios fundamentais para testar abordagens inovadoras de classificação de Formas de Terreno tropicais.

O procedimento proposto soluciona a dificuldade de discriminar essas formas por meio da construção de assinaturas geométricas com diferentes curvaturas. A classificação de similaridade (SCM) e a mínima distância (MD) são complementares. A primeira, reconhece o padrão da assinatura (N-Type e U-Type) e a segunda a intensidade da forma. Apesar do detalhamento conseguido, utilizando esses classificadores como etapas de uma mesma classificação, não foi possível individualizar uma única assinatura geométrica para determinar as formas planas. Foi verificado que as formas planas apresentam um padrão de assinatura que se aproxima de uma feição linear em todas as bandas de curvatura, sem diferenciar os dois tipos de padrões, N-Type e U-Type. Entretanto, a partir da compreensão do padrão da assinatura, e optando por classificar apenas pela mínima distância é possível individualizar uma assinatura para a forma plana, que, por sua vez, foi utilizada no estudo regional.

O resultado da classificação das Formas de Terreno na Bacia do Rio Jardim permitiu que a análise pode ser em diferentes níveis de detalhe. Utilizando a similaridade e a mínima distância foi possível definir três níveis de classificação: (1) o nível mais simples com três classes, convexo, transicional e côncavo; (2) o nível intermediário com as mesmas três classes, mas em padrões diferentes, N-Type e U-Type, totalizando 6 classes; (3) o nível mais detalhado com 12 classes (HiNCx, LoNCx, HiNTr, LoNTr, LoNTr, LoNCc, HiNCc, HiUCx, LoUCx, HiUTr, LoUTr, LoUTr, LoUCc e HiUCc). 
As Formas de Terreno do contexto regional foram classificadas, utilizando apenas a mínima distância, o que possibilitou a delimitação de 7 formas representativas. Cada forma foi correlacionada com os seguintes relevos: residuais (HiCx), residuais/denudados (LoCx), denudados (Cx-Cc), denudados/dissecados/depositados (Cc-Cx), dissecados/depositados (LoCc) e dissecados (HiCc). Essa adaptação metodológica foi necessária para diminuir a quantidade de classes e individualizar uma única assinatura geométrica para as formas planas que é imprescindível para o estudo da fragmentação do relevo e sua correlação com o modelo de etchplanação. Então, é importante salientar, que o método poderá ser aplicado integralmente (com maior requinte de detalhe) ou adaptado (próprio para regiões que apresentam relevo plano) a depender dos objetivos a serem alcançados e da área de estudo.

De acordo com o modelo de etchplanação para o contexto regional da área de estudo, ocorrem diferentes estágios de evolução: Etchplano Mantado levemente dissecado (PRP), Etchplano Mantado dissecado (PRBC), Etchplano Parcialmente Denudado (PDAC) Etchplano Denudado (PDPC e DCVB), Etchplano Coberto (DCPC) e Etchplano Coberto/Exumado (DCPB). Esses estágios apresentam arranjos específicos de Formas de Terreno que representam a evolução geomorfológica.

A organização dessas Formas de Terreno representa os estágios de evolução dos etchplano e foram medidas por compartimento, considerando a Frequência, Número de Patches, Proporção de Patches, métricas que avaliam o tamanho do patch (MPS e PSSD), o tamanho do contorno (MPE), a complexidade (MPAR), a diversidade (SHDI) e a densidade (PD e ED).

O dado de Frequência mostrou o balanço que existe entre os relevos convexos, côncavos e planos. Os Planaltos Retocados apresentaram formas convexas mais recorrentes do que formas côncavas e alta frequência de formas planas. Porém, quanto mais denudado e dissecado for o compartimento maior será a contribuição das formas côncavas. Nos Planaltos Dissecados as formas côncavas são mais frequentes que as formas convexas, mas a frequência das formas convexas permanece elevada decorrente da amplitude entre o relevo residual e o relevo dissecado. Praticamente não são encontradas formas planas nesses planaltos, mas ainda podem ser encontrados em setores, onde foi observada uma denudação diferencial abaixo dos rebordos. Nas Depressões 
Cársticas a frequência dos relevos côncavos é maior do que dos relevos convexos, porém com aumento progressivo de formas planas.

Esse balanço entre os relevos reflete na fragmentação das Formas de Terreno que foi medido primeiramente pela diferença entre a Proporção de Patches e a Frequência (PP-Fr). Normalmente a proporção de patches apresentou valores maiores que os valores de frequência. Quanto maior for essa diferença, maior será a fragmentação da forma. A frequência foi maior do que a proporção de patches nos relevos residuais $\mathrm{HiCx}$ e nos relevos dissecados $\mathrm{HiCc}$ em todos os compartimentos. Os relevos residuais/denudados LoCx, os relevos depositados/dissecados LoCc, e os relevos denudados/depositados/dissecados $\mathrm{Cc}-\mathrm{Cx}$, ocorreram com frequência maior do que a proporção de patches apenas no Planalto Retocado Bambuí-Canastra. A forma Pl representando os relevos suaves de baixa amplitude topográfica apresentaram essa configuração nos Planaltos Retocados e na Depressão Cárstica Paranoá-Bambuí que representa a superfície mais aplainada dentre as depressões. Sempre que a frequência for maior do que a proporção de patches, as classes de Formas de Terreno serão menos fragmentadas.

Essa dinâmica entre a Proporção de Patches e a Frequência possibilitou a criação de um índice denominado de Índice Geomorfométrico de Denudação (IGD), tanto para Frequência (IGDf), quanto para a Proporção de Patches (IGDn). O índice é baseado na relação entre relevos convexos e côncavos (IGDf Cx/Cc e IGDn $\mathrm{Cx} / \mathrm{Cc}$ ) e na relação entre relevos planos e côncavos (IGDf Pl/Cc e IGDn Pl/Cc).

O IGDf Cx/Cc mostrou que os valores decrescem progressivamente do Etchplano levemente dissecado, PRP, ao Etchplano Coberto/Exumado, DCPB, decorrente da dissecação representada pelo relevo côncavo e da denudação do relevo convexo. Nos ambientes planálticos, o IGDf Pl/Cc decresce do Etchplano levemente dissecado, PRP, ao Etchplano Denudado, PDPC, principalmente pela a diminuição da presença de formas planas. Nas depressões, o IGDf $\mathrm{Pl} / \mathrm{Cc}$ aumenta no sentido do Etchplano Coberto/Exumado, DCPB, decorrente do aumento da frequência do relevo plano.

O IGDn $\mathrm{Cx} / \mathrm{Cc}$ nos planaltos decresce do Etchplano levemente dissecado, PRP, ao Etchplano Denudado, PDPC, decorrente do aumento da proporção de patches dos relevos côncavos. O IGDn $\mathrm{Pl} / \mathrm{Cc}$ apresentou um padrão dentro das unidades 
geomorfológicas. Nos Planaltos Retocados, este índice aumentou em direção ao Etchplano Parcialmente Denudado levemente dissecado, PRBC, decorrente da proporção de patches aumentar na Pl (mais fragmentado) e diminuir na Cc (menos fragmentado). Nos Planaltos Dissecados o índice decresceu em direção ao Etchplano Denudado, PDPC, decorrente da menor proporção de relevo plano, e a maior proporção de relevo côncavo. Nas Depressões Cársticas, o IGDn $\mathrm{Pl} / \mathrm{Cc}$ decresce em direção ao Etchplano Coberto/Exumado, DCPB, decorrente da menor fragmentação do relevo plano na superfície aplainada.

Se de um lado a Frequência e a Proporção de Patches auxiliam a visualizar o balanço entre os relevos convexos, côncavos e planos dos etchplanos por meio da diferença dos dois parâmetros e pela elaboração de índices, por outro lado, as métricas avaliam como a fragmentação se comporta em relação ao tamanho, densidade, complexidade e diversidade da Forma de Terreno. As métricas MPS, PSSD, MPE, MPAR, SHDI, PD e ED foram determinadas para o contexto do compartimento (Landscape Metrics). A partir das Landscape Metrics avaliadas pela Análise de Principais Componentes foram obtidos os seguintes resultados: as métricas que avaliam o tamanho e a complexidade determinam os Planaltos Retocados, ou seja, etchplanos mais preservados; as métricas que avaliam a densidade determinam os Planaltos Dissecados, etchplanos mais denudados; e métricas que avaliam a diversidade determinam as Depressões Cársticas, etchplanos mais pedimentados. As Class Metrics abarcam o detalhamento desse arranjo por Formas de Terreno.

O balanço entre o relevo convexo e côncavo emprega geralmente pares complementares de Formas de Terreno com valores máximos e mínimos de uma determinada métrica. O padrão mais uniforme foi representado pelas métricas de densidade (PD e ED) com os maiores valores sempre localizados nas $\mathrm{Cx}-\mathrm{Cc}$ e $\mathrm{Cc}-\mathrm{Cx}$ e os menores nas $\mathrm{HiCx}$ e HiCc independente se o compartimento é um planalto ou uma depressão. Nesse sentido, as formas mais densas estão relacionadas com a porção intermediária da paisagem entre o relevo residual e o relevo dissecado. $\mathrm{O}$ destaque aos Planaltos Dissecados para essas formas deve-se à baixa frequência das formas $\mathrm{Cx}-\mathrm{Cc} \mathrm{e}$ $\mathrm{Cc}-\mathrm{Cx}$ e à elevada proporção de patches e, ao mesmo tempo, à elevada frequência de HiCx e HiCc e baixa proporção de patches. A forma plana sempre será mais densa quanto maior a dissecação quando avaliada pelo PD. No Caso da ED é necessário que haja o aplainamento para que o valor aumente. 
A maior e a menor complexidade medida pela MPAR também foram registradas nos respectivos pares de formas $\mathrm{Cx}-\mathrm{Cc}$ e $\mathrm{Cc}-\mathrm{Cx}$ e $\mathrm{HiCx}$ e HiCc. Ou seja, os relevos residuais e dissecados são menos densos e menos complexos e os relevos denudados, depositados e levemente dissecados localizados sempre a HiCx e a HiCc são mais densos e mais complexos. Apenas no Etchplano Coberto/Exumado observa-se que a maior complexidade está associada às LoCx e LoCc decorrente do avanço do aplainamento. $\mathrm{O}$ aplainamento isola o relevo residual denudado $\mathrm{LoCx}$ dentro da depressão assim como parte da depressão apresenta níveis de dissecação classificadas pela LoCc. Essas formas ainda são encontradas como resultado denudação dos patamares no contato com o Planalto Retocado Bambuí-Canastra. Assim, a heterogeneidade de relevos denudados, dissecados e depositados leva ao aumento da complexidade. A forma plana tende a ser mais complexa quanto menor for o aplainamento.

Nas métricas que avaliam o tamanho (PSSD, MPS e MPE) invertem a posição dos valores máximos e mínimos no Planalto Retocado do Paranoá e nos Planaltos Dissecados. Assim, a HiCx e a HiCc apesar de apresentarem as menores densidade e complexidade, mostram a maior variação de tamanho (PSSD), o maior tamanho médio (MPS) e o maior contorno médio (MPE). A $\mathrm{Cx}-\mathrm{Cc}$ e a $\mathrm{Cc}-\mathrm{Cx}$ apresentam as maiores densidade e complexidade e a menor variação de tamanho (PSSD), o menor tamanho médio (MPS) e o menor contorno médio (MPE). O estágio de evolução intermediárias do Planalto Retocado Bambuí-Canastra que não é um etchplano tão preservado quanto o Planalto Retocado do Paranoá, mas também não é tão denudado quanto os Planaltos Dissecados, favorecem as formas LoCx (maiores valores de PSSD e MPE), Cc-Cx (maior valor de PSSD), LoCc (maiores valores de PSSD e MPE) e HiCc (menores valores de PSSD e MPE).

As métricas que avaliam tamanho mostraram que os pares complementares de Formas de Terreno localizados simetricamente nos máximos e mínimos indicam equilíbrio na configuração das Formas de Terreno. Esse equilíbrio é localizado no Etchplano Mantado levemente dissecado, PRP, no Etchplano Parcialmente Denudado, PDAC, e Etchplano Denudado, PDPC. Ambos apresentam um equilíbrio entre relevos residuais e dissecados (HiCx e HiCc, respectivamente) e nos relevos denudados (Cx-Cc) e depositados, dissecados ou denudados $(\mathrm{Cc}-\mathrm{Cx})$. A diferença está que no primeiro as formas denudadas, depositadas e as dissecações mais recentes ainda estão em formação. Nos dois últimos, a denudação desses relevos intermediários já ocorreu em grande parte 
dos compartimentos, favorecendo o equilíbrio entre o relevo residual e o relevo dissecado. O Etchplano Mantado dissecado representado pelo Planalto Retocado Bambuí-Canastra é a fase intermediária em pleno processo de denudação e por isso apresenta um (des)equilíbrio diferenciado entre os pares de Formas de Terreno, favorecendo algumas formas que estão entre o relevo residual e o relevo dissecado. Ainda é preciso citar a influência da forma Pl nessa organização. Nos Etchplanos Mantados, a denudação gera também superfícies planas abaixo dos interflúvios. Essas formas planas apesar de serem depósitos, também são formas residuais que estão sendo dissecadas. A presença dessas formas abaixo dos interflúvios ajuda a preservar o relevo a montante da denudação. Essas formas apresentaram o maior contorno médio (MPE) e o maior tamanho médio (MPS) no Planalto Retocado Bambuí-Canastra decorrente das rampas extensas abaixo dos interflúvios. O Planalto Retocado do Paranoá apresentou o maior valor de desvio padrão medido pelo PSSD por apresentar extensas chapadas preservadas e superfícies planas abaixo dos interflúvios mais curtas, provavelmente decorrente do controle estrutural.

A dinâmica das métricas que representam o tamanho parecem concordar com a ideia de equilíbrio entre os pares complementares. Entretanto, o equilíbrio está registrado no etchplano que apresenta a mais extensa superfície de aplainamento: Etchplano Coberto/Exumado, DCPB, que apresenta os menores valores de PSSD, MPE e MPS na LoCx e na LoCc. A Depressão Cárstica Vazante-Bambuí é a depressão menos aplainada, que apresenta o menor valor de PSSD na LoCc. A Depressão Cárstica Paranoá-Canastra apresentou os menores valores de MPE.

Em Depressões Cársticas, essas formas tendem a ser eliminadas decorrente do avanço do aplainamento. A forma $\mathrm{LoCx}$ é normalmente parte de um processo de denudação de um relevo residual, e consequentemente, a porção do relevo residual mais susceptível ao intemperismo. A forma LoCc será frequente enquanto existir amplitude entre os relevos mais elevados e o nível de base local e assim desenvolver padrões de diferentes tamanhos.

Assim colocado, a fragmentação e a frequência estabeleceram uma relação com a gênese e evolução geomorfológica que nesse trabalho foi tratado a partir do modelo de etchplanação. Contudo, essa abordagem ainda pode ser aplicada em diversos estudos, como, por exemplo: dinâmica da água em bacias hidrográficas; comparação dos níveis de dissecação de diferentes sub-bacias; relação solo-relevo para melhor compreensão do 
balanço entre o processo morfogenético e pedogenético; relação da cobertura da terra e dinâmica de uso associadas aos padrões geomorfológicos. Além disso, ainda existe espaço para explorar outras métricas que avaliam a fragmentação e que não foram ainda utilizadas para o estudo do relevo. 


\section{REFERÊNCIAS}

Ab'Saber, A.N., Bigarela, J.J., 1961. Superfícies aplainadas do primeiro planalto do Paraná. Boletim Paranaense de Geografia, 4/5, 116-125.

Ab'Saber, A.N., 1963. Contribuição à geomorfologia da área dos Cerrados. In: Símpósio sobre Cerrado. São Paulo, USP, 97-104.

Ab’Saber, A.N., 1965. Da Participação das Depressões Periféricas e Superfícies Aplainadas da Compartimentação do Planalto Brasileiro". Tese de Livre-Docência da FFLCH-USP. São Paulo, 97pp.

Ab'Saber, A.N., 1970. Províncias geológicas e domínios morfoclimáticos no Brasil. Geomorfologia/ USP, 20, São Paulo, 26pp.

Adams, J.B., Gillespie, A.R., 2006. Remote Sensing of Landscapes with Spectral Images: A Physical Modeling Approach. Cambridge University Press, New York, 356 pp.

Adediran, A.O., Parcharidis, I., Poscolieri, M., Pavlopoulos, K., 2004. Computer-assisted discrimination of morphological units on north-central Crete (Greece) by applying multivariate statistics to local relief gradients. Geomorphology 58 (1), 357-370.

Almeida, F.F.M., 1955. As camadas de São Paulo de a Tectônica da Serra da Cantareira. Boletim da Sociedade Brasileira de Geologia, 4 23-40.

Almeida, F.F.M., 1964. Fundamentos geológicos do relevo paulista. In: Instituto Geográfico e Geológico. Geologia do Estado de São Paulo. Boletim IGG, 41 167-263.

Almeida, F.F.M. 1967. Origem e evolução da Plataforma Brasileira. D.N.P.M, (Boletim 241), 36pp.

Almeida, F.F.M. 1969. Diferenciação Tectônica da Plataforma Brasileira. Anais do XXIII Congresso Brasileiro de Geologia, Salvador, 29-46.

Arrell, K.E., Fisher, P.F., Tate, N.J., Bastin, L., 2007. A fuzzy c-means classification of elevation derivatives to extract the morphometric classification of landforms in Snowdonia, Wales. Computers \& Geosciences 33 (10), 1366-1381.

Baldi, G., Guerschman, J.P., Paruelo, J.M., 2006. Characterizing fragmentation in temperate South America grasslands. Agriculture, Ecosystems and Environment, 116, 197-208.

Baptista, M.C., Silva, S.F., Dantas, M.E., Duarte, K.S., Almeida, B.F., Muricy Filho, A.F., Coutinho, C.I., Pedrosa, L. 2010. Aspectos gerais do meio físico. In: Geodiversidade do estado de Minas Gerais, Machado, M.F., Silva, S.F. Belo Horizonte, CPRM, $131 \mathrm{p}$.

Beltrame, A.V., 1997. Estudo das propriedades físicas do solo visando conhecer seu funcionamento hídrico: Sorocaba do Sul, Biguaçu. Tese (Doutorado em Geografi a 
Física) - Faculdade de Filosofia, Letras e Ciências Humanas, Universidade de São Paulo, $151 \mathrm{pp}$.

Bertran, G., 1971. Paisagem e Geografia Física Global - esboço metodológico. Trad. O.

Cruz - São Paulo, IGEOG/USP, Série Cadernos de Ciências da Terra, 13, 1-27.

Bigarella, J. J., Ab’Sáber, A. N., 1964. Paläogeographische und paläoklimatische Aspekte des Känozoikums in Südbrasilien. Zeitschrift für Geomorphologie, 8, 286-312.

Bishop, M.P., James, L.A., Shroder Jr, J.F., Walsh, S.J., 2012. Geospatial technologies and digital geomorphological mapping: Concepts, issues and research. Geomorphology $137,1,5-26$.

Boardman, J.W., 1993. Automated spectral unmixing of AVIRIS data using convex geometry concepts. In: Summaries of the Fourth JPL Airborne Geoscience Workshop, R.O. Green (Ed.), Pasadena, CA, JPL Publication 93-26, Pasadena, CA, vol. 1, pp. 11-14.

Boardman, J.W., 1994. Geometric mixture analysis of imaging spectrometry data. In: International Geoscience and Remote Sensing Symposium, 1994. IGARSS'94. Surface and Atmospheric Remote Sensing: Technologies, Data Analysis and Interpretation, vol. 4, pp. 2369-2371.

Boardman, J.W., Kruse, F.A., 1994. Automated spectral analysis: A geological example using AVIRIS data, northern Grapevine Mountains, Nevada. In: Proceedings, Tenth Thematic Conference on Geologic Remote Sensing, 9-12 May 1994, San Antonio, Texas, p. I-407 - I-418.

Boardman, J.W., Kruse, F.A., Green, R.O., 1995. Mapping target signatures via partial unmixing of AVIRIS data. In: Summaries of the Fifth Annual JPL Airborne Earth Science Workshop, Pasadena, CA, JPL Publication 95-1, vol. 1, pp. 23-26.

Bolongaro-Crevenna, A., Torres-Rodríguez, V., Sorani, V., Frame, D., Arturo Ortiz, M., 2005. Geomorphometric analysis for characterizing landforms in Morelos State, Mexico. Geomorphology 67(3), 407-422.

Bólos, M.C., 1981. Problemática Actual de los Estudios de Paisage Integrado. Revista de Geografia 15(1-2) 45-68.

Boulet, R., Godon, P., Lucas Y., Worou, S., 1984. Analyse Structurale de la Couverture Pedologique et Experimentation Agronomique em Guyane Française. Cah. ORSTOM, Sér. Pedologie, Paris, XXI (1), 21-31.

Boulet, R., Lucas, Y., Fritsch, E., Paquet, H., 1993. Géochimiedes dês paysages: Le role dês couvertures pédologiques. Coll. Sedimentologie et Géochimie de la Surface, àla mémoire de Georges Millot, 55-76.

Brasil, 1984. Ministério das Minas e Energia. Secretaria Geral. Projeto RadamBrasil. Folha SD 23 - Brasília. Levantamento de Recursoos Naturais, 19, Rio de Janeiro. 250pp 
Braucher, R., Lima, C.V., Bourlès, D.L., Gaspar, J.C., Assad, M.L.L., 2004. Stone-line formation processes documented by in situ-produced ${ }^{10} \mathrm{Be}$ distribution, Jardim River basin, DF, Brazil. Earth and Planetary Science Letters 222 (2), 645-651.

Braun, O.P.G., 1970. Contribuição à geomorfologia do Brasil Central. Revista Brasileira de Geografia, 32(3) 3-39.

Brown, D.G., Lusch, D.P., Duda, K.A., 1998. Supervised classification of types of glaciated landscapes using digital elevation data. Geomorphology 21 (3), 233-250.

Büdel, J., 1957. Die "doppelten Einebnungs fläche" in den feuchten Tropen. Zeitschrift für Geomorphologie 1 (2), 201-228.

Büdel, J. (1957) Die "Doppelten Einebnungsflachen" in den fenchten troppen. Zeif. Geomorph., 1(2) 201-228.

Büdel, J., 1963. Klima Genetische Geomorphologie. Geographi Rundschau, 15 (7), 269-285.

Büdel, J., 1982. Climatic geomorphology. Princeton: Princeton University Press. 443 pp.

Burrough, P.A., Van Gaans, P.F.M., MacMillan, R.A., 2000. High-resolution landform classification using fuzzy k-means. Fuzzy sets and Systems 113 (1), 37-52.

Campos, J.E.G., Monteiro, C.F., Rodrigues, L.N., 2006. Geologia e Zoneamento Hidrogeológico da Bacia do Rio Preto, DF/GO/MG. Boletim Pesquisa - Embrapa Cerrados, 54pp.

Campos, M.C.C., Marques Júnior, J., Souza, M.Z., Siqueira, D.S., Pereira, T.P., 2012 Discrimination of geomorphic surfaces with multivariate analysis of soil attributes in sandstone - basalt lithosequence. Revista Ciência Agronômica, 43(3) 429-438.

Castro, S.S. Sistema de transformação pedológica em Marilia, SP: B latossólicos e B texturais. 1989. Tese (Doutorado) - Faculdade de Filosofia, Letras e Ciências Humanas, Universidade de São Paulo, São Paulo, 286pp.

Chauvel, A.; Boulet, R.; Lucas, Y., 1987. On the genesis of the soil mantle of the region of Manaus, Central Amazonia, Brazil. Experientia, 43, 234-241.

CODEPLAN, Compahia de Desenvolvimento do Planalto Central, 1984. Atlas do Distrito Federal. Brasília: GDF.

Conacher, A.J., Dalrymple, J.B., 1977. The nine-unit landsurface model: an approach to pedogeomorphic research. Geoderma 18 (1-2), 1-154.

Cooper, M., Vidal-Torrado, P., Lepsch, I.F., 2002. Stratigraphical discontinuities, tropical landscape evolution and soil distribution relationships in a case study in SE-Brazil. R. Bras. Ci. Solo, 26 673-683. 
CPRM, Serviço Geológico do Brasil, 2008. Mapa Geológico 1:500.000. In: GEOLOGIA do Estado de Goiás e Distrito Federal. (Org.) Moreira, M.L.O, Moreton, L.C., Araújo, V.A., Lacerda Filho, J.V., Costa, H.F. Goiânia: CPRM/SIC-FUNMINERAL.

Dalrymple, J.B., Blong, R.J., Conacher, A.J., 1968. A hypothetical nine unit landsurface model. Zeitschrift für Geomorphologie 12, 60-76.

Daniels, R.B., Gamble, E.F., Cady, J.G., 1971. The relation between geomorphology and soil morphology and genesis. Adv. Agron., 23 51-87.

Dantas, M.E., 2002. Mapa Geomorfológico. In: Zoneamento-Ecológico-Econômico da Região Integrada de Desenvolvimento do Distrito Federal e Entorno: Fase I. Rio de Janeiro. CPRM. Serviço Geológico do Brasil; Embrapa; MI/SCO.

Dantas, M.E., Scislewski, G., Thomé Filho, J.J. 2003. Geomorfologia. In: ZoneamentoEcológico-Econômico da Região Integrada de Desenvolvimento do Distrito Federal e Entorno: Fase I. Rio de Janeiro. CPRM. Serviço Geológico do Brasil; Embrapa; MI/SCO, vol. 2, p. 1-29.

Dardenne M.A. 2000. The Brasília Fold Belt. In: U.G. Cordani, E.J. Milani, A. Thomaz Filho, D.A. Campos (eds). Tectonic Evolution of South America. 31st Int. Geol. Congr., Rio de Janeiro, 231-263.

Davis, W.M., 1889. The Geographical Cycle. The Royal Geographical Society, 14(5) 481-504.

de Bruin, S., Stein, A., 1998. Soil-landscape modelling using fuzzy c-means clustering of attribute data derived from a Digital Elevation Model (DEM). Geoderma 83 (1), 17-33.

de Carvalho Júnior, O.A., Meneses, P.R., 2000. Spectral Correlation Mapper (SCM): An Improving Spectral Angle Mapper. In: Proceedings of Annual JPL Airborne Earth Science Workshop, Pasadena, CA, USA, 23-25 February 2000; pp. 65-74.

de Carvalho Júnior, O.A., Sampaio, C.S., da Silva, N.C., Couto Júnior, A.F., Gomes, R.A.T., de Carvalho, A.P.F., Shimabukuro, Y.E., 2008. Classificação de padrões de savana usando assinaturas temporais NDVI do sensor MODIS no Parque Nacional Chapada dos Veadeiros. Revista Brasileira de Geofísica 26 (4), 505-517.

de Carvalho Júnior, O.A., Guimarães, R.F., Gillespie, A.R., Silva, N.C., Gomes, R.A., 2011. A new approach to change vector analysis using distance and similarity measures. Remote Sensing 3 (11), 2473-2493.

de Carvalho Junior, O.A., da Silva, N.C., de Carvalho, A.P.F., Couto Júnior, A.F., Silva, C.R., Shimabukuro, Y.E., Guimarães, R.F., Gomes, R.A.T., 2012. Combining noiseadjusted principal components transform and median filter techniques for denoising MODIS temporal signatures. Revista Brasileira Geofísica 30 (2), 147-157.

de Carvalho Júnior, O.A., Maciel, L.M.D.M., de Carvalho, A.P.F., Guimarães, R.F., Silva, C.R., Gomes, R.A.T., Silva, N.C. (2014). Probability Density Components Analysis: A New Approach to Treatment and Classification of SAR Images. Remote Sensing 6 (4), 2989-3019. 
Dickson, B.L., Taylor, G.F., 2000. Maximum noise fraction method reveals detail in aerial gamma-ray surveys. Exploration Geophysics. 31, 73-77.

Dikau, R., 1989. Application of a digital relief model to landform analysis in geomorphology. In: Raper, J. (Ed.), Three Dimensional Application in Geographic Information Systems. Taylor \& Francis, London, pp. 51-77.

Dinesh, S. Analysis of Landform Metrics of Mountains Extracted from Multiscale Digital Elevation Models. 2009. Australian Journal of Basic and Applied Sciences, 3(4) 39974010 .

Dorner, B., Lertzman, K., Fall, J., 2002 Landscape pattern in topographically complex landscapes: issues and techniques for analysis. Landscape Ecology, 17, 729-743. doi: 10.1023/A:1022944019665.

Dessert, C., Dupré, B., Gaillardet, J., Francois, L., Allègre, C., 2003. Basalt weathering laws and global geochemical cycles, Chemical Geology, 202 (3-4), 257-273.

Ehsani, A.H., Quiel, F., 2008. Application of self-organizing map and SRTM data to characterize yardangs in the Lut desert, Iran. Remote Sensing of Environment 112 (7), 3284-3294.

Ehsani, A.H., Quiel, F., 2009. A semi-automatic method for analysis of landscape elements using Shuttle Radar Topography Mission and Landsat ETM+ data. Computers \& Geosciences 35 (2), 373-389.

Ehsani, A.H., Quiel, F., Malekian, A., 2010. Effect of SRTM resolution on morphometric feature identification using neural network-self organizing map. Geoinformatica 14 (4), 405-424.

Eschenbrenner, V. 1988. Les glébules des sols de Côte d'Ivoire : nature et origine en milieu ferrallitique, modalités de leur concentration, rôle des térmites. These Univ. Bourgogne, Dijon, 780pp.

Evans, I., 1972. General geomorphometry, derivatives of altitude and descriptive statistics. In: Chorley, R. (Ed.), Spatial Analysis in Geomorphology. Methuen \& Co., London, pp. 17-90, Chap. 2.

Evans, I.S. Geomorphometry and landform mapping: What is a landform? Geomorphology 137, 94-106.

Farr, T.G., Rosen, P.A., Caro, E., Crippen, R., Duren, R., Hensley, S., Kobrick, M., Paller, M., Rodriguez, E., Roth, L., Seal, D., Shaffer, S., Shimada, J., Umland, J., Werner, M., Oskin, M., Burbank D., Alsdorf, D., 2007. The Shuttle Radar Topography Mission. Reviews of geophysics, 45(2), RG2004, doi:10.1029/2005RG000183.

Felicísimo, A.M., 1999. Modelos Digitales del Terreno. Curso Introductorio. http://www6.uniovi.es/ feli/CursoMDT/CursoMDT.html.

Fernandes Barros, O. N., 1985. Análise estrutural e cartografia detalhada dos solos em Marilia, SP: ensaio metodológico. Dissertação (Mestrado em Geografi a Física) Faculdade de Filosofi a, Letras e Ciências Humanas, Universidade de São Paulo, 146pp. 
Fernandes Barros, O. N., 1996. Formação de horizontes pedológicos em solos sobre basaltos e ação biológica no intemperismo. Tese (Doutorado em Geografi a Física) Faculdade de Filosofi a, Letras e Ciências Humanas, Universidade de São Paulo, 1996.

Filizola, H. O papel da erosão geoquímica na evolução do modelado da bacia de Taubaté, 1993. Tese (Doutorado em Geografi a Física) - Faculdade de Filosofia, Letras e Ciências Humanas, Universidade de São Paulo, 168pp.

Fischer, J., Lindenmayer, D.B. 2007. Landscape modification and habitat fragmentation: a synthesis. Global Ecol. Biogeogr. 16, 265-280.

Florinsky, I.V., 1998. Accuracy of local topographic variables derived from digital elevation models. International Journal of Geographical Information Science 12 (1), 47-62.

Forman, R. T. T., Godron, M. Landscape ecology. New York: Wiley \& Sons Ed., 1986. $619 \mathrm{pp}$.

Frakes, L.A., 1979. Climate throughout Geological Times. Elsevier, 310pp.

Freitas, R.O., 1951. Relevos policíclicos na tectônica do Escudo Brasileiro. Boletim Paulista de Geografia, 7, 3-19.

Freitas-Silva, F.H. \& Campos, J.E.G. 1999. Geologia do Distrito Federal. In: Inventário Hidrogeológico e dos Recursos Hídricos Superficiais do Distrito Federal. Brasília. IEMA/SEMATEC/UnB. Vol. 1, Parte I. 86pp.

Fuck, R.A., 1994. A Faixa Brasília e a compartimentação tectônica na Província Tocantins. In: SBG, Simp. Geol. Centro-Oeste, 4, Brasília, Anais, 184-187.

Gaillardet, J., Dupré, B., Louvat, P., Allègre, C., 1999. Global silicate weathering of silicates estimated from large river geochemistry, Chemical Geology 159, 3-30.

Ghosh, S., Stepinski, T.F., Vilalta, R., 2009. Automatic annotation of planetary surfaces with geomorphic labels. IEEE Transactions on Geoscience and Remote Sensing 48 (1), 175-185.

Girouard, G.; Bannari, A.; El Harti, A.; Desrochers, A. Validated Spectral Angle Mapper Algorithm for Geological Mapping: Comparative Study between Quickbird and LandsatTM. Proceedings of XXth ISPRS Commission 4, Istanbul, Turkey, 12-23 July 2004; pp. 599-604.

Giles, P.T., Franklin, S.E., 1998. An automated approach to the classification of the slope units using digital data. Geomorphology 21 (3), 251-264.

Goudie, A.S., 1998. Encyclopedia of Geomorphology, volume 1. Routledge (Taylor and Francis Group), London e New York, 1202pp.

Green, A.A., Berman, M.; Switzer, P., Craig, M.D., 1988. A transformation for ordering multispectral data in terms of images quality with implications for noise removal. IEEE Transactions on Geoscience and Remote Sensing 6, 65-74. 
Guerra, A.J.T., Marçal, M.S., 2006. Geomorfologia Ambiental. Bertran Brasil, Rio de Janeiro, 189pp.

Guerra, A.J.T., Guerra, A.T., 2008. Novo Dicionário Geológico-Geomorfológico. Bertrand Brasil, Rio de Janeiro, 652pp.

Guimarães, R.F., de Carvalho Junior, O.A., Andrade, A.C., Gomes, R A.T.; Martins, E.S., Carvalho, A.P.F., 2010. Forest fragments distribution as related to geomorphological parameters. Revista Brasileira de Cartografia, 62, 373-384.

Hammond, E.H., 1954. Small-scale continental landform maps. Annals of the Association of American Geographers 44, 33-42.

Harris, L.D., 1984. The Fragmented Forest: Island Biogeography Theory and the Presevation of Biotic Diversity. University of Chicago Press, Chicago, IL, 211 pp.

Hargis, C. D., Bissonette, J. A., David, J. L. 1998. The behavior of landscape metrics commonly used in the study of habitat fragmentation. Landscape Ecol 13, 167-186.

Hengl, T., Rossiter, D.G., 2003. Supervised landform classification to enhance and replace photo-interpretation in semi-detailed soil survey. Soil Science Society of America Journal 67 (6), 1810-1822.

IBGE, Instituto Brasileiro de Geografia e Estatísitca. Manual Técnico de Geomorfologia, Rio de Janeiro, IBGE, 2009, 175pp.

Irvin, B.J., Ventura, S.J., Slater, B.K., 1997. Fuzzy and isodata classification of landform elements from digital terrain data in Pleasant Valley, Wisconsin. Geoderma 77 (2), 137154.

Iwahashi, J., Pike, R.J., 2007. Automated classifications of topography from DEMs by an unsupervised nested-means algorithm and a three-part geometric signature. Geomorphology 86(3), 409-440.

Jaeger, J.A.G., 2000. Landscape division, splitting index, and effective mesh size: new measures of landscape fragmentation. Landscape Ecology, 15, 115-130.

Jasiewicz, J., Stepinski, T.F., 2013. Geomorphons - a pattern recognition approach to classification and mapping of landforms. Geomorphology 182, 147-156.

Jenny, H., 1941. Factor of soil formation: a system of quantitative pedology. New York, McGraw-Hill. 281 pp.

Kang, S., Choi, W., 2014. Forest cover changes in North Korea since the 1980s. Regional Environmental Change, 14, 347-354.

Khattree, R., Naik, D.N., 2000. Multivariate Data Reduction and Discrimination with SAS Software. SAS Institute, Cary, NC. 574pp.

King, L.C., 1953. Canons of landscape evolution. Bull. Geol. Soc. Am. 64, 721-752. 
King, L.A., 1956. Geomorfologia do Brasil Oriental. Revista Brasileira de Geografia, 18 147-265.

Krcho, J., 1991. Georelief as a subsystem of landscape and the influence of morphometric parameters of georelief on spatial differentiation of landscape-ecological processes. Ecology (CSFR), 10 (2), 115-157.

Lagacherie, P., Cazemier, D.R., van Gaans, P.F., Burrough, P.A., 1997. Fuzzy k-means clustering of fields in an elementary catchment and extrapolation to a larger area. Geoderma 77 (2), 197-216.

Latrubesse, E.M., Carvalho, T.M., 2006. Geomorfologia do Estado do Goiás e Distrito Federal. Série Geologia e Mineração, n.2, 128pp.

Lee, J.B., Woodyatt, A.S., Berman, M., 1990. Enhancement of High Spectral Resolution Remote Sensing Data by a Noise-Adjusted Principal Components Transform. IEEE Transactions on Geoscience and Remote Sensing 28, 295-304.

Lehner, B., Verdin, K., Jarvis, A., 2006. HydroSHEDS technical documentation, World Wildlife Fund, Washington, D. C. (Available at http://hydrosheds.cr.usgs.gov).

Lehner, B., Verdin, K., Jarvis, A., 2008. New global hydrography derived from spaceborne elevation data. EOS, Transactions American Geophysical Union 89 (10), 93-94.

Lepsch, I.F., Buol, S.W., Daniels, R.B., 1977. Soil landscape relationships in the occidental plateau of São Paulo, Brazil: I geomorphic surfaces and soil mapping units. Soil Sci. Soc. Am. J., 41, 104-109.

Lucas, Y., Chauvel, A., Boulet, R., Ranzani, G., Scatolini, F., 1984. Transição Latossolospodzois na região de Manaus, Amazônia, Brasil. Revista Brasileira de Ciência do Solo, $8,325-335$.

Macedo, J.; Bryant, R.B., 1987. Morphology, mineralogy, and genesis of a hydrosequence of Oxisols in Brazil. Soil Science Society of America Journal 51 (3), 690-698.

MacMillan, R.A., Pettapiece, W.W., Nolan, S.C., Goddard, T.W., 2000. A generic procedure for automatically segmenting landforms into landform elements using DEMs, heuristic rules and fuzzy logic. Fuzzy sets and Systems 113 (1), 81-109.

MacMillan, R.A., Shary, P., 2009. Landforms and landform elements in geomorphometry. In Hengl, T., Reuter, H.I. (Eds.), Geomorphometry: Concepts, Software, Applications. Elsevier, Amsterdam, pp. 227-254.

McFarlane, M.J., 1976. Laterite and Landscape. Academic Press, London, 151pp.

McFarlane, M.J., 1983. Laterites. In: Goudie, A.S., Pye, K. (Eds), Chemical Sediments and Geomorphology. Academic Press, London, 7-58.

Maignien, R., 1966. Review of Research on Laterites, Vol. 4. UNESCO Natural Resources Research, Paris, 136 pp. 
Marttone, E., 1943. Problemas Morfológicos do Brasil Tropical Atlântico (Primeiro Artigo). Revista Brasileira de Geografia, 4, 3-30.

Marttone, E., 1944. Problemas Morfológicos do Brasil Tropical Atlântico (Segundo Artigo). Revista Brasileira de Geografia, 4, 3-26.

Marini, O.J., Fuck, R.A., Danni, J.C., 1981. A evolução geotectônica da Faixa Brasília e do seu embasamento. In: Simpósio sobre o Cráton do São Francisco e suas faixas Marginais, Salvador. Anais... 100-113.

Marques, J.J, Schulze, D.G., Curi, N., Mertzman, S.A., 2004. Major element geochemistry and geomorphic relationships in Brazilian Cerrado soils. Geoderma, 119, 179-195.

Marques, J.J, Schulze, D.G., Curi, N., Mertzman, S.A., 2004. Trace element geochemistry in Brazilian Cerrado soils. Geoderma, 121, 31-43.

Marques Jr., J., Corá, J.E., Souza, C.K., Pereira, G.T. 2001. Soil, landform, erosion and sugarcane yield relationship. In: International Conference On Land Degradation And Meeting Of The Iuss Subcommission C-ICLD3, 3. Proceendings. Rio de Janeiro, CDROM.

Martins, E.S., 2000. Petrografia, mineralogia e geomorfologia dos rególitos lateríticos no Distrito Federal. Tese de Doutorado. Depto. Geologia/ UnB,

Martins, E.S., Reatto, A., de Carvalho Junior, O.A., Guimarães, R.F., 2004a. Ecologia de Paisagem: conceitos e aplicações. Boletim de Pesquisa - Embrapa Cerrados, 35pp.

Martins, E.S., Reatto, A., de Carvalho Junior, O.A., Guimarães, R.F., 2004b. Evolução Geomorfológica do Distrito Federal. Boletim de Pesquisa - Embrapa Cerrados, 57pp.

McGarigal, K., Marks, B.J., 1994. FRAGSTATS - spatial pattern analysis program for quantifying landscape structure, version 2. Forest Science Department. Oregon States University, 67pp.

McGarial, K., Tagil, S., Cushman, S.A., 2009. Surface metrics: an alternative to patch metrics for the quantification of landscape structure. Landscape Ecol., 24, 433-450.

Migoń, P., 2013. Weathering Mantles and Long-Term Landform Evolution, In: Treatise on Geomorphology, edited by John F. Shroder, Academic Press, San Diego, p. 127-144.

Meybeck, M., 1987. Global chemical weathering of surficial rocks estimated from river dissolved loads, American Journal of Science 287, 401-428.

Miliaresis, G.C., 2001. Geomorphometric mapping of Zagros Ranges at regional scale. Computers \& Geosciences 27 (7), 775-786.

Millot, G., 1964. Géologie des argiles. Masson, Paris. 494 pp.

Millot, G., 1980. Les grands aplanissements des socles continentaux dans les pays subtropicaux, tropicaux et désertiques. In : Livre jubilair du cent-cinquantenaire 18301980, Société géologique de France, Mémoire Hors 10, 295-305. 
Millot, G., 1983. Planation of continents by intertropical weathering and pedogenetic processes. In: Melfi, A.J., Carvalho, A. (Eds.), Lateritisation processes. Proceedings 2nd Internat. Seminar on Lateritisation Processes, São Paulo, Brasil (1982). Universidade de São Paulo, pp. 53-63

Minár, J., Evans, I.S., 2008. Elementary forms for land surface segmentation: The theoretical basis of terrain analysis and geomorphological mapping. Geomorphology 95 (3), 236-259.

Milne, G., 1935. Some suggested units of classification and mapping, particularly for East African Soils. Soil Res., 4 183-198.

Mitasova, H., Hoffierka, J., 1993. Interpolation by regularized spline with tension: II. Application to terrain modelling and surface geometry analysis, Mathematical Geology $25,657-669$.

Moore, I.D., Grayson, R.B., Ladson, A.R., 1991. Digital terrain modelling: a review of hydrological, geomorphological, and biological applications. Hydrological Processes 5 (1), 3-30.

Motta, E.F., Carvalho Filho, A., Ker, J.C., Pereira, N.R., Carvalho Junior, W., Blacaneaux, P. 2002. Relações solo-superfície geomórfica e evolução da paisagem em uma área do Planalto Central Brasileiro. Pesquisa Agropecuária Brasileira. 37(6) 869878.

Muniz, D.H.F., Moraes, A.S., Freire, I.S., Cruz, C.J.D.C., Lima, J.E.F.W., Oliveira-Filho, E.C., 2011. Evaluation of water quality parameters for monitoring natural, urban, and agricultural areas in the Brazilian Cerrrado. Acta Limnologica Brasiliensia, 23 (3), 307317.

Naime, U.J., Motta, P.E. Carvalho Filho, A., Reatto, A., Martins, E.S., Lima, J.A.S., 2002. Mapa de Reconhecimento de Intensidade dos Solos. Zoneamento-EcológicoEconômico da Região Integrada de Desenvolvimento do Distrito Federal e Entorno: Fase I. Rio de Janeiro. CPRM. Serviço Geológico do Brasil; Embrapa; MI/SCO.

Novaes Pinto, M., 1986a. Caracterização morfológica do curso superior do Rio São Bartolomeu - Distrito Federal. Revista Brasileira de Geografia, 48, 377-397.

Novaes Pinto, M., 1986b. Unidades Geomorfológica do Distrito Federal. Geografia, 11(21) 97-109.

Novaes Pinto, M., 1987. Superfícies de aplainamento do Distrito Federal. Revista Brasileira de Geografia, 49, 9-27.

Novaes Pinto, M., 1988. Aplainamento nos Trópicos - uma revisão conceitual. Geografia, 13(26) 119-129.

Novaes Pinto, M. 1994. Caracterização geomorfológica do Distrito Federal. In: Novaes Pinto, M. (org). Cerrado: caracterização, ocupação e perspectivas. Brasília. Editora UnB. 2a ed., 285-320. 
Pengra, B.W., Johnston, C.A., Loveland, T.C., 2007. Mapping an invasive plant, Phragmites australis, in coastal wetlands using the EO-1 Hyperion hyperspectral sensor. Remote Sensing of Environment, 8 (1), 74-81.

Pennock, D.J., Zebarth, B.J., De Jong, E., 1987. Landform classification and soil distribution in hummocky terrain, Saskatchewan, Canada. Geoderma 40 (3), 297-315.

Penteado, M.M., 1976. Tipos de concreções ferruginosas nos compartimentos geomorfológicos do planalto de Brasília. Notícia Geomorfológica, 16(32), 39-53.

Phillips, J.D., 2002. Erosion, isostatic response, and the missing peneplains. Geomorphology, 45, 225-241.

Pike, R. J., 1986. Geometric Signatures of Intermediate-Scale Topography. Geol. Soc. Amer. Abst. Prog., v. 18, no. 2, p. 171.

Pike, R.J., Rozema, W.J. 1975. Spectral analysis of landforms. Annals of the Association of American Geographers, 65(4), 499-516.

Pike, R.J., 1988. The geometric signature: quantifying landslide terrain types from digital elevation models. Mathematical Geology 20 (5), 491-511.

Pike, R.J., Evans, I.S., Hengl, T., 2009. Geomorphometry: a brief guide. In: Hengl, T., Reuter, H.I. (Eds.), Geomorphometry: Concepts, Software, Applications. Elsevier, Amsterdam, pp. 3-30.

Pimentel, M.M., Dardenne, M.A., Fuck, R.A., Viana, M.G., Junges, S.L., Fischel, D.P., Seer, H.J., Dantas, E.L., 2001. Nd isotopes and the provenance of detrital sediments of the Neoproterozoic Brasilia Belt, Central Brazil. Journal of South American Earth Sciences 14 (6), 571-585.

Prima, O.D.A., Echigo, A., Yokoyama, R., Yoshida, T., 2006. Supervised landform classification of Northeast Honshu from DEM-derived thematic maps. Geomorphology 78(3), 373-386.

Rabus, B., Eineder, M., Roth, A., Bamler, R., 2003. The shuttle radar topography mission - a new class of digital elevation models acquired by spaceborne radar. ISPRS Journal of Photogrammetry and Remote Sensing 57 (4), 241-262.

Raines, G.L. 2002. Descript ion and comparison of geologic maps with FRAGSTATS -a spatial statistics program. Computers \& Geosciences, 28, 169-177.

Reatto, A., Martins, E.S., Guimarães, E.M., Spera, S.T., Simm, K.M.C.B., Correia, J.R., 1999. Variabilidade Mineralógica de Latossolos da Bacia do Rio Jardim, DF. Boletim de Pesquisa - Embrapa Cerrados, Planaltina, 24pp.

Reatto, A., Correia, J.R., Spera, S.T., Chagas, C.S, Martins, E.S., Andahur, J.P., Godoy, M.J.S., Assad, M.L.L., 2000. Levantamento Semidetalhado dos Solos da Bacia do Rio Jardim - DF, escala 1:50.000. Boletim de Pesquisa - Embrapa Cerrados, Planaltina, $63 \mathrm{pp}$. 
Reatto, A., Martins, E.S., Farias, M.F.R., Silva, A.V., de Carvalho Júnior, O.A., 2004. Mapa Pedológico Digital - SIG atualizado do Distrito Federal escala 1:100.000 e uma síntese do texto esxplicativo. Boletim de Pesquisa - Embrapa Cerrados, Planaltina, $31 \mathrm{pp}$.

Reatto, A., Bruand, A., Martins, E.S., Muller, F., Silva, E.M., de Carvalho Júnior, O.A., Brossard, M., 2008.Variation of the kaolinite and gibbsite content at regional and local scale in Latosols of the Brazilian Central Plateau. Comptes Rendus Geoscience 340 (11), 741-748.

Reatto, A., Bruand, A., Martins, E.S., Muller, F., Silva, E.M., de Carvalho Júnior, O.A., Brossard, M., Richard, G., 2009. Development and origin of the microgranular structure in latosols of the Brazilian Central Plateau: Significance of texture, mineralogy, and biological activity. Catena 76 (2), 122-134.

Rocha, C.H., Souza, M.L.P., Milano, M.S., 1997. Ecologia da Paisagem e Manejo Sustentável dos Recursos Naturais. Geografia, 22(2) 57-79.

Rodrigues, T.E., Klamt, E., 1978. Mineralogia e gênese de uma seqüência de solos do Distrito Federal. R. Bras. Ci. Solo, 2 132-139.

Ross, J.L.S., 2009. Ecogeografia do Brasil: subsídios para planejamento ambiental. São Paulo: Oficina de textos. 208pp.

Ruhe, R.V., 1956. Geomorphic Surfaces and the nature of soils. Soil Sci., 82, 441-445.

Ruhe, R.V., Walker, P.H., 1968. Hillslope models and soil formation II: open systems. In: Proceedings of 9th Congress of the International Soil Science Society, vol. 4. International Soil Science Society, Adelaide, Australia, 551-560.

Santos, L.J.C., 2000. Pedogênese no topo do platô de Bauru (SP): o caso da bacia do córrego da Ponte Preta. 2000. Tese (Doutorado em Geografi a) Faculdade de Filosofi a, Letras e Ciências Humanas, Universidade de São Paulo, 183pp.

Saunders, D., Hobbs, R., Margules, C., 1991. Biological consequences of ecosystem fragmentation: a review. Cons Biol, 5, 18-32.

Schmidt, J., Dikau, R., 1999. Extracting geomorphometric attributes and objects from digital elevation models - semantics, methods, and future needs. In Dikau, R. and Sourer, H. (Eds.), GIS for earth surface systems. Gebrüder Borntraeger, Berlin, pp. 153-173.

Schmidt, J., Evans, I.S., Brinkmann, J., 2003. Comparison of polynomial models for land surface curvature calculation. International Journal of Geographical Information Science 17(8), 797-814.

Schmidt, J., Hewitt, A., 2004. Fuzzy land element classification from DTMs based on geometry and terrain position. Geoderma, 121(3), 243-256.

Scislewski, G., Frasca, A.A.S., Araújo, V.A., Rodriques, J.B., Gonçalves, H.S., 2002. Mapa Geológico. In: Zoneamento-Ecológico-Econômico da Região Integrada de Desenvolvimento do Distrito Federal e Entorno: Fase I. Rio de Janeiro. CPRM. Serviço Geológico do Brasil; Embrapa; MI/SCO. 
Scislewski, G., Araújo, V.A., 2003. Geologia. In: Zoneamento-Ecológico-Econômico da Região Integrada de Desenvolvimento do Distrito Federal e Entorno: Fase I. Rio de Janeiro. CPRM. Serviço Geológico do Brasil; Embrapa; MI/SCO, p. 9-15.

Sena-Souza, J.P., de Carvalho Junior, O.A. Martins, E.S., Vasconcelos, V., Couto Junior, A.F., Gomes, R.A.T., Guimarães, R.F., 2016. Comparação dos métodos de classificação por ângulo espectral e distância euclidiana no mapeamento das formas de terreno. Revista Brasileira de Geomorfologia, 17(3), no prelo.

Shary, P.A., 1995. Land surface in gravity points classification by a complete system ofcurvatures. Mathematical Geology 27(3), 373-390.

Shary, P.A., Sharaya, L.S., Mitusov, A.V., 2002. Fundamental quantitative methodsof land surface analysis. Geoderma 107(1), 1-32.

SIEG, Sistema Estadual de Geoinformação, 2005. Mapa de Solos - Projeto RadamBrasil. Determinação de áreas prioritárias para unidades de preservação - Cons.Imagem/WWF RADAMBRASIL.

Skidmore, A.K., Ryan, P.J., Dawes, W., Short, D., O’Loughlin, E., 1991. Use of an expert system to map forest soils from a geographical information system. International Journal of Geographical Information Systems 5, 431-445.

Smith, B., Sandwell, D., 2003. Accuracy and resolution of Shuttle Radar Topography Mission data. Geophysical Research Letters 30(9), 1467, doi:10.1029/2002GL016643.

Smith, M.J., Rose, J., Booth, S., 2006. Geomorphological mapping of glacial landforms from remotely sensed data: An evaluation of the principal data sources and an assessment of their quality. Geomorphology 76(1), 148-165.

Southworth, J., Munroe, D., Nagendra, H., 2004. Land cover change and landscape fragmentation - comparing the utility of continuous and discrete analyses for a western Honduras region. Agriculture, Ecosystems and Environment, 101, 185-205.

Speight, J.G., 1990. Landform. In: McDonald, R.C., Isbell, R.F., Speight, J.G., Walker, J., Hop, M.S. (Eds.), Australian Soil and Land Survey Field Handbook. Inkata Press, Melbourne, 9-57.

Strauch, M., Lima, J.E.F.W., Volk, M., Lorz, C., Makeschin, F., 2013. The impact of Best Management Practices on simulated streamflow and sediment load in a Central Brazilian catchment. Journal of Environmental Management 127, S24-S36.

Su, S.; Xiai, R.; Zhang, Y., 2012. Multi-scale analysis of spatially varying relationships between agricultural landscape patterns and urbanization using geographically weighted regression. Applied Geography, 32, 360-375.

Summerfield, M.A., 1991. Global Geomorphology: an introduction to study of landforms. Longman Scientific \& Technical, United Kingdon, 537pp.

Summerfield, M.A., Hulton, N.J., 1994. Natural controls of fluvial denudation rates in major world drainage basins. Journal of Geophysical Research 99 (13) 871-883. 
Sun, J.; Huang, Z.; Zhen, Q.; Southworth, J.; Perz, S., 2014. Fractally deforested landscape: Pattern and process in a tri-national Amazon frontier. Applied Geography, $52,204-211$.

Swanson F.J., Kratz T.K., Caine N. and Woodmansee R.G., 1998. Landform effects on ecosystem patterns and processes. BioScience, 38, 92-98.

Swanson F.J., Wondzell S.M., Grant G.E., 1992. Landforms, disturbance, and ecotones. In: Hansen A.J., di Castri F. (eds), Landscape boundaries: consequences for biotic diversity and ecological flows. Springer Verlag, New York, New York, USA, 304-323.

Tardy, Y., 1997. Petrology of Laterites and tropical soils. Masson, Paris, 419pp.

Thomas, M.F., 1974. Tropical geomorphology. A study of weathering on landform development in warm climate. NY, John Wiley \& Sons. 313pp.

Thomas, M.F., 1989a. The role of etch professes in landform development. I. Etching concepts ond their applications. Zeits. Geomorph., 33(2) 129-142.

Thomas, M.F., 1989b. The role of etch processes in landform development. II etching and the formation of relief. Zeits. Geomorph., 33(3). 257-274.

Thomas, M.F., 1994. Geomorphology in the Tropics: a study of weathering and denudation in low latitudes. John Wiley \& Sons, Chichester, $460 \mathrm{pp}$.

Thomas, M.F., 2001. Landscape sensitivity in time and space - an introduction. Catena, 42, 83-98.

Tohver, E., Trindade, R.I.F., Solum, J.G., Hall, C.M., Riccomini, C., Nogueira, A.C., 2010. Closing the Clymene Ocean and bending a Brasiliano belt: evidence for the Cambrian formation of Gondwana from SE Amazon craton. Geology 38, 267-270.

Troeh,F.R.,1965. Landform equations fitted to contour maps. American Journal of Science 263, 616-627.

Turner, M.G., 1989. Landscape ecology: the effect of pattern on process. Annual Review of Ecology and Systematics, 20, 171-197.

Turner, M.G., Gardner, R.H., O'Neill, R.V., 2001. Landscape ecology in theory and practice. New York: Springer-Verlag, 406pp.

Twidale, C.R., Vidal-Romani, J.R., 1994. On the multistage development of etch forms. Geomorphology., 11. p. 107-124.

Underwood, E.; Ustin, S.; DiPietro, D., 2003. Mapping non-native plants using hyperspectral imagery. Remote Sensing of Environment 86, 150-161.

Valadão, R. C., 1998. Evolução de longo-termo do relevo do Brasil oriental (desnudação, superfícies de aplanamento e soerguimentos crustais). Tese (Doutorado) - Instituto de Geociências, Universidade Federal da Bahia, 243 pp. 
Valeriano, C.M., Dardenne, M.A., Fonseca, M.A., Simões, L.S.A., Seer, H.J.A., 2004. Evolução tectônica da Faixa Brasília. In: Mantesso-Neto V, Bartorelli A, Carneiro CDR, Brito-Neves BB (Eds.). Geologia do Continente Sul-Americano: Evolução da Obra de Fernando Flávio Marques de Almeida. São Paulo: Beca Produções Culturais, p. 575-592.

Van Zyl, J.J., 2001. The Shuttle Radar Topography Mission (SRTM): a breakthrough in remote sensing of topography. Acta Astronautica 48(5), 559-565.

Vasconcelos, V., Carvalho Junior, O.A., Martins, E.S., Couto Junior, A.F., Guimarães, R.F., Gomes, R.A.T., 2012. Sistema de classificação geomorfométrica baseado em uma arquitetura sequencial em duas etapas: Árvore de Decisão e Classificador Espectral, no Parque Nacional Serra da Canastra. Revista Brasileira de Geomorfologia, 13(2) 171186.

Vidal-Torrado, P., Lepsch, I.F., Castro, S.S., 2005. Conceitos e Aplicações das Relações Pedologia-Geomorfologia em Regiões Tropicais Úmidas. In: Vidal-Torrado, P.; Alleoni, L.R.F., Cooper, M., Silva, A.P., Cardoso, E.J., Prochnow, L. I. (org.). Tópicos em Ciência do Solo. Viçosa: SBCS, 4, 145-192.

Vitte, A.C., 2001. Considerações sobre a teoria da etchplanação e sua aplicação nos estudos das formas de relevo nas regiões tropicais quentes e úmidas. Terra Livre, 16, 11-24.

Vitte, A.C., 2005. Etchplanação dinâmica e episódica nos trópicos quentes e úmidos. Revista do Departamento de Geografia, 16, 105-118.

von Blanckenburg, F., 2006. The control mechanisms of erosion and weathering at basin scale from cosmogenic nuclides in river sediment. Earth Planet. Sci. Lett. 242, 224239.

Wayland, E.J., 1933. Peneplains and some other erosional plataforms. Ann. Rept. Bull. Protectorate of Uganda Geol Surv., 1, 77-79.

Wilson, J.P., Gallant, J.C., 2000. Terrain analysis: principles and applications, New York: John Wiley \& Sons, 150pp.

Wong, S.T., 1968. A Multivariate Statistical Model for Predicting Mean Annual Flood in New England. Annals of the Association of American Geographers, 43 (3), 298-311.

Wood, J., 1996. The geomorphological characterisation of digital elevation models. $\mathrm{PhD}$ Dissertation, University of Leicester, http://www.soi.city.ac.uk/_jwo/phd/S (accessed 24 march 2014), 193pp.

Zevenbergen, L.W., Thorne, C.R., 1987. Quantitative analysis of land surface topography. Earth Surface Processes and Landforms 12 (1), 47-56. 


\section{ANEXO 1}

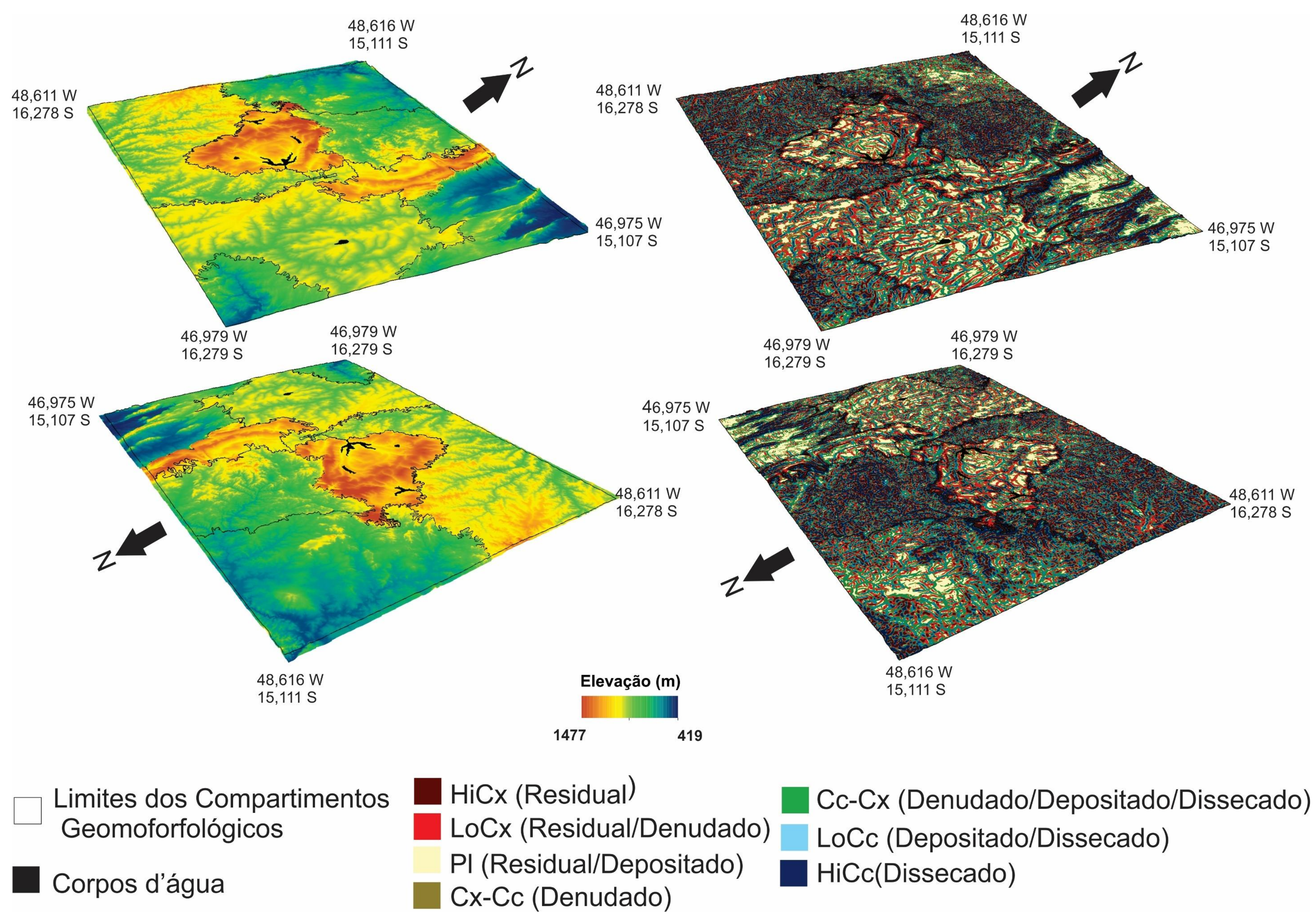

Anexo 1 - Modelo Digital de Elevação e classificação das Formas de Terreno em diferentes perspectivas com exagero vertical de 3x. 